

\section{. . . .}

CANADIAN THESES ON MICROFICHE

THESES. CANADIENNES SUR MICROFICHE

National Library of Canada

Collectons Development Branch

Canadian Theses on

- Microfiche Setvice

Qttawa, Canada

K1A ON4
Bibliothèque natıonale du Cąnada

Drection du développement des collections

" Service dés thèses canadiennes sur microfiche .

\section{NOTICE}

The quality of this microfiche is heavily dependent upon the quality of the original thesis submitted for microfilming. Every effort has been made to énsure the highest quality of reproduction possible.

If pages are missing, contact the university which.' granted the degree.

Some pages may have indistinct print especially if the original plages were typed with.a poor. typewriter ribbon or if the university sent us a poor photocopy.

Prevously copyrighted materials (journal articles, published tests, etc.) are not filmęd.

Reproduction in full or in part of this film is gov. erned by the Conadian Copyright Act, R.S.C. 1970, c. C.30. Please read the authorization forms which accompany this thests.

\section{I.S.B.N.}
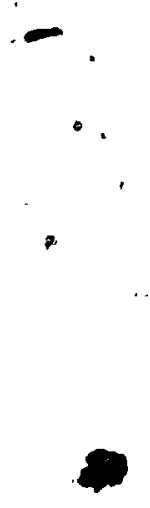


$$
\begin{aligned}
& \text { national Library } \\
& \text { of Canada } \\
& \text { Bibliothèque national } \\
& \text {. du Canada } \\
& \text { Canadian Theses Division Division dep theses canadiennes } \\
& \text { Ottawa, Canada } \\
& \text { K1AON4 } \\
& 55609
\end{aligned}
$$

PERMISSION TO MICROFILM - AUTORISATION DE MICROFILMER

- Please print or type - Écrire en litres moulées on dactylographier

Full Name of Author - Nom complex de l'auteur

$$
0-.12-97671 \ldots-
$$

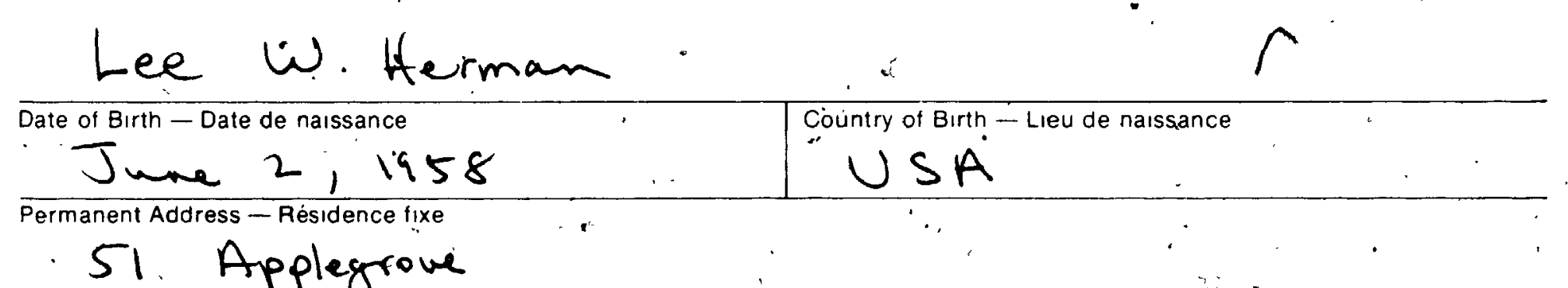

51. Applegrove

* Dollar does Oracavex, P.Q.

Hat iwis:-

Title of Thesis - Titre de la these

Investigations of Cannabinoid

Synthesis: Chromeres

University - Université

CARLETON U.

Degree for which thesis was presented - Grade pour lequel cote these fut présentée

MISC. CHEM.

\begin{tabular}{l|l|l|}
\hline Year this degree conferred - Annex d'obtention de ce grade & Name of Supervisor - Nom, du directer de these \\
\hline
\end{tabular}

Permission is hereby granted to the NATIONAL LIBRARY OF CANADA to microfilm this thesis and to lend or sell copies of the film

The author reserves other publication rights, and neither the thesis nor extensive extracts from it may be printed or otherwise reproduced without the author's written permission.
L'autorisation est, par la présente. accorded a la BIBLIOTHĖQUE NATIONALE'DU CANADA de microfilmed cote these de prêter au de ventre de exemplars du film

L'auteur se reserve les autres drafts de publication. nI la these ni de longs extracts de celle-ci nee doivent être imprımés ow autrement reprodults san's l'autorisation écrite de l'auteur.

$\operatorname{Tan} \cdot 15 / 82:$ signature


98

$\therefore \quad$ investigation OF

CANNABINOID SYNTHESIS:

- CHROMENES

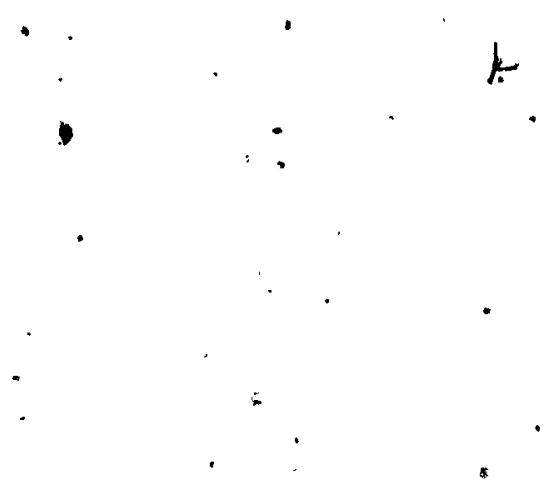

-

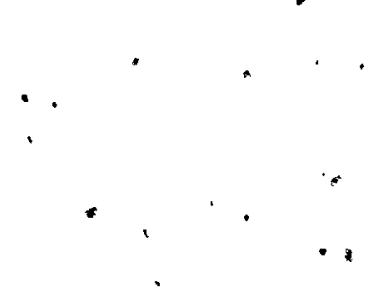

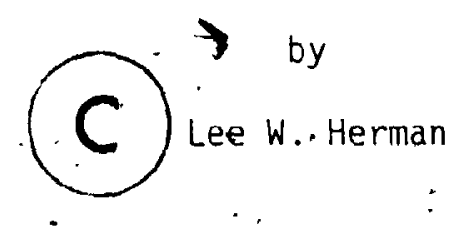

A. the is submitted to the Faculty of Graduate Studies in partial fulfilment of the - requirements for the degree of - Master of Science

Department of Chemistry

$$
\begin{gathered}
\text { Carleton University } \\
\text { Ottawa, Ontario } \\
\text { Canada } \\
\text { Januáry. } 1982
\end{gathered}
$$


The undersigned recommend to the Faculty

of Graduate Studies acceptance of the the is

- "Investigations of Cannabinoid Synthesis:

Chromenes"

submitted by Lee W. Herman

in partial fulfilment of the requirements for
the degree of Master of Science

al fulfilment of the requirements
the degree of: Master of Science

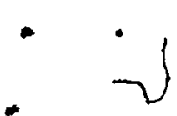

a.
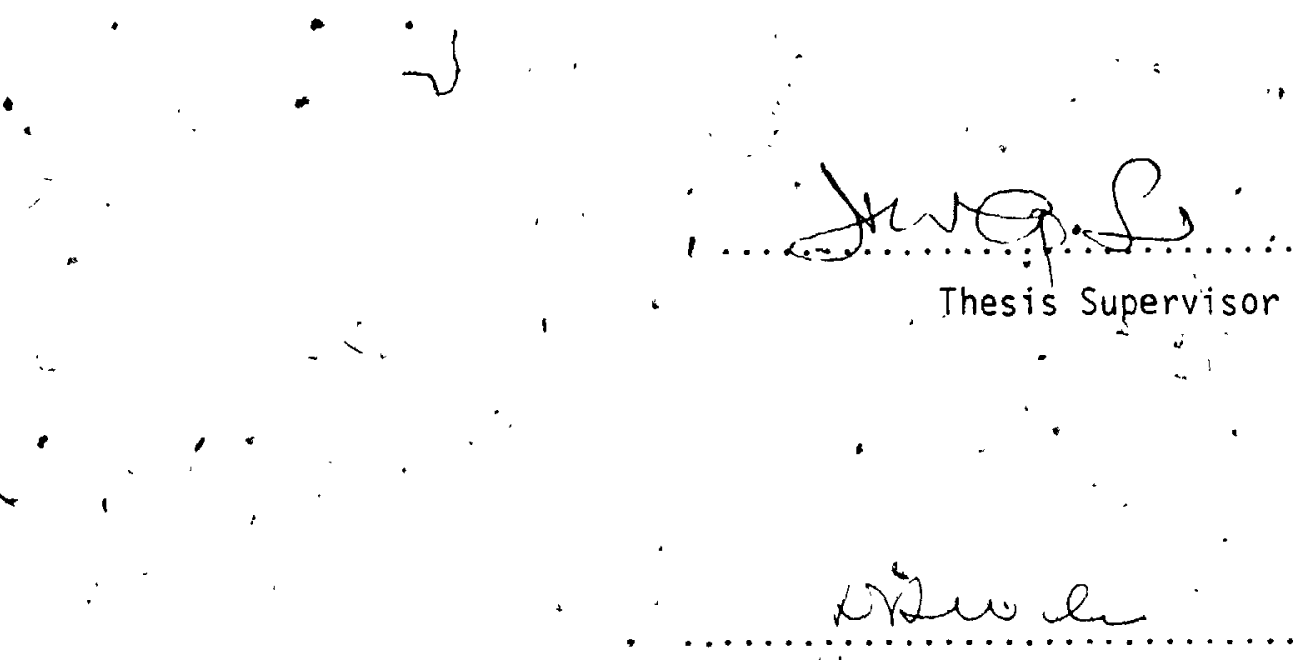

Chairman, Department of Chemistry.

Carleton University

January 1982 
;

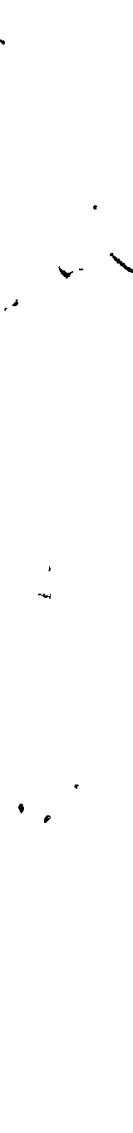

$\overline{1}$

$\because$ The synthesis of the chromene $\Delta^{3}-2,2$-dimethy $1-5$-hydroxy benzopyran (103) was, undertaken, in an attempt to study a proposed novel. base catalyzod alkylation for the construction of the $C$-ring of the cannabinoid skeleton. Chromanone 118 , formed by the pyrrolidine catalyzed condensation of 2,6-hydroxy acetophenone and acetone, was reduced to chromanol 123 and the phenol-protected as the phenacyl ether (125). Dehydration, f followed by phenol regeneration, gave the chromene 103 in good.yield. However, NMR studies failed to show the formation of the , reactive species necessary for the desired alkylation. Chromene 103 was also unreactive in a Diels-Alder sense. Other alkylations, at $\mathrm{C}-3$ of chromanone 140 were. investigated. An undesirable aromatic substitution, under acidic conditions, was encountered, as well as the eluaidation of an appropriate base catalyzed alkylation with an allylic halide using $\mathrm{LiH}$ in the presence of HMPA. This 'reaction could be useful in the total synthesis of 7-oxo cannabinoids. 
ii.

ACKNOWLEDGEMENTS

I would like to thank Dr. John ApSimon for his remarkable patience and encouragement. Also uniquely valuable were discussions with my, friends of the laboratory, who were a constant source of consultation and amusement.

I would also like to thank Mr. Karl Diedrich, who

was instrumental in the acquisition of lab supplies, and Mrs. Marilyn Stock for the typing of this thesis.

In addition, I am grateful to the Department of

Chemistry, Carleton University, and again to Dr. Apsimon for funding throughout the project period. 
TABLE OF CONTENTS

Abstract

i

Acknowledgements

i i

Table of Contents

i i i

Foreword

iv

Introduction

A) Cannabinoids: An overview

B) Chromenes: Biological Activity

C) Chromenes: Synthetic Strategies

Results and Discussion Synthesis of 7-OH Chromenes.

Synthesis of $5-\mathrm{OH}$ Chromenes

Synthes is of 5,7-dihydroxy-4-chromanones

Suggestions for future research

Experimental

References
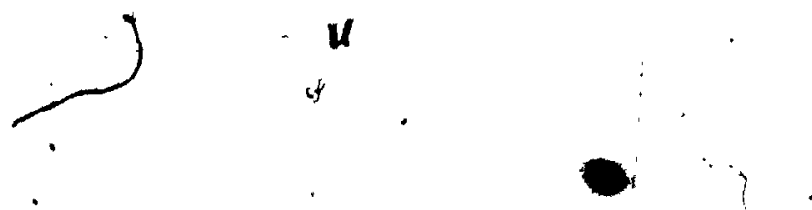


\section{FOREWORD}

Structural formulae representing synthetic materials containing asymmetric centers depict only one enantiomer but refer to racemic mixtures throughout In the text the $( \pm)$ prefix.'is amitted for conventence.

The following is a representation of the benzopyran numbering system used in the text:

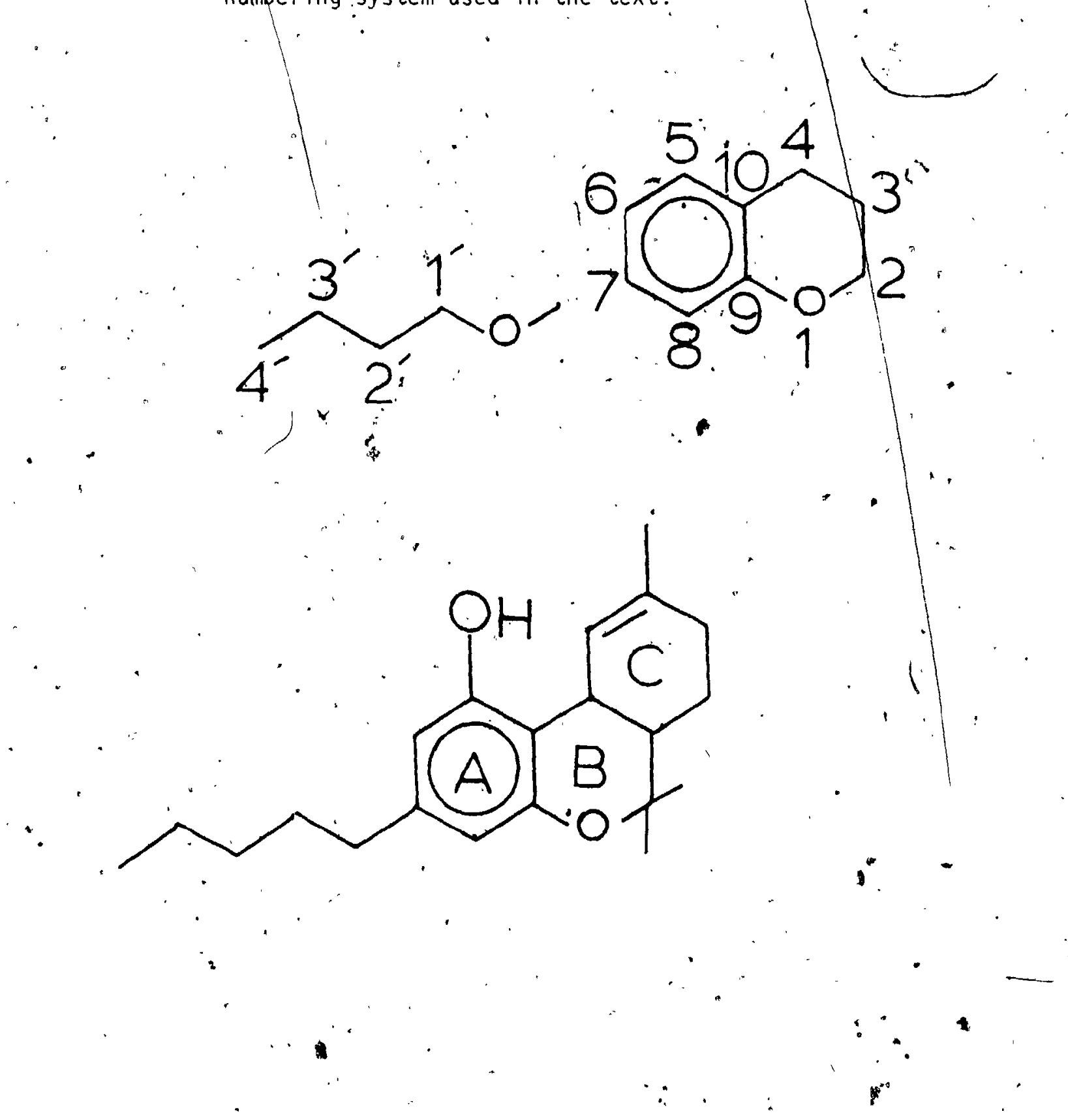


Introduction.

\section{A) Cannabinoids : An overview}

- In this chapter, the class of compounds known as the cannabinoids will be introduced in terms of their potential uses in contemporary society and synthetic schemes will be touched on. Then, a new class of insecticides called chromenes will be examined, as they represent possible starting material for cannabinoid synthesis. The biological activity and synthesis of chromenes will be presented in some depth.

The term cannabinoids refers to the class of compounds commonly found in the plant Cannabis sativa. The major physiologically active component is $(4)-\Delta^{9}$ 3,4-trans-tetrahydrocannabinol (THC) (1).

The use of cannabis was widespread in ancient Chinese, Indian and Middle Eastern medical lore for the treatment of insomnia, neuralfia, migraine pain, rheumatism, asthma, bronchitis, loss of appetite,

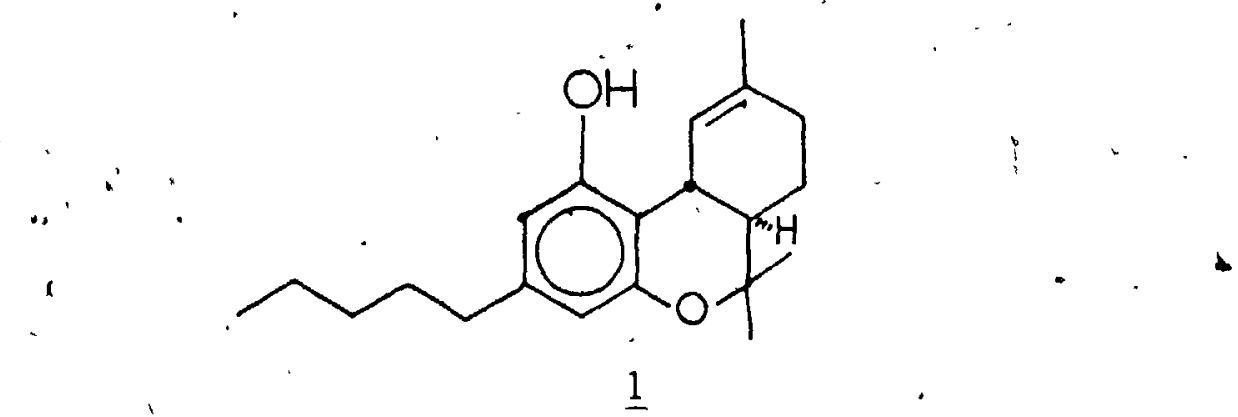


and gynecological and obstetrical problems. It is still used in Aynvedic and Tildoi systems, of Indian medicine.

The great increase in cannabis use among Western cultures in the 1960's had tremendous sociological impact. A vast number of studies have examined the effect of THC on human biology (i.e. metabolism, enzyme systems, hormonal effects, (gross morphọlogical effects) and psychology (learning, perception, sugglstibility affect, communication), but the conclusions that may be drawn are controversial, to say the least.

-Pharmacologically, the most prominent effeuts of $\Delta^{9}-$ THC are decreased locomotor activity, increased sensitivity to external stimuli such as sound and touch ("popcorn effect"), general depression and at high doses, static and dynamic ataxia. As a class of compounds, however, the cannabinoids are extraordinary in the degree that the pharmacological effects may be separated through structural variation, while still maintaining their low toxicity. This has led to the development of a number of cannabinoid drugs. Illicit use of cannabis among patients on cancer chemotherapy suggested their value as effective combatants of nausea associated with this kind of treatmen. Some synthetic anti-nausea cannabinoidlike compounds include Nabilone (2) Nabitan ( $\underline{3})$, and A-41988 $(\underline{4})^{4}$. 


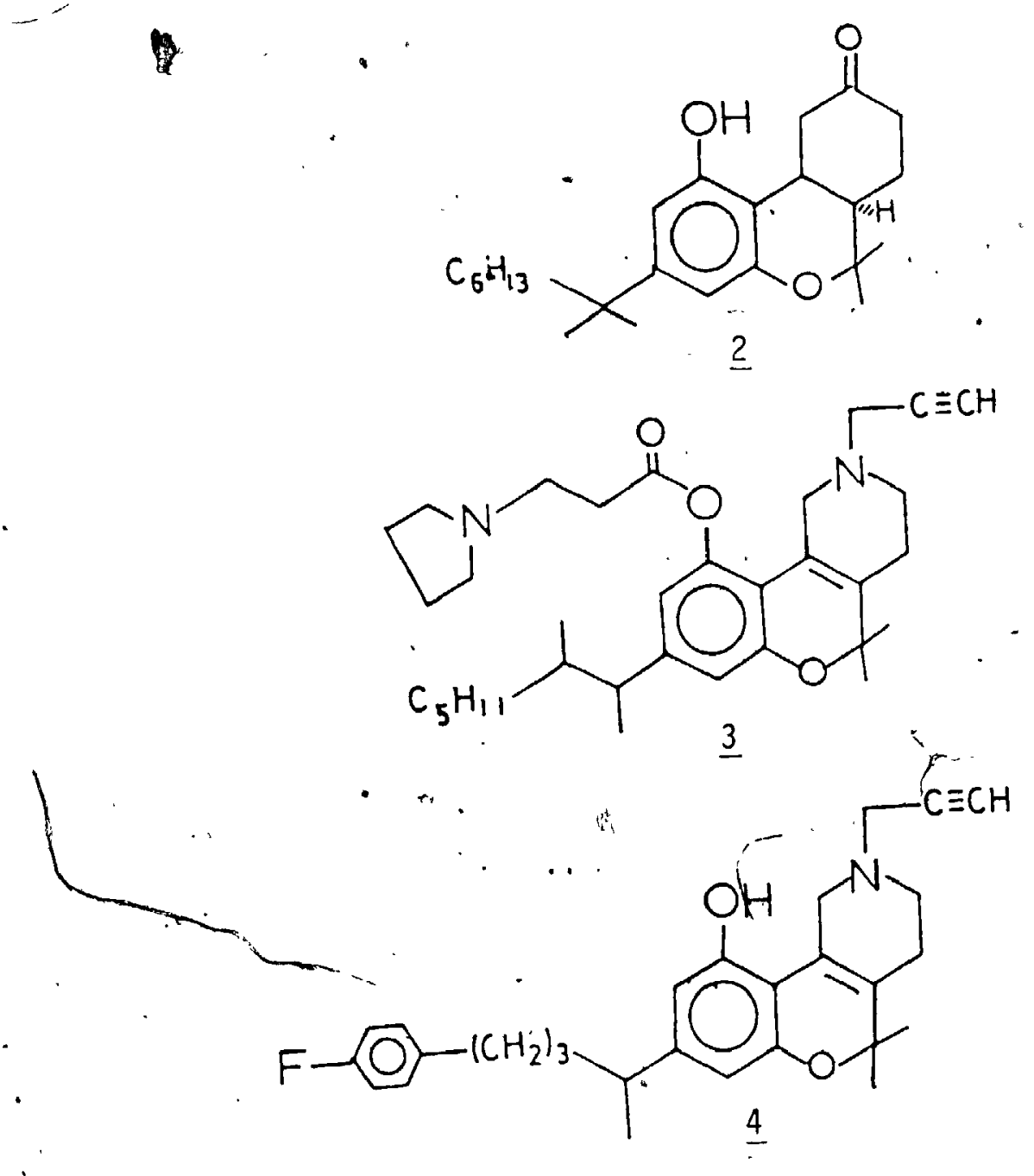

1
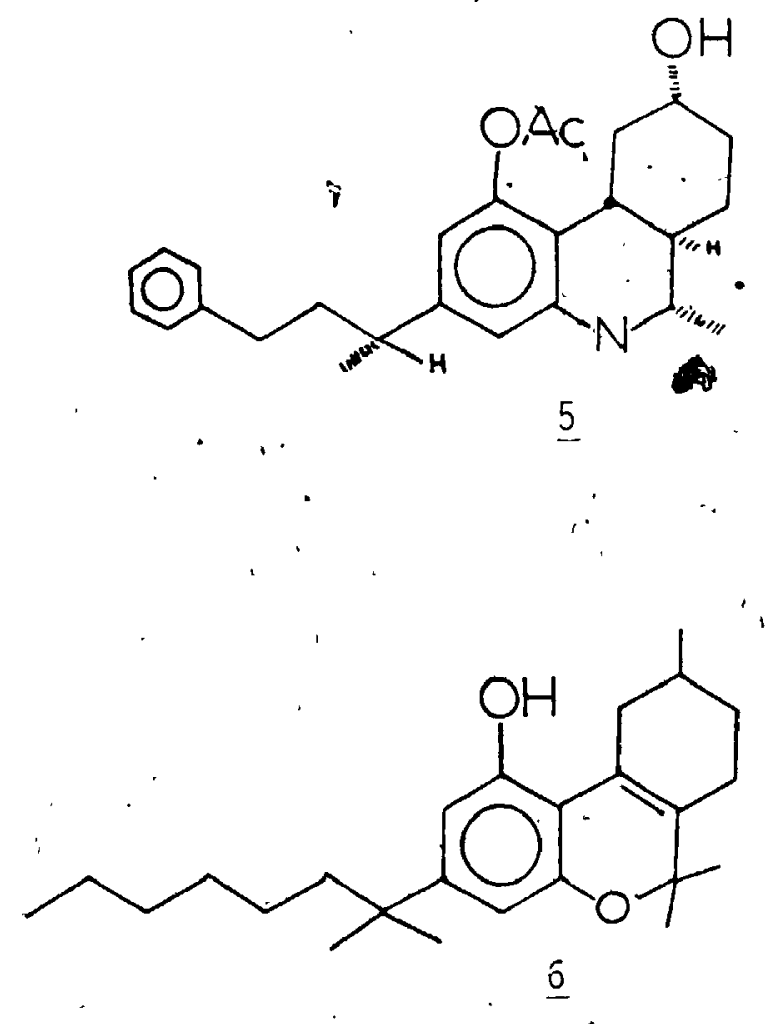
- Cannabinoids characteristically possess analgesic activity. This potential has been shown for both ( $\Delta 1)$ THC $^{5}$ and Nabitan 6,7 . Nantradol $(\underline{5})$ has been shown ${ }^{8}$ to

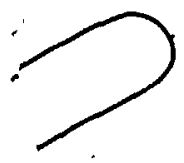
be 9-30 times more potent than morphine as an analgesic. It is unique in that it does not seem to bind to opiate receptors, as it is not antagonized by Naloxone. This suggests that" it would not cause the usual opiate dependence, instead it is postulated that it operates through some effect on prostaglandin metabolism.

In 1974, 'it was shown ${ }^{9}$ that DMHP (6) has hypotensive action at doses too low to show CNS effects. Nabilone has shown promise as a tranquilizing àgent ${ }^{10}$ and $\Delta^{9}-$ THC has been used as an antiasthmatic ${ }^{3}$ and an appatite stimulator 12 . There are clinical. indications ${ }^{14}$ that cannabis may alleviate some of the symptoms of epilepsy, and great interest has been placed on $\Delta^{9}$ as an agent forr reducing intraocular pressure of the eye in sufferers of glaucoma ${ }^{14}$. Research in animal physiology has shown potential for cannabinoids as antiinflammatory, antipyretic, antitussive, antispasmodic, antidiarrheal, sedative-hypnotic, antridepressant, anticancer and antialcoholic agents.

Since the first total synthesis of $\Delta^{9}-T H C$ by Mechou lam and Gaoni ${ }^{\text {H5 }}$ in 1965, a great number of syntheses have been published. The most widely used approach involves the condensation of a monoterpenoid moiety with 
$\cdot+i$

01 ivetol in the presence of an acid catalyst followed by cyclization of the benzofuran ring (Figure 1$)^{16}$. Using the steroid convention of ring notion this represents an $A+C \rightarrow A C \rightarrow A B C$ approach.

$$
A \text { much less exploited approafh is the } A \rightarrow A B+A B C
$$
approach. In 1967, Fahrenholtz (Figure 2) and co-workers 17 . pioneered this approach. The von Pechmann condensation
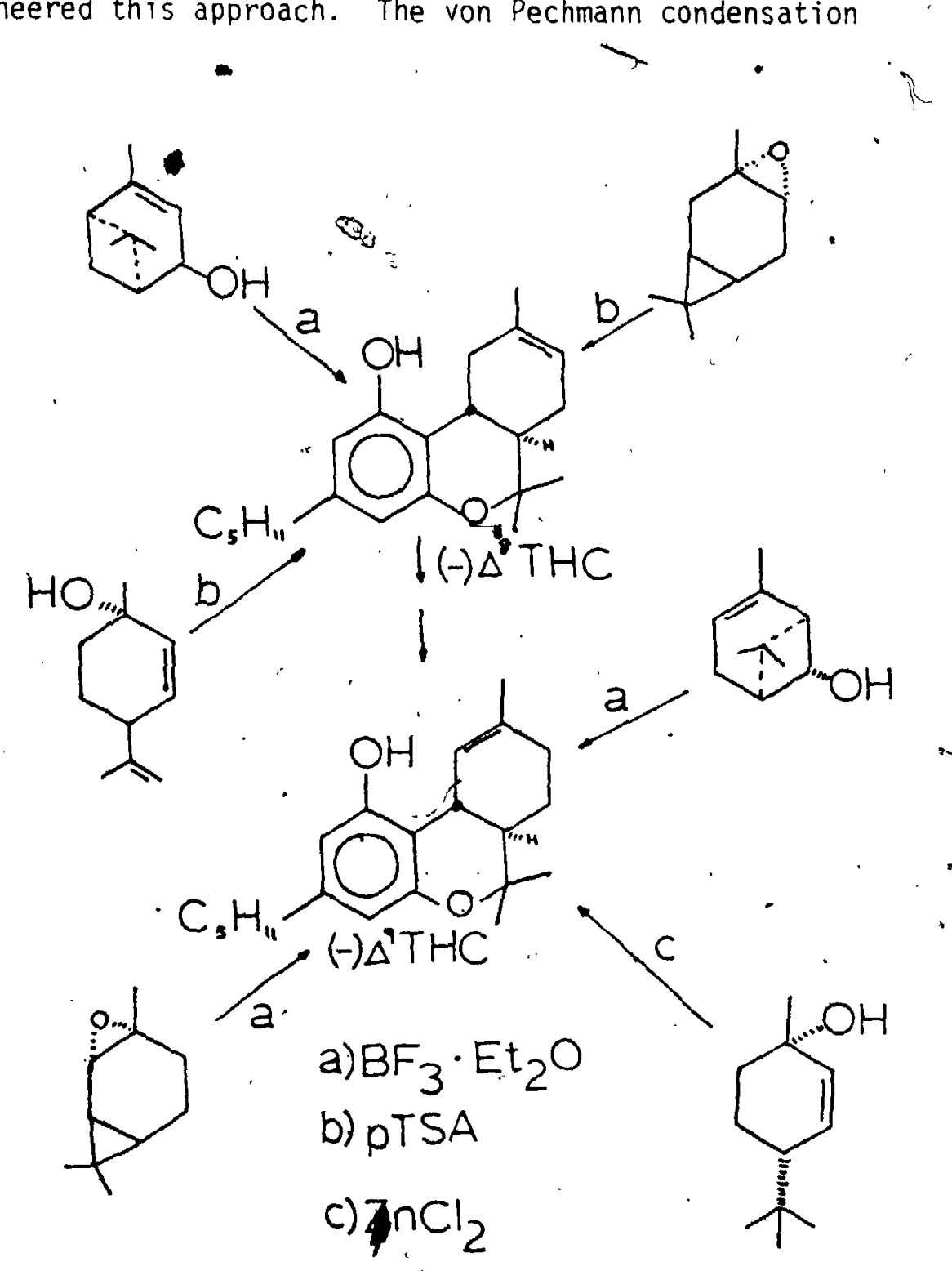

FIGURE I 
$\therefore$ of 01 ivetol and diethyl $\alpha$-acetoglutarate ( $\underline{8}$ ) in the presence of phosphoryl chloride afforded only one coumarin 9.' $\mathrm{C}$ - ring cýclization was effected by treatment with $\mathrm{NaH}$ in. OMSO. After protection of the ketone as its ethylene ketal, the coumarin was treated with MeMgI, whereupon treatment with acid re-cyclized rina $B$; regenerated the - C-ring ketone, and moved the C-6a double bond into conjugation with the ketone. Reduction the double bond with $\mathrm{Li}^{\circ} / \mathrm{NH}_{3}$ afforded the natural trans ring. junction (11).<smiles>CCCCCc1cc(O)cc(O)c1</smiles>

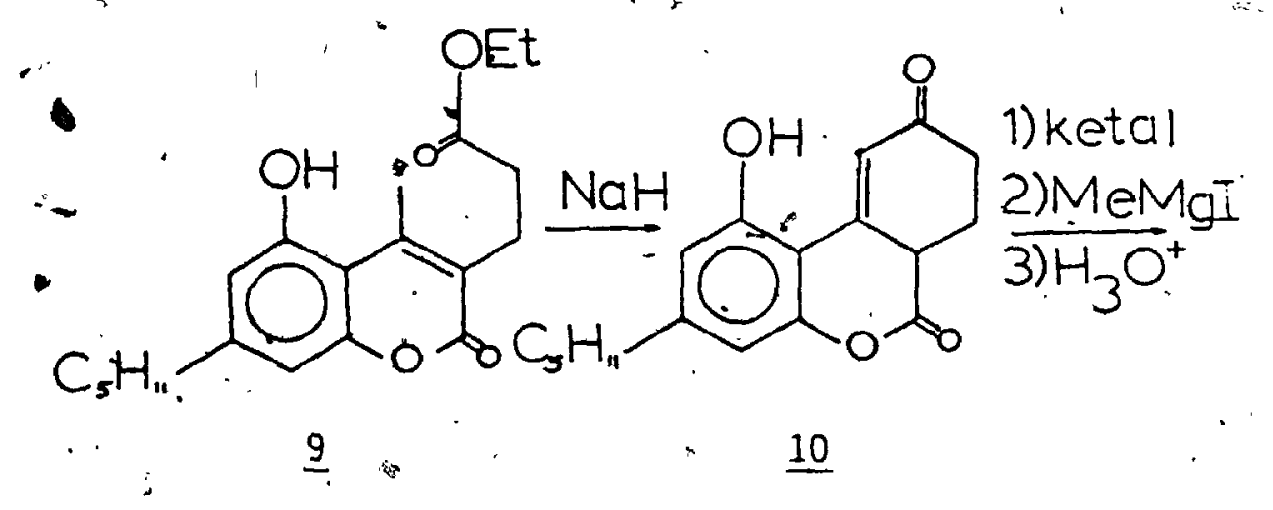<smiles>CCCCc1cc(O)c2c(c1)OC1(C)C[C@]13CCC(=O)CC23</smiles> 
The synthesis of Nabilone (2) was achieved by Archer et a ${ }^{18}$ in 1976 using the same method.

Fahrenholtz also synthesized the C-ring ketone via a 2,3-dimethyl chromanone (Fiqure 3). Condensation of olivetol with 3,3-dimethyl acrylic acid (13) gavf a mixture of the "natural" 3-pentyl (14) and the "unnatural" 1-pentyl (15) chromanones. After separation, treatment -of 14 with ethyl formate and $\mathrm{NaH}$ gave the hydroxymethylene derivative 16 which underwent a Robinson annelation upon treatment with MVK in the presence of triethylamine, to give the ketocannabinoid (11).

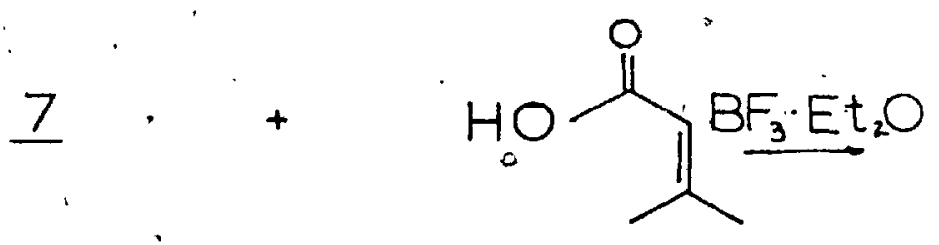

$\underline{13}$.

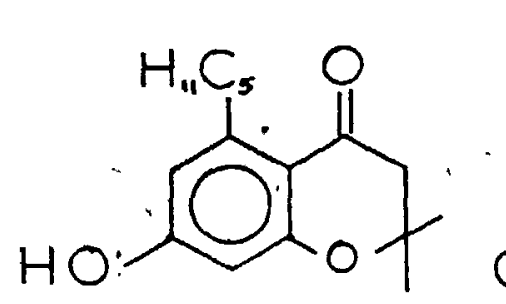

14

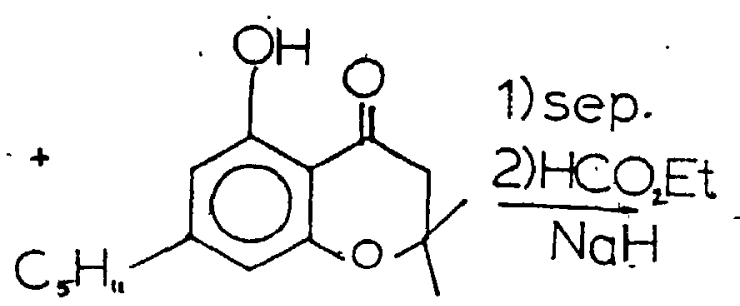

15<smiles>CC1(C)Oc2cc([14CH3])cc(O)c2[C@H](O)/C1=C/O</smiles>

FIGURE 3 , 
- An unexplored $A \rightarrow A B \rightarrow A B C$ approach involves the use of an intermediate 2,2-dimethyl chromene system such as 17 (Figure 4 ). If alkylation at $\mathrm{C}-3$ would occur, then cyclization would yield the saturated $\mathrm{C}$-ring ketone system with a trans ring junction without the need for a stereoselective reduction.
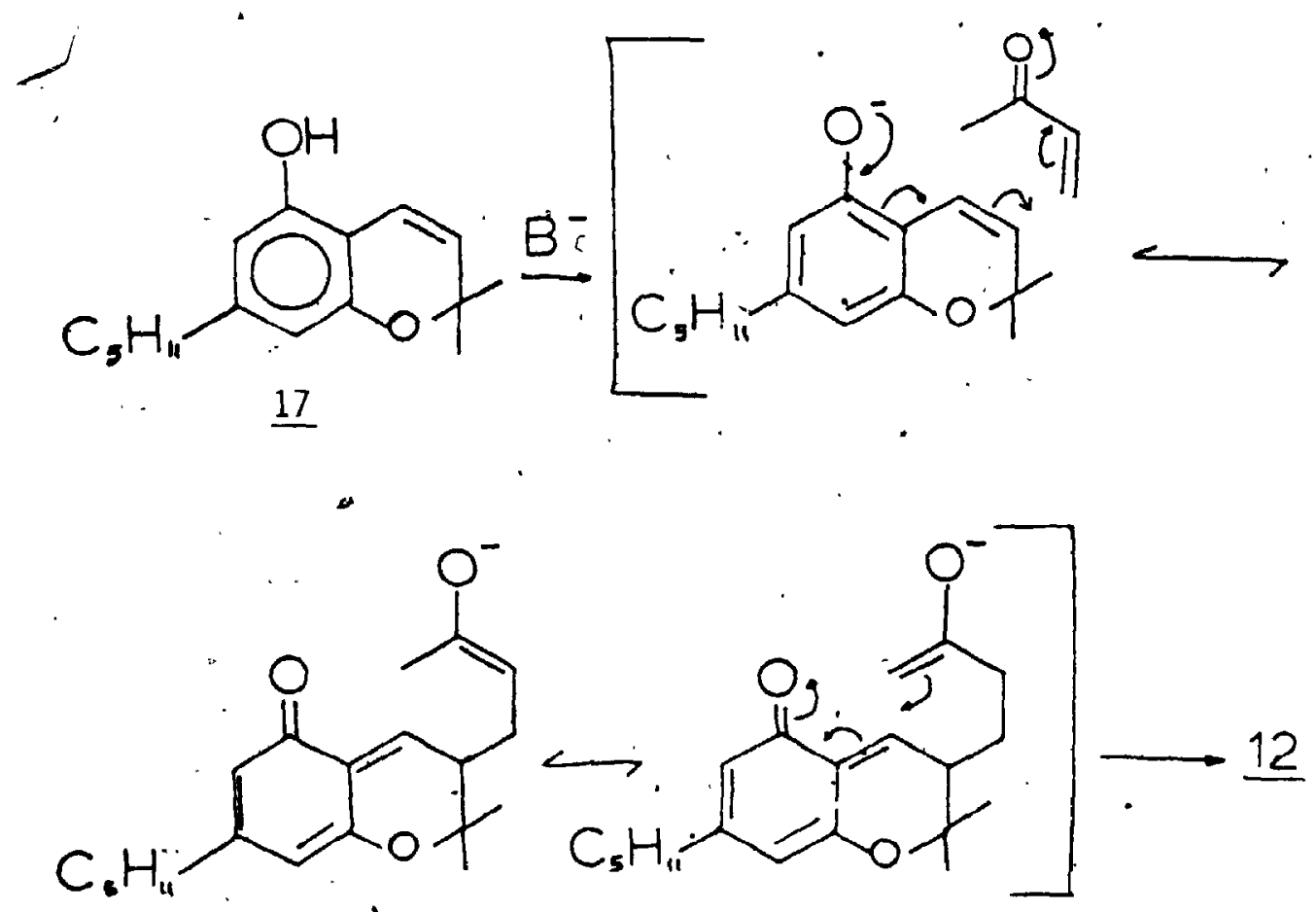

FIGURE 4

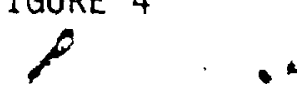

In addition, chromene 17 could be used as a Diels.

Alder precursor. In 1977, Handrick and co-workers ${ }^{19}$ (Figure 5) formed the C-ring by Diels Alder reaction of coumarin 18 with isoprene to give the cis ring junction coumarin 19. Since the cis ring junction may be isomerized to the trans using $\mathrm{AlCl}_{3}{ }^{18}$, this represents a. yseful route.

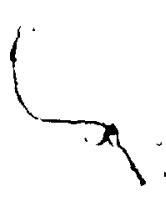




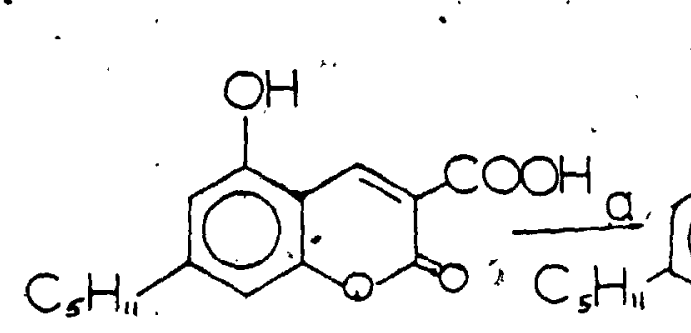

18<smiles>CC1=CCC2C(=O)Oc3ccc(C)cc3[C@H]2C1</smiles>

19

FIGURE 5

a)

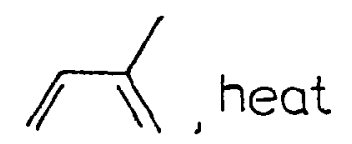

Other examples of C-ring formation are syntheses by Jen

- et $a 1^{20}$ who condensed an olivetol cinnamic acid (20) with 2-methyl-1,3-butadiene (Figure 6) and Kochi and Matsui ${ }^{21}$ who reacted MVK with the appropriate diene 24 to give the ketone 25 (Figure 7 ).

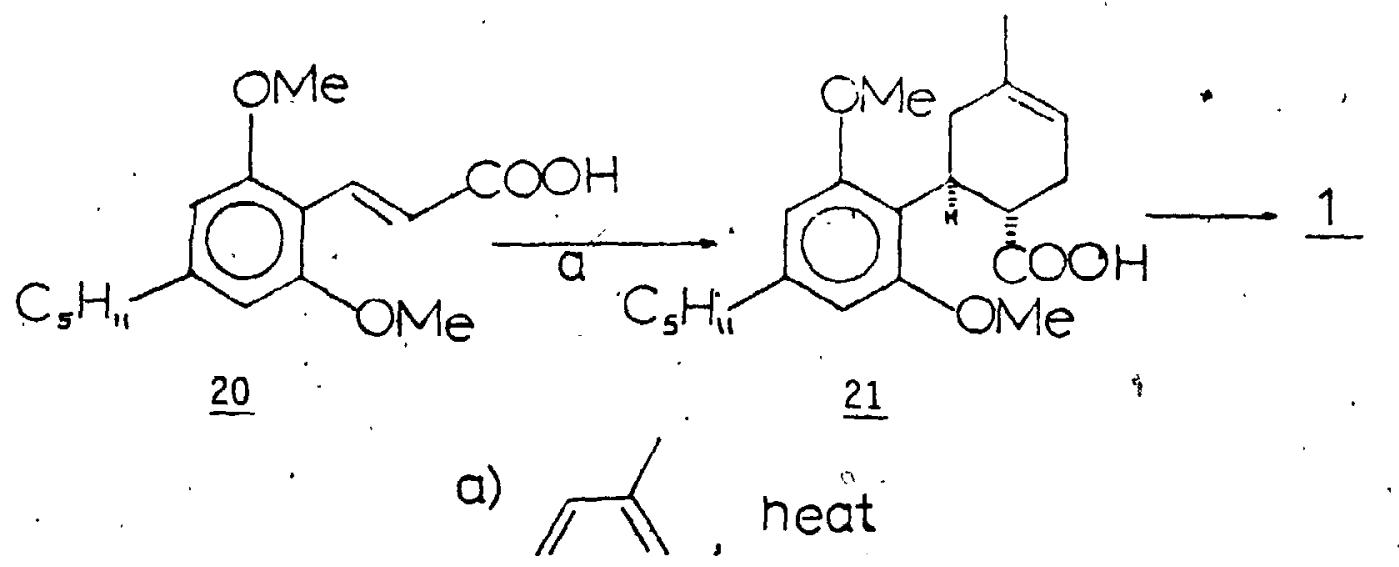

FIGURE 6

B) Chromenes : Biological Activity

Recently a class of chromene known as precocenes

have emerged as potential fourth generation insecticides. In 1961 Schmialek $^{22}$ showed the activity of farnesol (26) and farnesal (27) as juvenile hormones (JH). JH's affect 

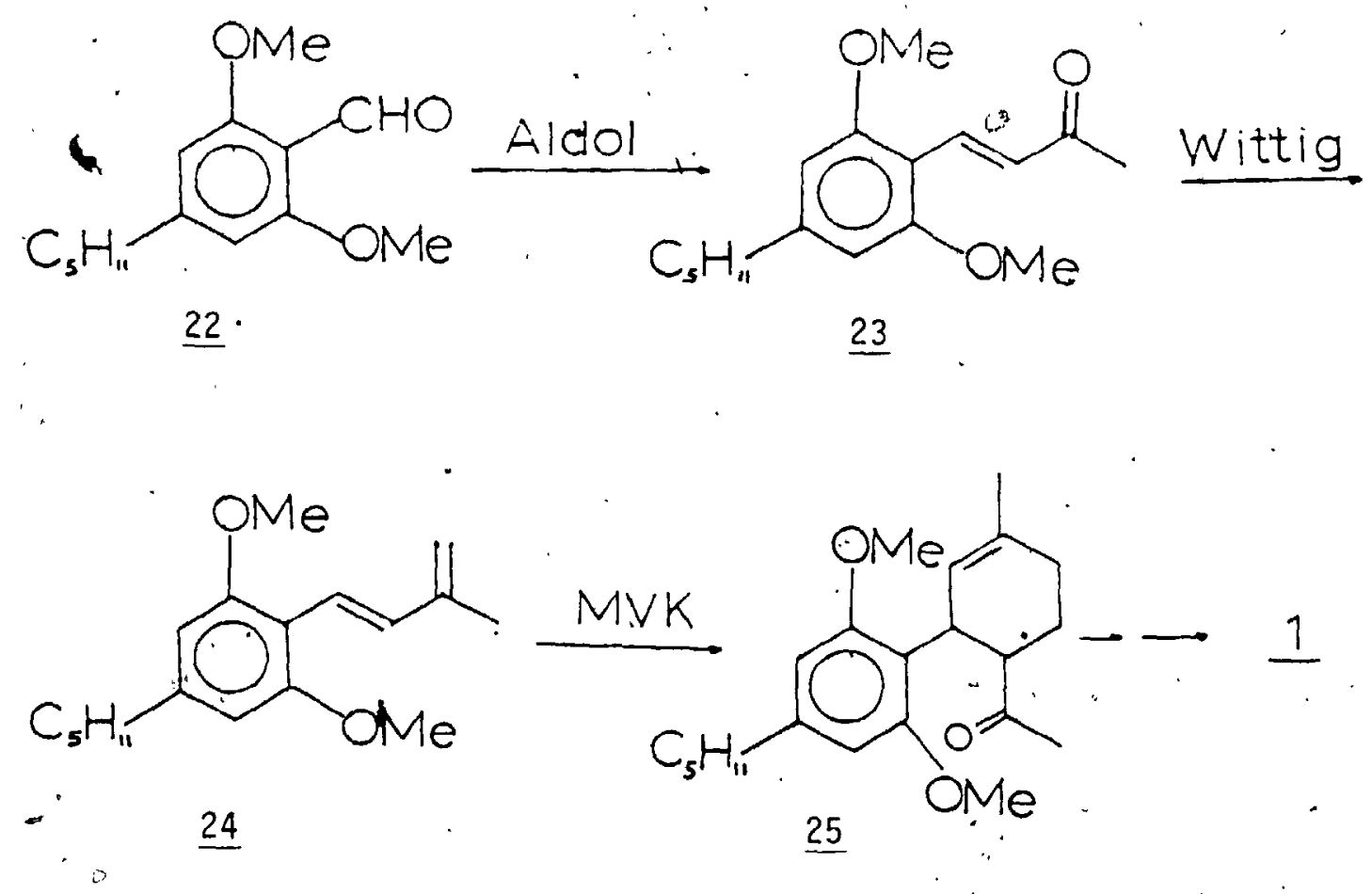

FIGURE 7

biological processes which are unique to irtsects. In

$\therefore$. man, adult development is triggered by hormones surh as hypophyseal gonadotropins, while in insects ' $J H^{\prime}$ 's prevent the" development of larva to adults; they (ie. the JH's) must be absent during metamorphosis. If $\mathrm{JH}$ is applied to an insect during metamorphosis, an insect with both aduit and - juvenile characteristics results and this "mosaic" insect cannot feed, mate, or reproduce ${ }^{23}$. After metamorphosis, the insect again produces $\mathrm{JH}^{\prime} \mathrm{s}$. In addition, a Tack of JH's during adult life induces a condition, the diapause state, where the insect dŏes not feed or mate in order to withstand adverse conditions. $\mathrm{JH}^{\prime} \mathrm{s}$. have also been shown to be responsible for ovarian development and the release of sex attractants. 



Thus it is clear that JH's themselves are not practical as an insecticide, since, they would have to be applied exactly during metamorphosis. However, if $\mathrm{JH}$ production were interrupted before metamorphosis, the insect would develop precosiously to an adult. This adult couldn't reproduce due to lack of eqgs, would be thrown into a state of diapause unnecessarily, or would not produce sex attractants. 
Farnasol was shown by Judy artd co-workers' 24 to be a natural JH in tobacco hookworm, while from cecropia other JH's where isolated 25,26 (28, 29). The development of $\mathrm{JH}_{\mathrm{H}}$ analogs with aromatic moieties, found to be at least 1000 more potent than the natura] $\mathrm{JH}^{\prime} \mathrm{s}^{25,26}$ (30,3i), led to Methoprene 27 (32) which is used for floodwater mosquito control and for the control of flies that breed on manure.

. In 1976, Bowers ${ }^{28}$ isolated two compounds from the plant Ageratum houstanianum which caused precocious. metamorphosis, prevented ovarian development, and induced diapause. These compounds, which he called Precocene 1 (33) and Precocene 2 (34) were already known as 6demethoxy ageratochromene 29 and ageratochromene ${ }^{30}$ by the groups who had characterized them. Later, Bowers and Pratt ${ }^{31}$ showed that Precocene II acted by the suppression of endogenous $\mathrm{JH}^{\prime} \mathrm{s}$, and Pever and co-workers 32 subsequently demonstrated that this suppression was due to atrophy of the corpora allata (CA), the organ responsible for the synthesis of JH's in insects.

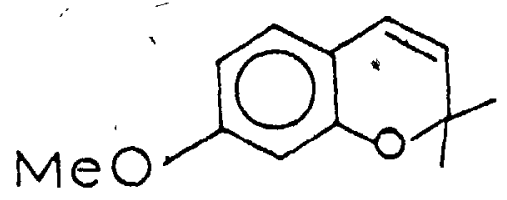

$\underline{33}$<smiles>COc1cc2c(cc1OC)OC(C)(C)C=C2</smiles>

34 
The metabolism of Precosene II was studied by Bowers and co-workers $33-36$ who hypothesized the existence of an active epoxide metabolite, which wạs isolated as a diol after reaction, with water, as well as o-demethylated and hydrated products (Figure 8).. Chromene epoxides have been shown to be very reactive to nucleophites 36,37 giving cis-diols by a proton catalyzed ring opening or trans diols by a nucleophilic mechanism. Pratt and coworkers. 38 showed that certain insects may be protected from the action of Precocene by treatment with mixed function oxidase inhibitors, supporting the theory of metabolic activation. Later they demonstrated ${ }^{39}$ the

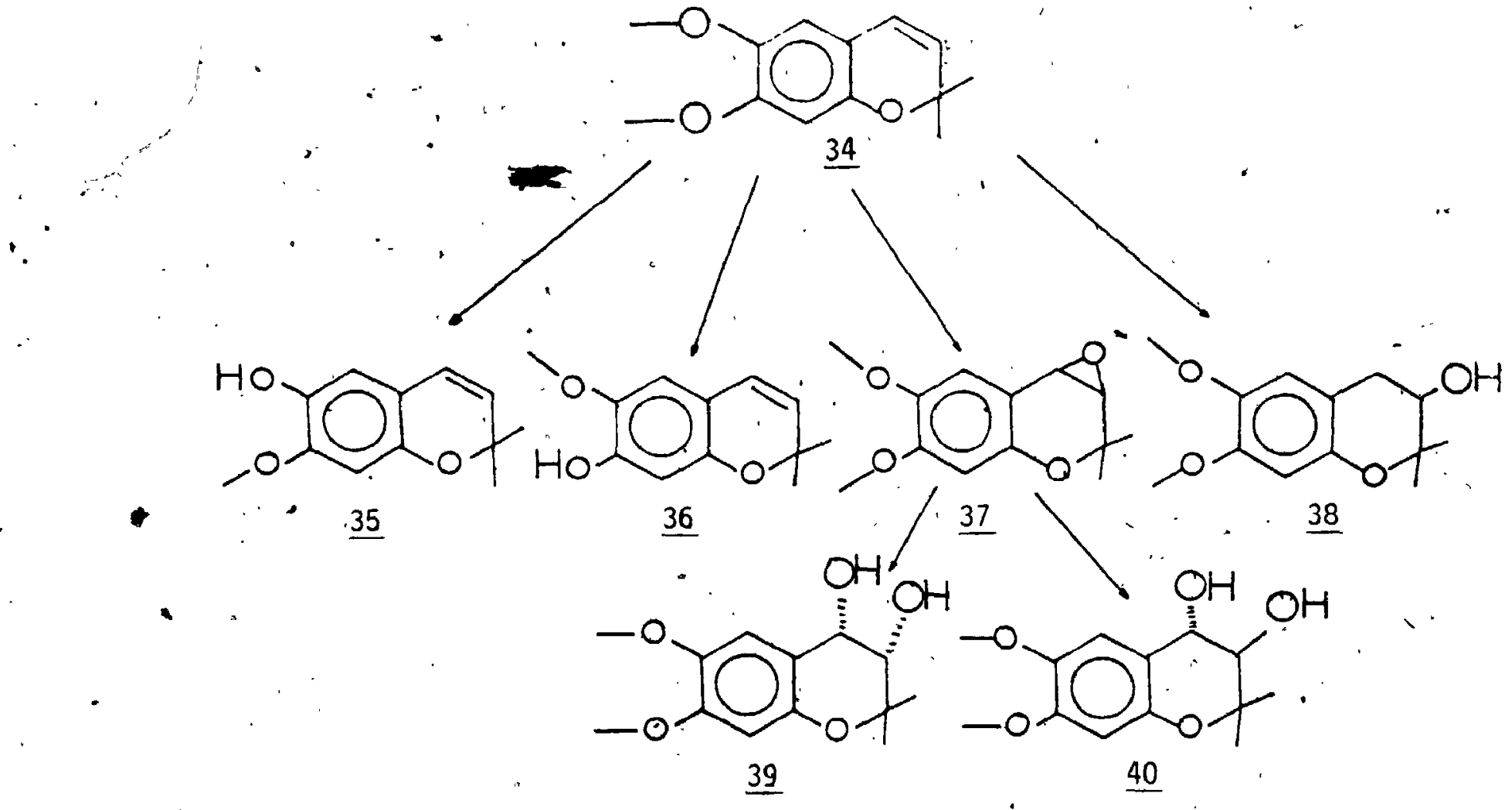

FI GURE 8 
covalent attachment of labelled Precocenes in the CA, - and the concentration of diols in that same organ. However, in 1980 Bergot and co-workers 40 showed that in some insects the 6 -and $7-0-\beta$ glucopyranosides .41; 42) were the major metabolites, rather than the diols, which'sheds doubt on the actual, mechanism of action of the Precocenes.

$\because 5$ Vyas and Mulchandani 41 examined the biosynthes is of Precocenes I and I.I. Using labelled acetate and mevalonic acid it was shown that the acetate moiety carbon's become, the aromatic nucleus, while the mevalonic acid accounts for the activity of. the * radioactivity of one of the gem-dimethyls. They suggest that the aromatic ring condenses with

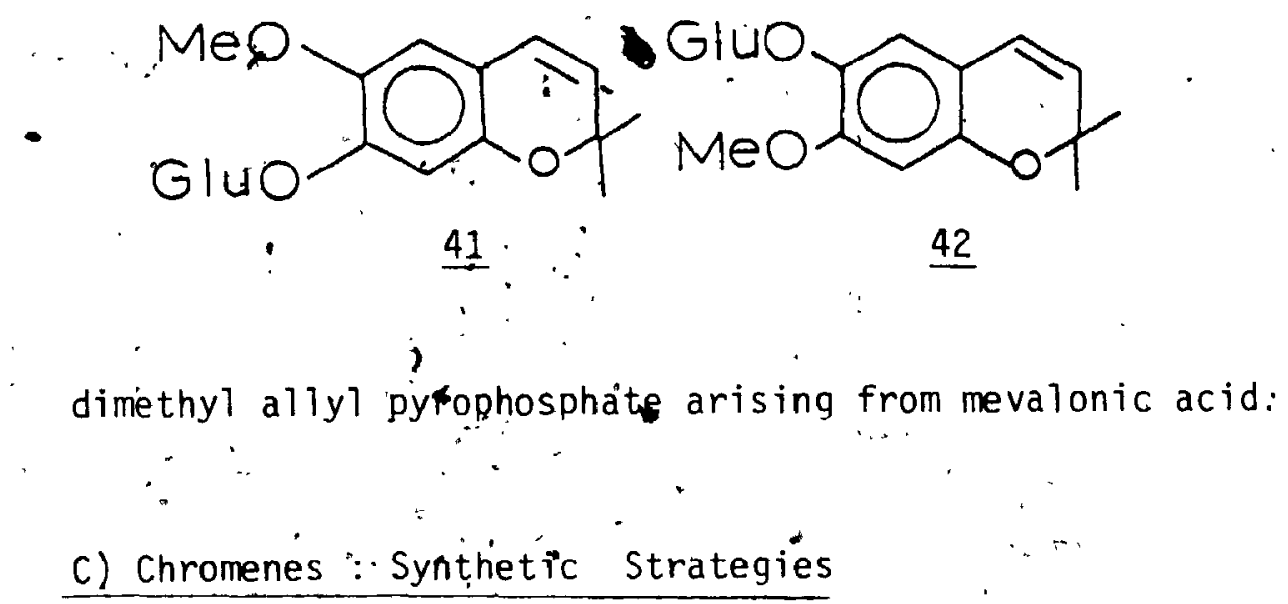

- The synthesis of 20dimethyl chromenes may be approached either by the preparation of another related ring system with subsequent variation of functionality. 
or by alkyiation of a free phenol followed by cyclization onto the aromatic ring. Among the former, the earliest approach was the aikylation of a coumarin with a Grignard reagent ${ }^{42}$. In $190^{\circ}$, Fellenberg and Decker ${ }^{43}$ showed that the mechanism involves an intermediate pyrilium salt (45) which was isolated after neutralization with $\mathrm{HCl}$ (Figure 9).

The most popular route to 2,2-dimethyl chromenes uses the 4-chromanone system as an intermediate. The first example was published by Beneze and co-workers 44 who synthesized 2,2-dimęthyl-5,7-dimethoxy-3-chromene by reduction of the chromanone with $L A H$. followed by dehydration with phosphoryl chloride in pyridine (Figure 10). Other dehydration agents used have included $\mathrm{HCl}^{45,46}, \mathrm{p}$-toluene sulphonic acid ${ }^{47}$, and aluminum oxide 48 . Not âr 4-chromanols may be dehydrated under acidic conditions, however. On<smiles>O=c1ccc2ccccc2o1</smiles>
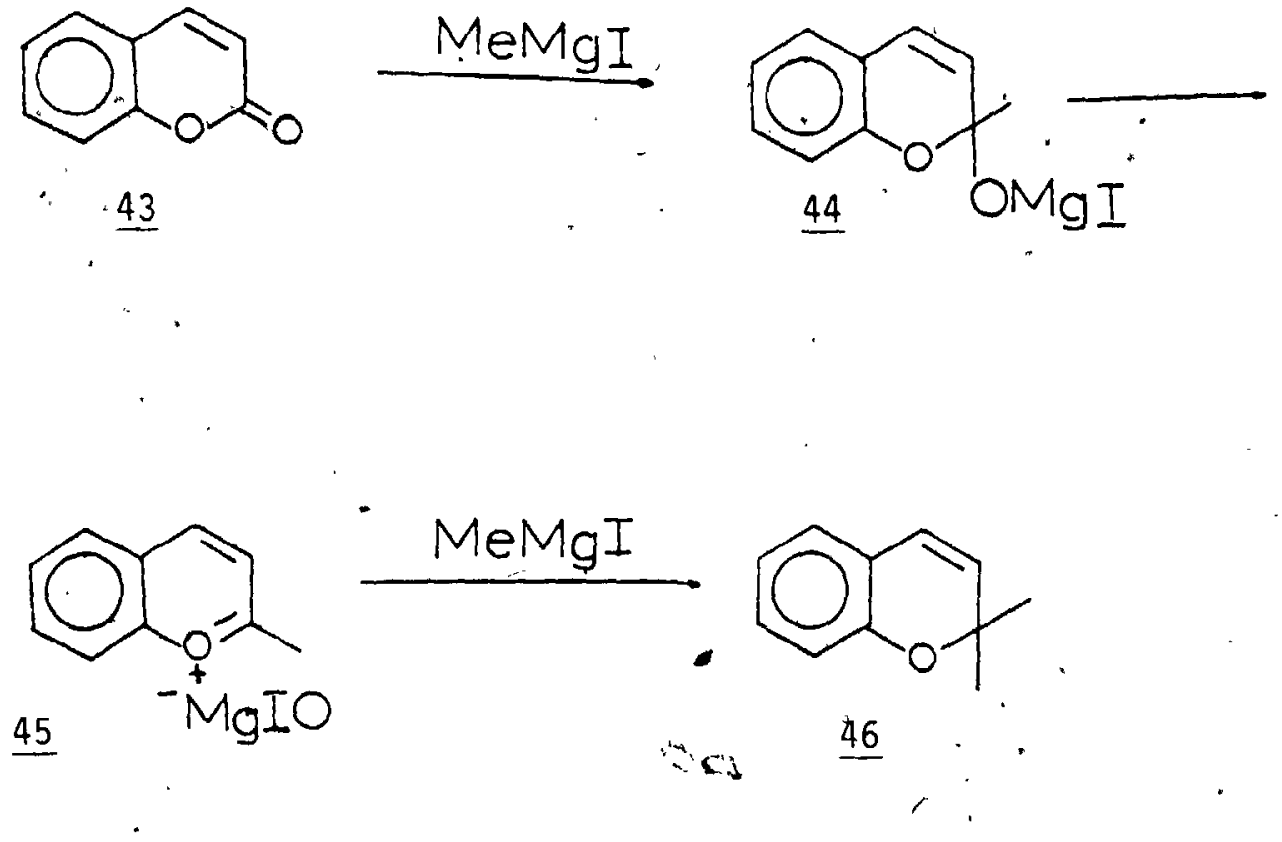

FIGURE 9 


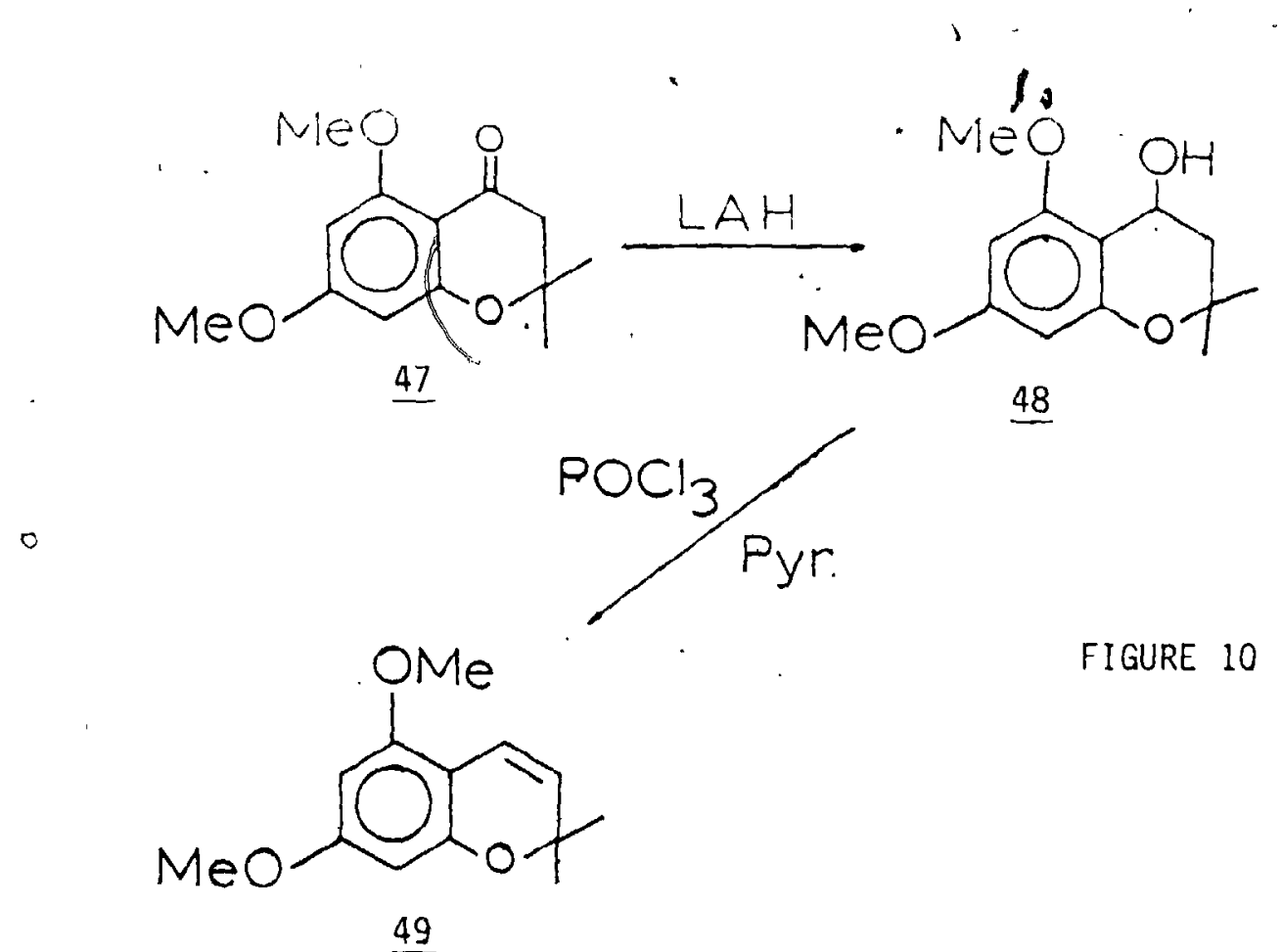

the basis of results. by Livingstone and Whiting ${ }^{49}$,

Fukami and co-workers ${ }^{50}$ reparted the synthesis of dimer 50 by letting 51 stand in $20 \% \mathrm{H}_{2} \mathrm{SO}_{4}$. This same group also reported the synthesis of intractable red resins in the attempted demethylation of $\underline{51}$ with $H I$ or aluminum chioride. Kasturi and Manithomas ${ }^{51}$ isolated a dimer of Precocene II and based on NMR data assigned structure

$\sim$<smiles>COc1cccc2c1C1C3c4c(OC)cccc4OC(C)(C)C3C1C(C)(C)O2</smiles><smiles>COc1cccc2c1C=CC(C)(C)O2</smiles> 


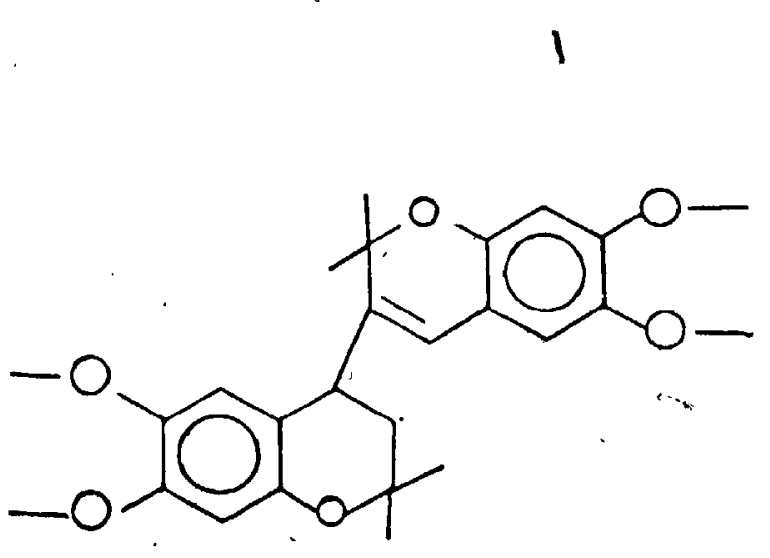

8

52. Schwartz ${ }^{52}$ confirmed this synthes is and showed that

Precocene I does not dimerize in an analogous fashion, but polymerizes.

The synthesis of 2,2-dimethyl-4-chromanones may be accomplished by two general methods. The simplest is the condensation of an $\alpha, \beta$-unsaturated acid with a phenol in the presence of an acid catalyst (Figure 11). Successful. catalysts have been $\mathrm{HF}^{53}$, antimony chloride ${ }^{53}$, a mixture . of zinc chloride and phosphoryl chloride ${ }^{54}$, polyphosphoric $\operatorname{acid}^{55}, \mathrm{BF}_{3}$ etherate ${ }^{56}$, and methane sulphonic acid ${ }^{57}$, the reagent of choice. Condensation withresorcinol affords only the $7-0 \mathrm{H}$ regioisomer. Alternately, the 4-chromanone system may be synthesized via the appropriate o-hydroxy acetophenone. Aldol condensation with acetone in the<smiles>CC(C)=CC(=O)O</smiles> 

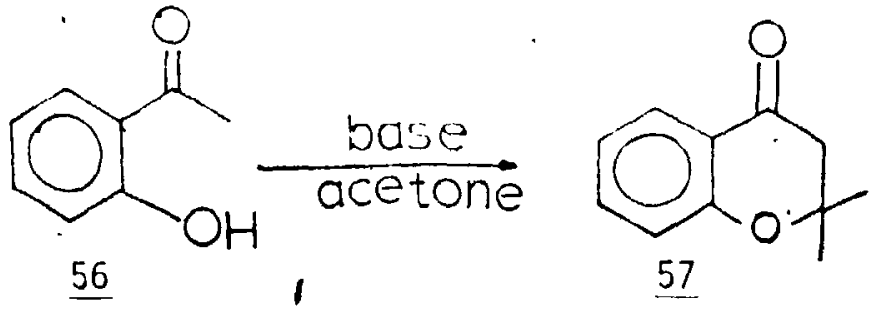

FIGURE 12

presence of bases (Figure 12) such as LDA ${ }^{58}$ or pyrollidine 57

affords the chromanone in generally good yields.

The 2,2-dimethyl chroman system is another widely used precursor to chromene systems. Early syntheses started with the corresponding 4-chromanone system, reducing the ketone, under clemmensen conditions 60 or with diborane 61 . Gujral and Gupta 62 , in the ir synthes is of 6-desoxyjacáreubin (58) and 6-desoxyisojacareubin (59), formed a chroman ring sys,tem by preniylation of an aromatic intermediate 60 with 2-methylbut-3-en-2-ol (Figure 12a) in the presence of $\mathrm{BF}_{3} \cdot \mathrm{Et}_{2} \mathrm{O}$. This method was also successfully used by Jain and co-workers ${ }^{63}$ in their synthesis of lupinifolin $(\underbrace{62})$. Jain and co-workers ${ }^{64}$<smiles>CCCCCC</smiles>

$\underline{60}$

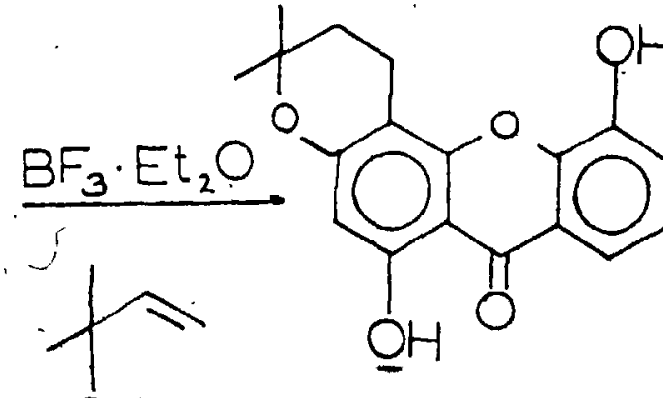

$\underline{61}$ 

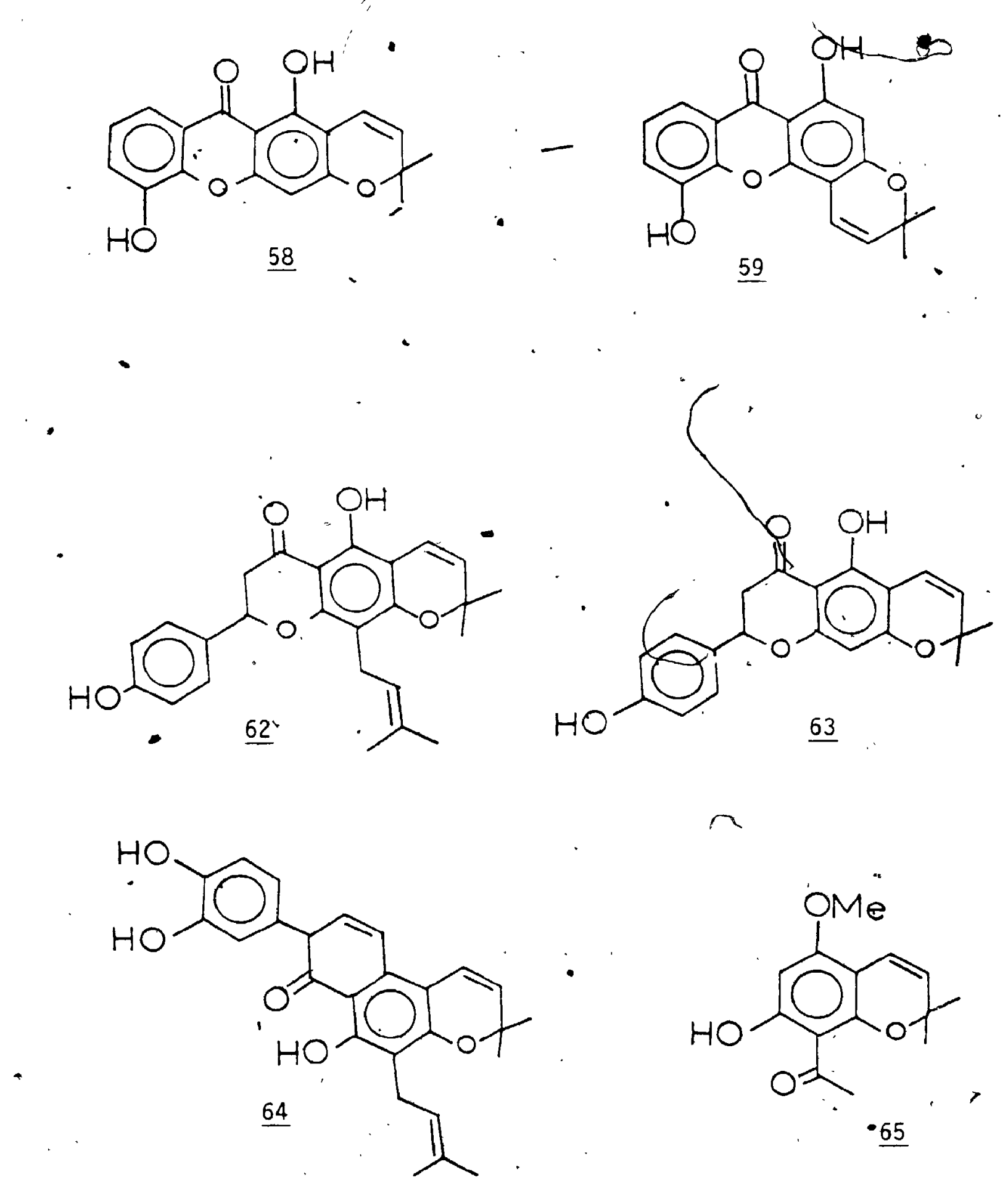


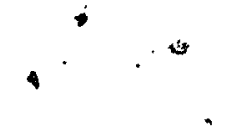

in their synthesif of the carpachromene 63, prenylated

- the aromatic precuysor with dimethylallyl bromide in the presence of sodium methoxide and,working with-still

* another group , elaborated a route to pomiferin (64) using virtually identical conditions. The dihydro .' derivative of alloevodionol-( $\underline{65})$ was synthesized by. Cardillo et al ${ }^{66}$ by prenylation of the aromatic nucleus with dimethylallyl bromide and n-BuLi. Steelink and Marsha $11^{67}$. prenylated 1-acety $1-2,4-$ dihydroxybenzene with"2-methyl-3-en- 01 and formic acid, but only obtained a $7 \%$ yield, Recently . Tachibana ${ }^{68}$ introduced a novel metal resin catalyst which he showed to be effective for the production of 7-OH chroman. systems from resoretnol and allylic bromides..

Camps and co-workers ${ }^{76}$ investigated bis[acetylacetonato]-nicke] as a catalyst for the. condensation of phenols with 1,3-dichloro-3-methyl butane (83), a stable and readily available material. In their hands the reaction of resorcinol monomethyl ether (82) and 83 gave a $65 \%$ yield of 7 -methoxy-2,2dimethyl chroman ( $\underline{84}$ ) and 5-methoxy-2,2-dimethyl chroman $(\underline{85})$ as a $2: 1$ mixture (Figure 16).

Formation of the chromene system from its corresponding chroman may be effected by halogenation-dehydrohalogenation or hydride abstraction. 


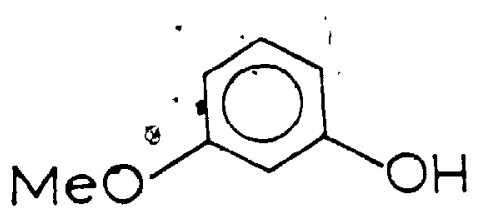

$\underline{82}$

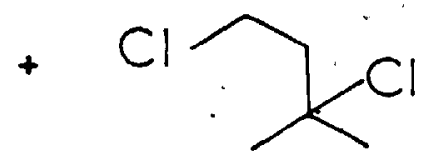

$\underline{83}$

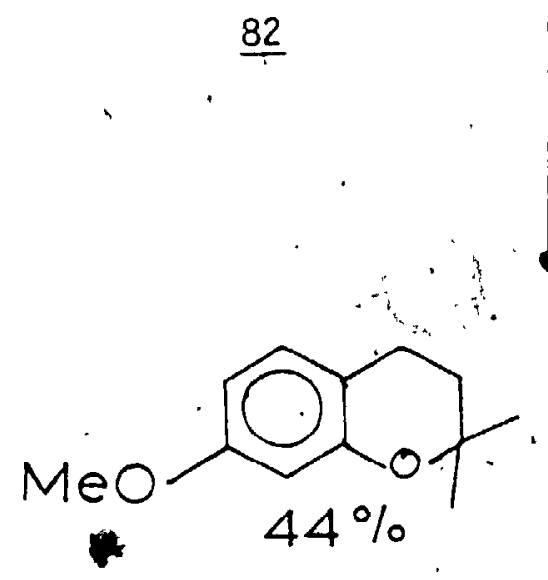

84

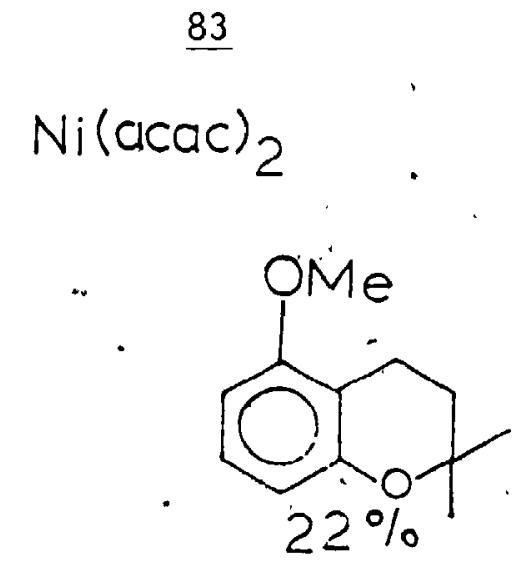

85 Fukami and Nakajima ${ }^{60}$ used NBS in $\mathrm{CCl}_{4}$ to benzylically brominate the acetate ester of '5-hydroxychroman, and then dehydrobrominated with triethanolamine. By far the most used method, however, is hydride abstraction with $\mathrm{DDQ} 66,62$, $70,65,64,63$. Meikle and Stevens ${ }^{71}$ fourd this reaction sensitive to substitution on the aromatic ring. Attempts to synthesize 5,7-dihydroxy-3-chromene by this route were unsuccessful as any phenol protecting group which could be removed under conditions which would not affecthe chromene system (e.g. acetyi, benzoyl, tosyl) prevented, any reaction from occurring. These workers noted that since no deep colouration was formed in solution after. addition of $D D Q$, a charge transfer complex was not forming. They blamed reduced electron density on the aromatic nucleus as the primary,factor, and considered steric factors to be relatively unimportant. 
<smiles>CC1=CCc2ccccc2O1</smiles>

$$
\underline{66}
$$

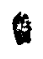<smiles>CC(C)=CC=C1C=CC=CC1=O</smiles>

$\underline{68}$

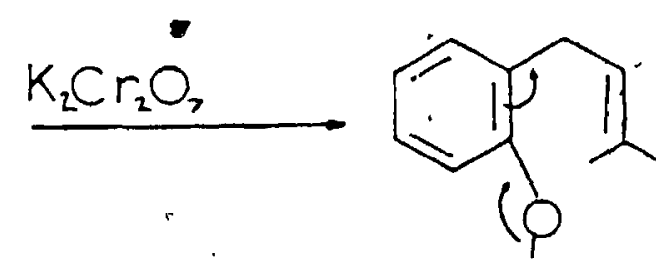

$O=C_{0} r=0$

$\underline{67}$

FIGURE 13

Alternately, the prenylated aromatics may be directly cyclized to a chromene system. Cardillo and co-workers ${ }^{69}$ reported the reaction of ortho-prenyi phenols with potassium dichromate in benzene in the presence of a phase transfer catalyst, Adogen 464. They proposed an intermediate chromate ester (므) which decomposes to an o-quinoneallide (요), followed by cyclization (Figure 13). He also described the same reaction using DDQ (70) in diethyl ether. In 1979, Bongini and co-workers ${ }^{72}$. described the same cyclisation with n-iodosuccinimide<smiles>N#CC1=C(C#N)C(=O)C(Cl)=C(Cl)C1=O</smiles> 
$f$

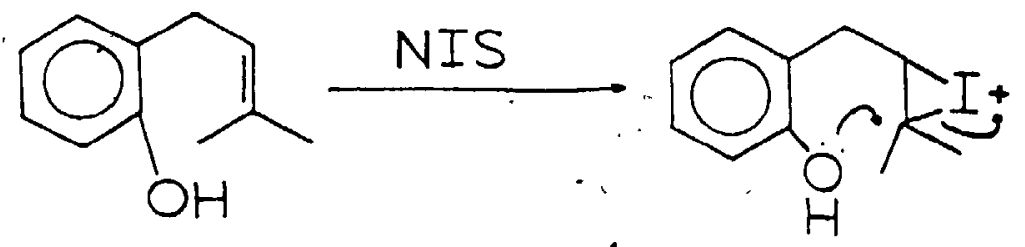

66

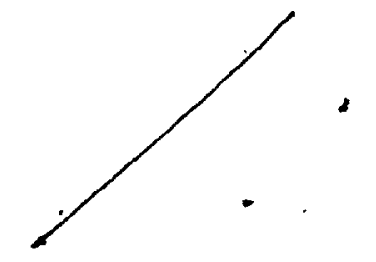

71.

FIGURE 14

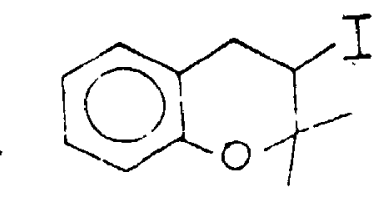

2ㅡ
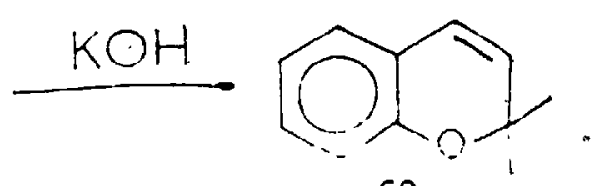

69

(Figure 14). This method is unsuccessful, however, with materials where the aromatic ring has many electron donating groups, facilitating ring iodination: The attempted synthesis of Precocene I, however, gave the correct material in $82 \%$ yield.

After having observed that citral reacts with $\mathrm{m}-$ dihydroxy phenols, with one of the hydroxyls chelated, to give chromenes, Crombie and co-workers synthesized a variety of 2,2-dimethyl chromenes using the synthon 3-hydroxy-3-methy1-1,1-dimethoxy butane (73). For example, reaction of 73 with 2,4-dihydroxyacetophenone in pyridine gives a $59 \%$ yield of 6-acetyl-5-hydroxy-2,2dimethyl chrom-3-ene. Using this method, this group<smiles>COC(CC(C)(C)O)OC</smiles> 

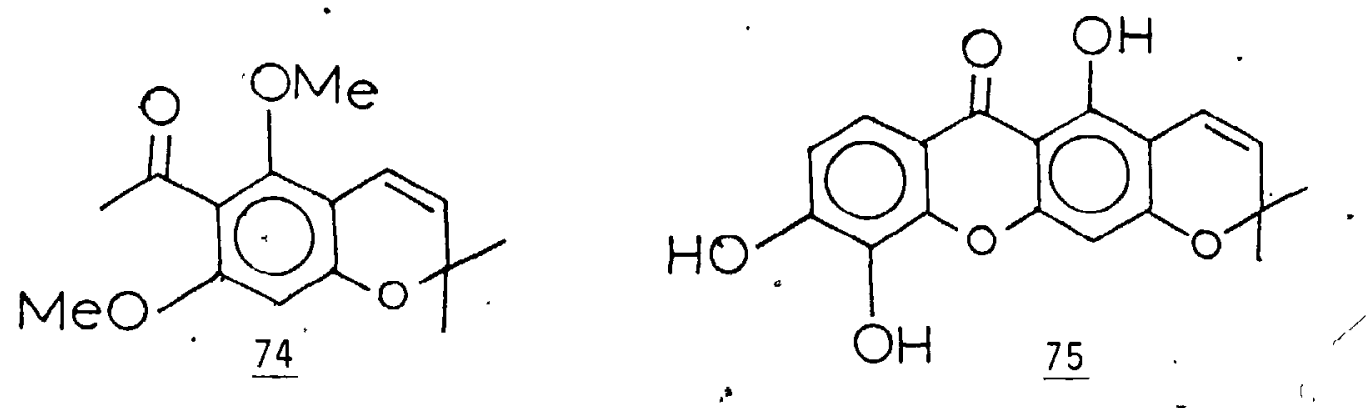

easily synthesized evodionol 7-methyl ether (74), and . jacareubin (75). 23 does not significantly dehydrate in pyridine at the reaction temperatures ( $90 \%$ recovered

-) after 48 hrs), so the reaction probably does not proceed through 3-methyl-but-2-enal dimethyl acetal. Camps and co-workers ${ }^{74}$ used this method to produce the trifluoromethyl analogue of Precocene II (76), using acetal $\underline{77}$.

The mesylate was necessary to offset the increased carbon-oxygen bond strength due to the trifluoromethyl group. Sartori and co-workers ${ }^{75}$ reacted metal phenotates with $\alpha, \beta$-unsaturated aldehydes and ketones in toluene and obtained good yields of chromenes. Titanium, magnesium,

- tin and aluminum phenolates were all found to be reactive species, but highly co-ordinating solvents (e.g. DMF,
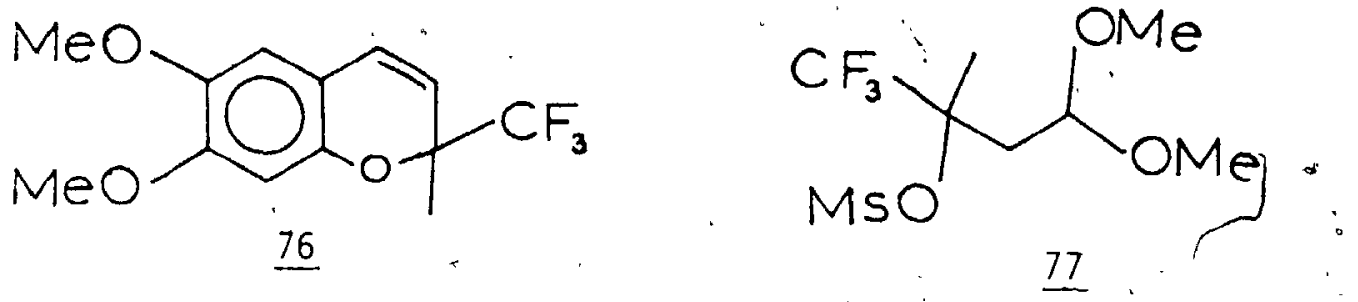


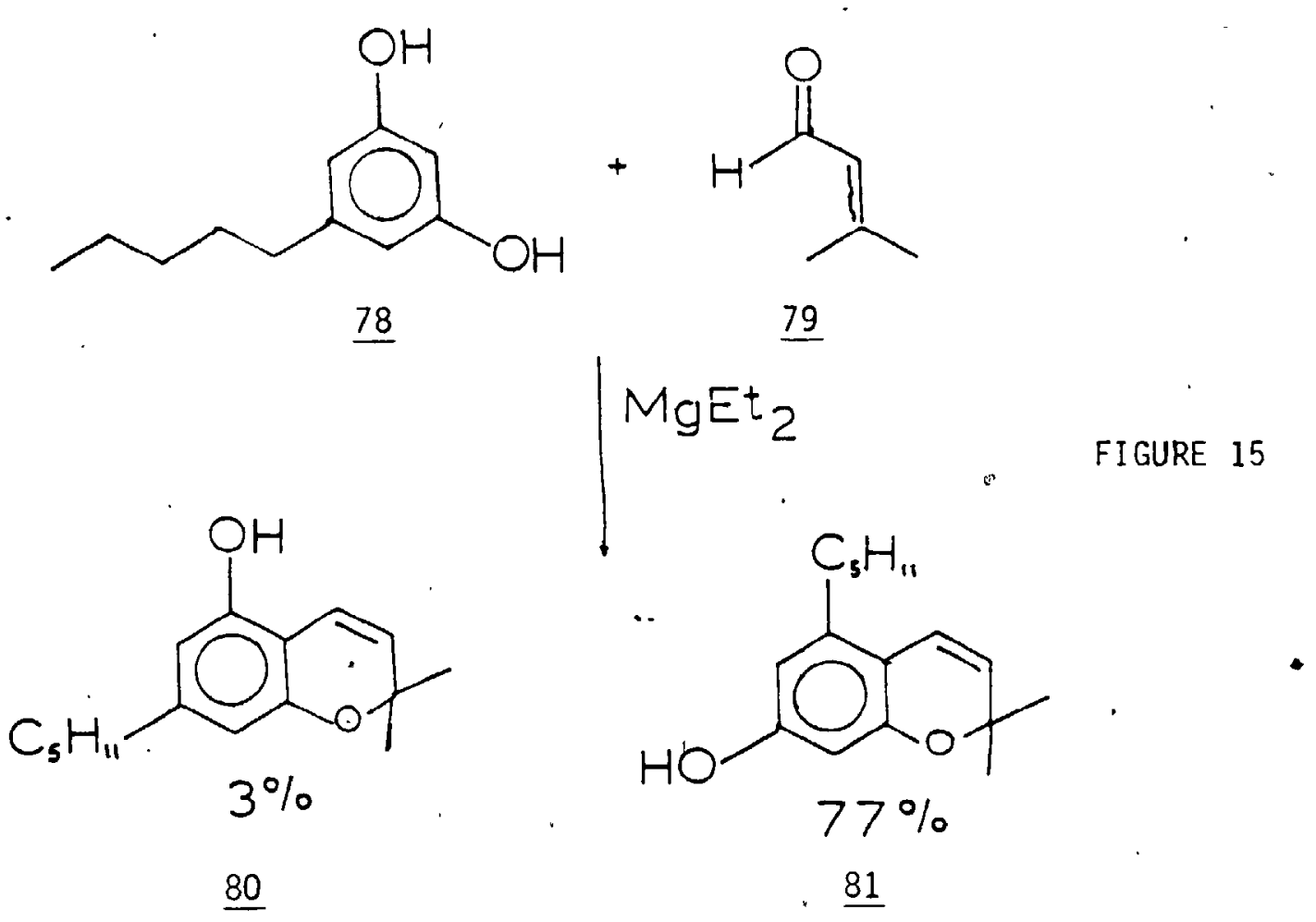

glyme, HMPA, TMEDA) causes failure of the reaction. The reaction is highly regioselective. The condensation of olivetol (78) with 3-methyl-2-butenal (11) gives the "unnatural" 5-pentyl isomer in $77 \%$, and only $3 \%$ of the "natural" 7-pentyl isomer (Figure 15).

In 1962, Iwai and Ide ${ }^{76}$ first reported the synthes is of chromenes from the claisen rearrangement of propargyi aryl ethers. Hlubecek and co-workers ${ }^{77}$ developed syntheses of Precocene I and II; 0-alkylation of 3-methoxy or 3, 4-dimethoxy phenol with 3-chloro-3-methyl-1-butyne in acetone in the presence of potassium cárbonate, followed by cyclization in $\mathrm{N}, \mathrm{N}$-diethylaniline, gives the chromenes in $70-90 \%$ yield (Figure 16). Ansari and co-workers ${ }^{78}$ used 


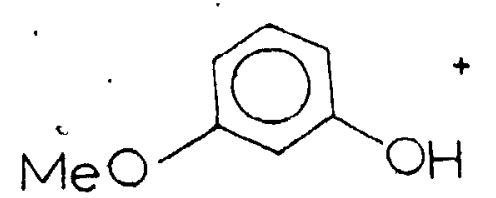

$\underline{82}$

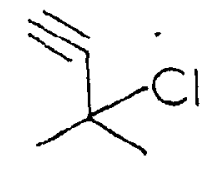

86
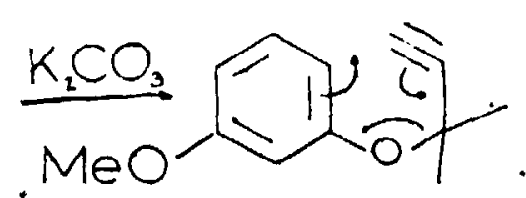

87

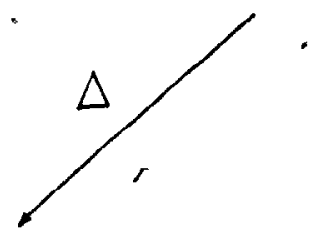

FIGURE 16<smiles>C=CC1C=CC(OC)=CC1=O</smiles>

$\underline{88}$

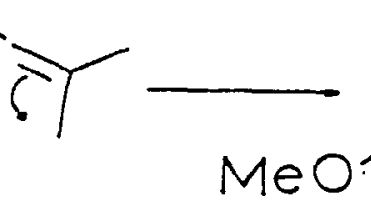

•

33

this method starting with 2-hydroxy-4;6-ditosyloxy acetophenone ( 89 ) and got only the 8-acetyl chromene (90) (Figure 17) as product, without any rearrangement to the 6-acetyl dèrivative, as was reported in similar cases 79,80 . As we 11,C-propargylation was inhibited,as described for phloroacetophenone 81 (91) and 2-hydroxy-4-methoxy ace tophenone $^{82}\left(\underline{92)}\right.$. Ahluwalia and co-workers ${ }^{83}$ synthesized

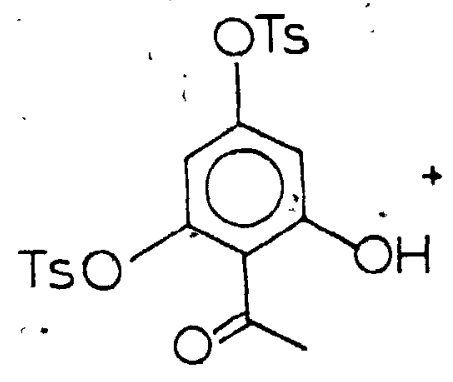

89<smiles>C#CC(C)(C)Cl</smiles>

$\underline{90}$ 


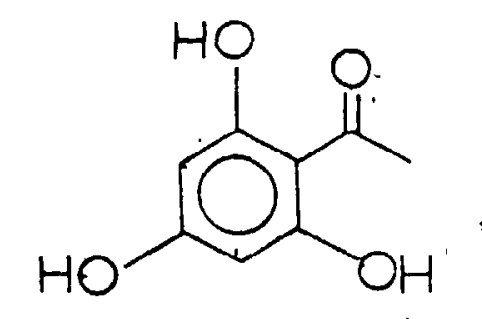

91

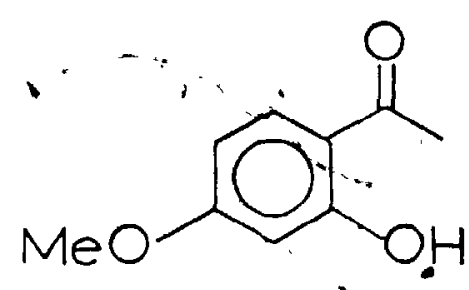

: 92

various linear pyranocoumarins, controlling the cyclisation of the chromene with a blocking group which could be later ; removed. Thus, reaction of 7-hydroxy-5-methoxy coumarin (93) with iodine/periodic acid gave the 8 -iodo derivative 94, which was 0-alkylated with 3-chloro-2-methyl-1-butyne. Refluxing in DMF cyclized and eliminated iodide, giving xanthoxyletin (96) in about $27 \%$ yield from 93 (Figure 18 ).

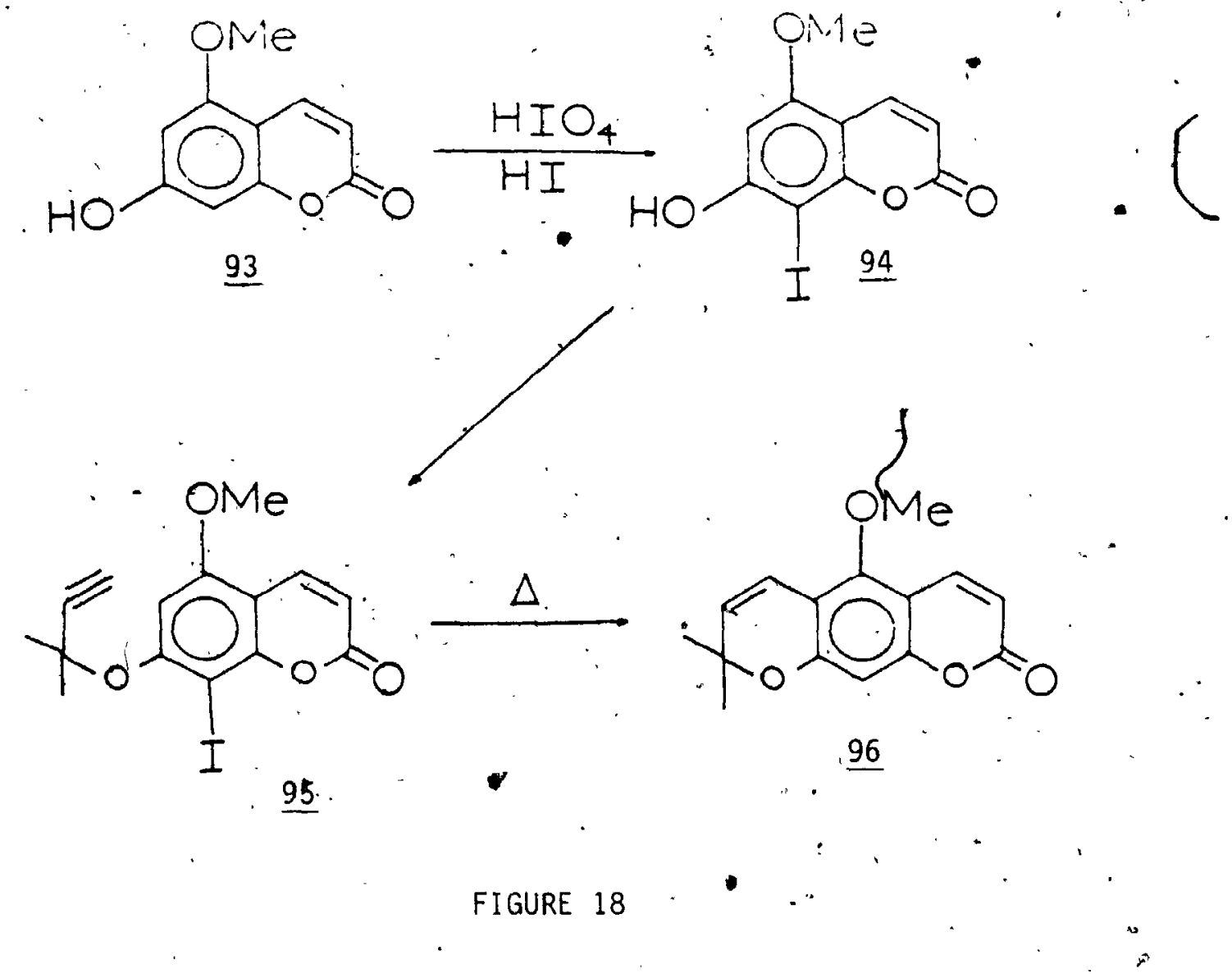


- Begasse and Le Corre ${ }^{81}$ synthesized a variety of chromenes from o-hydroxybenzyl triphenylphosphonium salts. and $\alpha$-halo carbonyl compounds in the presence of base

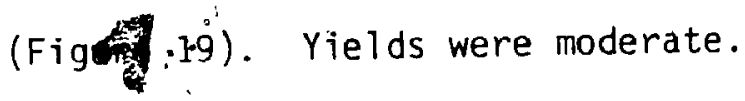
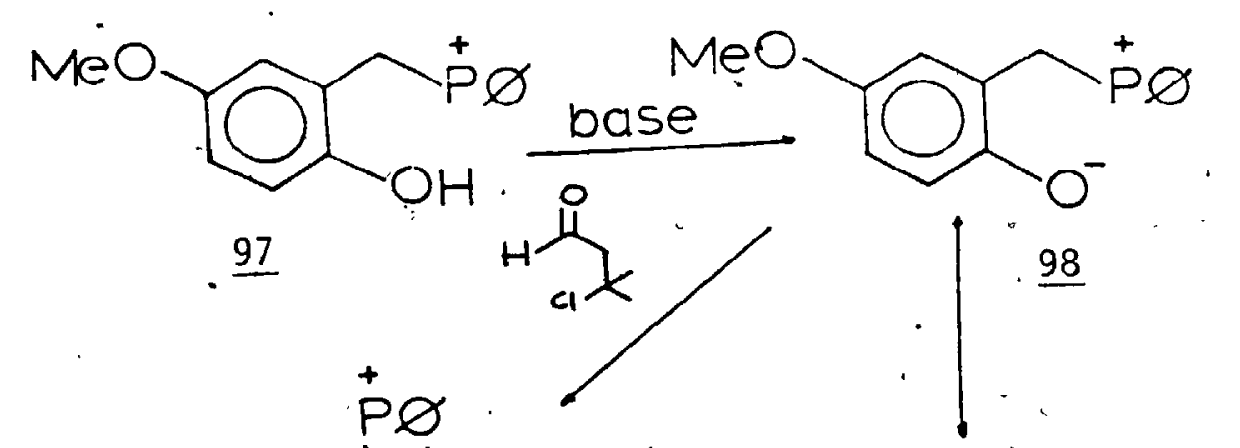

$\underline{97}$
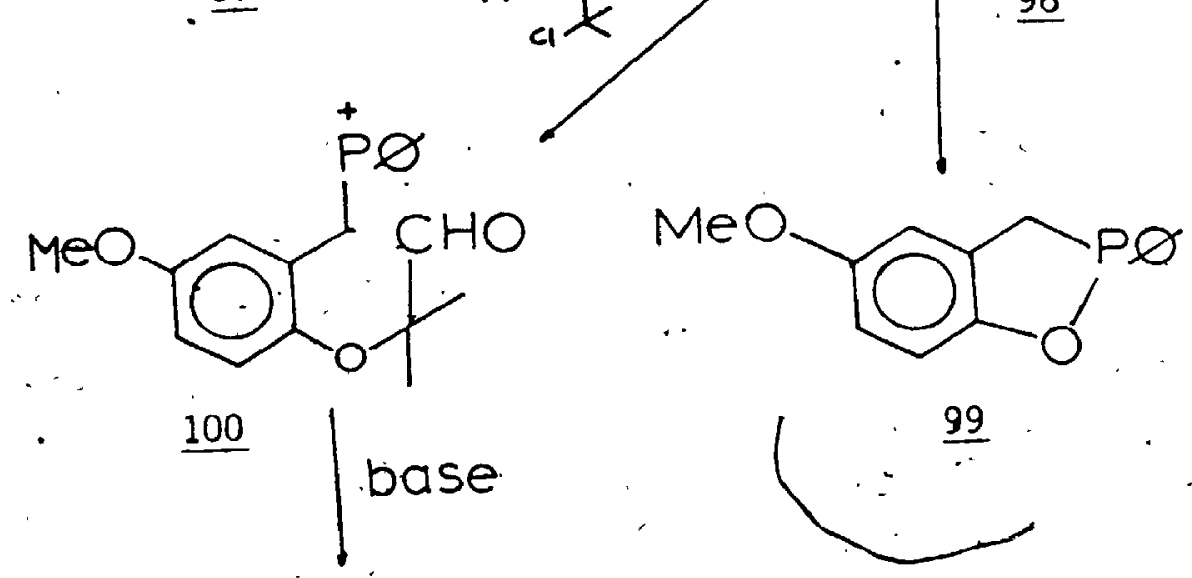

99
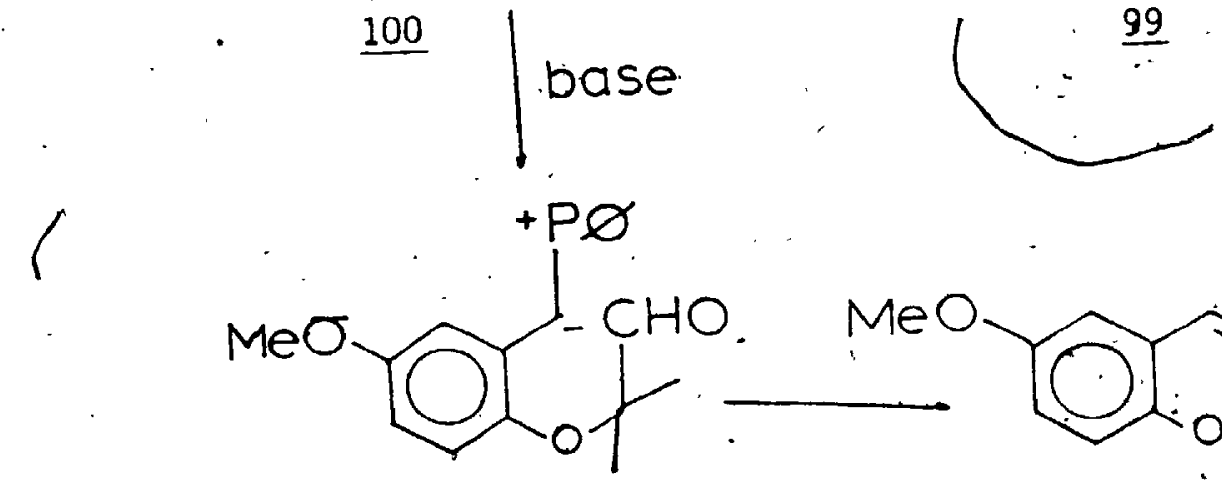

101

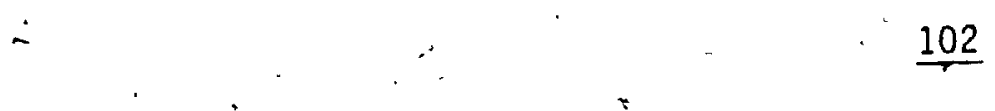

FIGURE 19- 


\section{Results and Discussion}

To investigate the synthetic utility of the approach outlined in Figure 4, a chromene hydroxylated in the five Dosition, such as $\underline{17}$, was required. 2,2-dimethy1-5-hydroxy chromene (103) was chosen as a model compound and its synthesis undertaken. The initial approach is outlined in Fiqure 20. The formylation of 104 occurred in $40-50 \%$ yield, but this reaction has been improved by the use of DMF 85 as the formylating aqent. Reaction of 105 with the stable phosphorane 86106 occurred cleaniy in high yield. However, the one pot Grignard fusion methylation and dealkylation ${ }^{15}$ gave only about $30 \%$ of the desired.
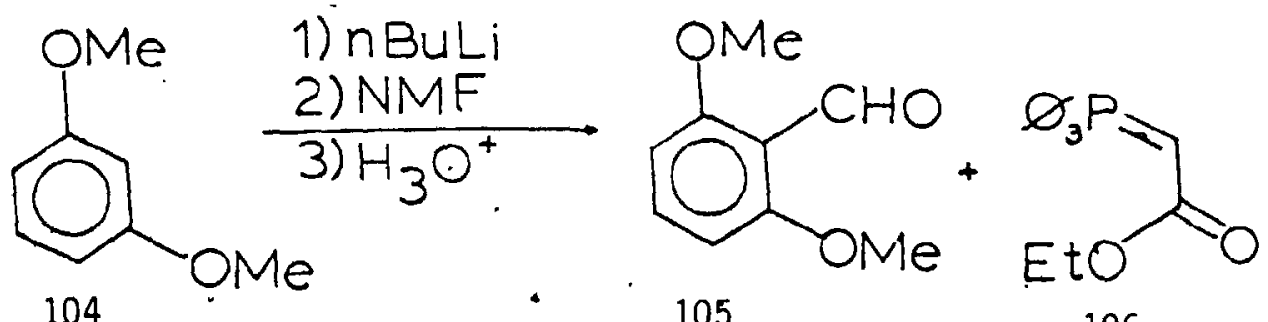

$\underline{104}$
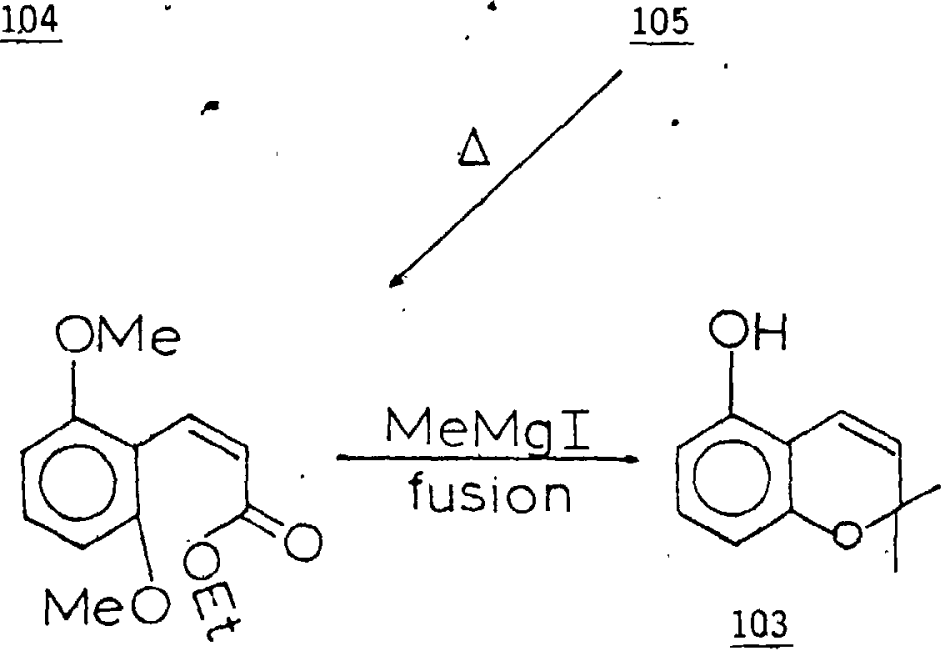

$\underline{103}$ 
product. Although this route would provide enough material for any desired model studies, it was unsatisfactory for a multistep cannabinoid total synthesis; alternate methods were required. Low yields also plaqued the syntheses of 103 and its methyl ether 51 devised by Fukami and co-workers ${ }^{50}$, and so it was not considered further. However, their work clearly demionstrated that selection of the appropriate phenol protecting group was paramount, since it hagto withstand a variety of reaction conditions and yet be removed by conditions which would not disturb the labile chromene double bond. Synthesis of 7-OH chromenes - A Model System

As a first attempt, the tosyl group was used to protect the phenol on the readily available chromanone

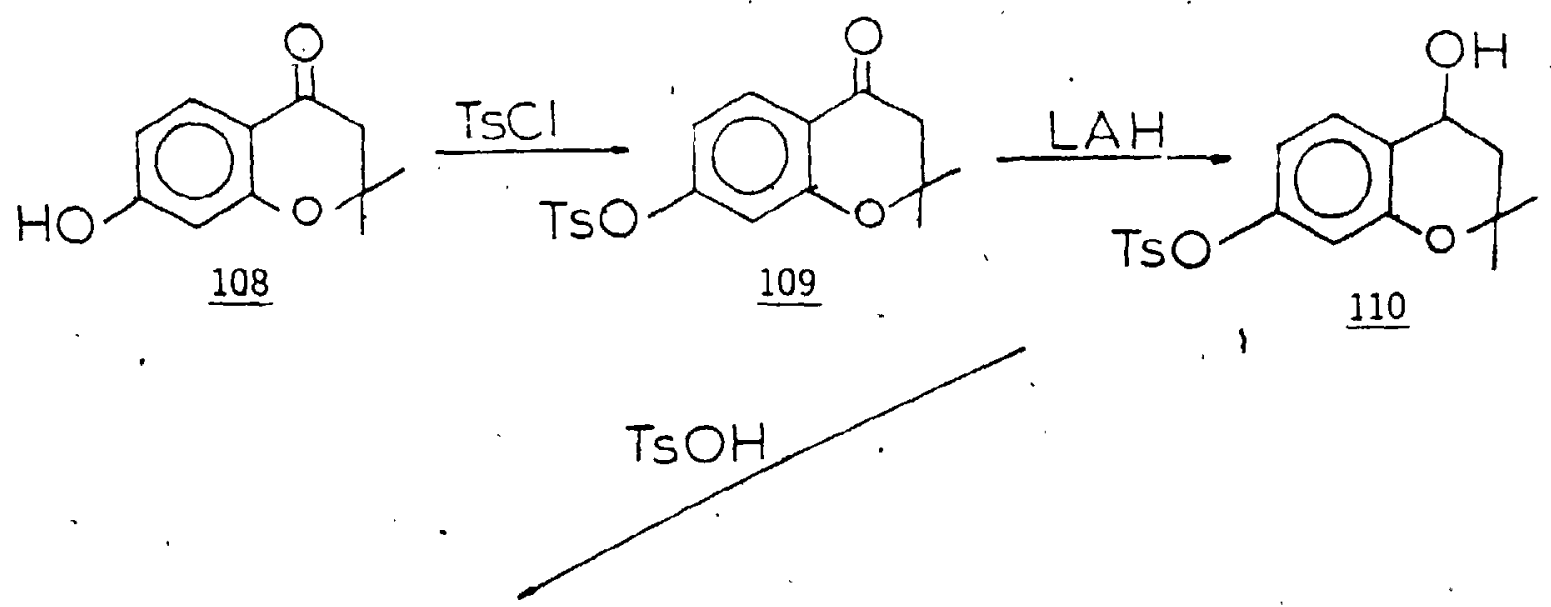<smiles>CC1(C)C=Cc2ccc(OS)cc2O1</smiles>

111<smiles>CC(O)C(C)(C)O</smiles>

$\therefore 112$

FIGURE 21 
system 108 (Figure 21). Generation of the chromene system was possible in a simple fashion, the only problem being the loss of a small amount $(220 \%)$ of the chromanol 110 due to competing detosylation by LAH. However, hydrolys is of the tosyl group did not occur on treatment with $\mathrm{KOH}$ and only tars were iso; ated; photochemical cleavage was also ineffective. 87 In addition, reaction of 111 with the Danishefsky ${ }^{88}$ diene 1-methoxy-3-trimethyls ilyloxy-1,3butadiene failed to givé any Diels-Alder adduct.

Several rather simple routes to the $7-\mathrm{OH}$ chromene were synthesized in $50 \%$ yield but gave only tars on reaction with DDQ. The second was an attempt to react resorcinol

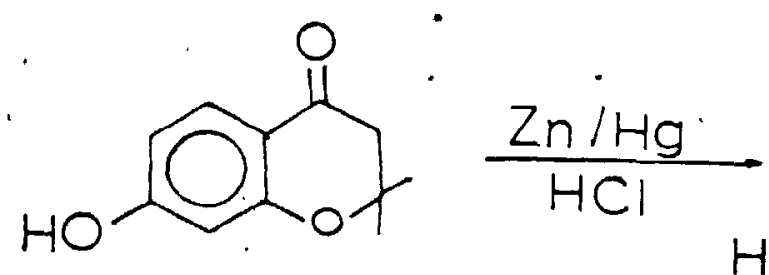

108

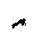

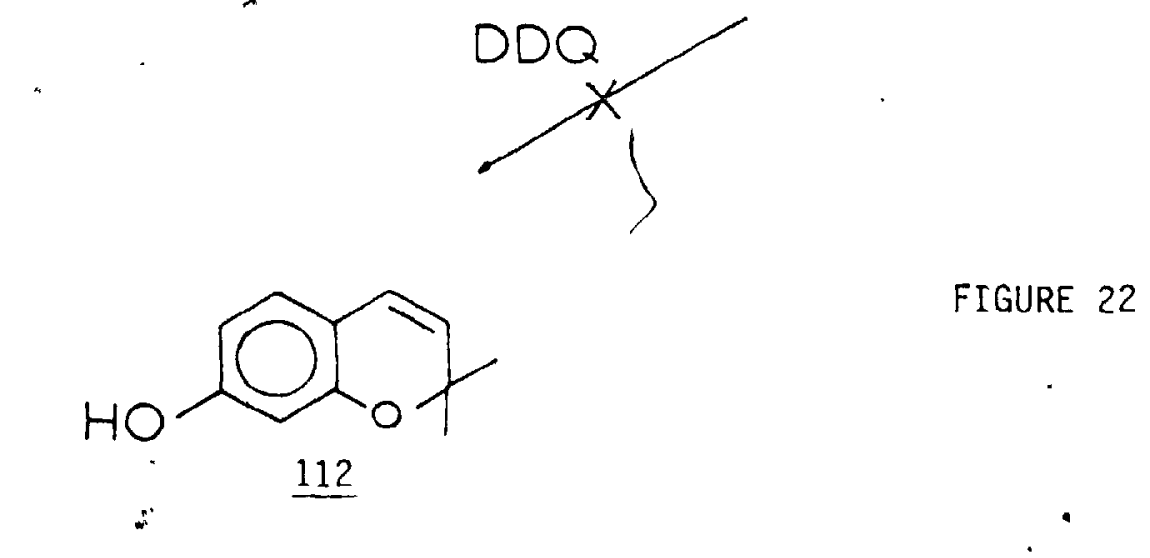

FIGURE 22

\section{$\underline{113}$}

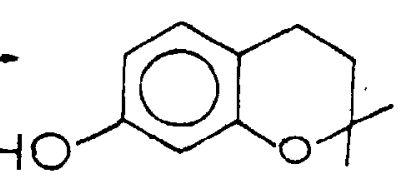<smiles>[Mg][Mg]</smiles> 
(53) with 73 despite the absence of a chelated hydroxyl in 53 (Figure 23); no reaction was detected.

As the methodology for the syn'thes is of 5-hydroxylated chromanones was developed in parallel studies, work on this series of compounds was discontinued. 's' Synthesis of 5-OH Chromenes

Since the reaction of $B, B$-dimethyl acrylic acid. with resorcinol qives only the $7-\mathrm{OH}$ chromanone, a method of insuring the correct $5-\mathrm{OH}$ regioisomer was necessary. Formylation such as was described earlier was not likely using unprotected phenols. However, it is possible to" synthesize, in high yields, 2,6dihydroxyacetophenone (117) from resorcinol via

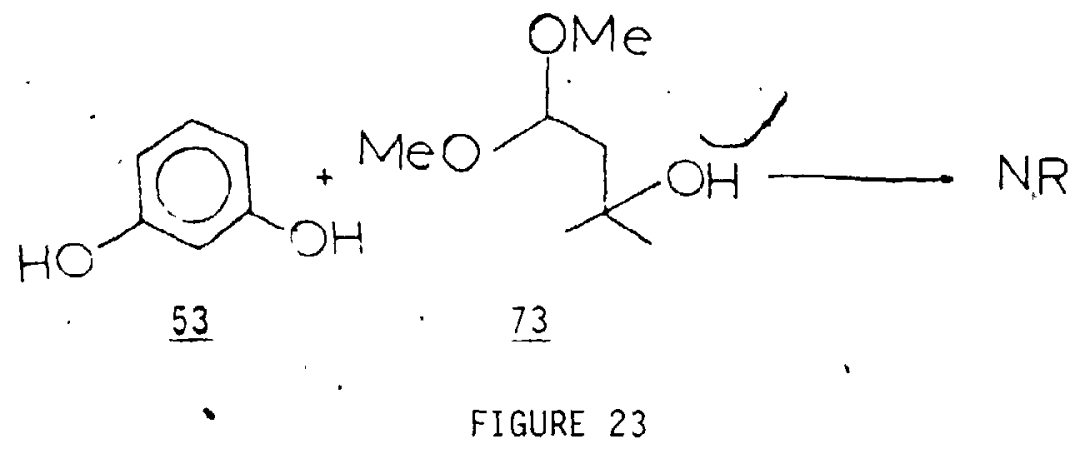

the appropriately substituted coumarins ${ }^{89}(114 \rightarrow 116$, Figure 24). Cyclization to the chromanone (118) with pyrrolidine and acetone using conditions developed by Kabbe $^{59}$ occurred cleaniy in $\sim 75 \%$ yield (Fiqure 25 ). 


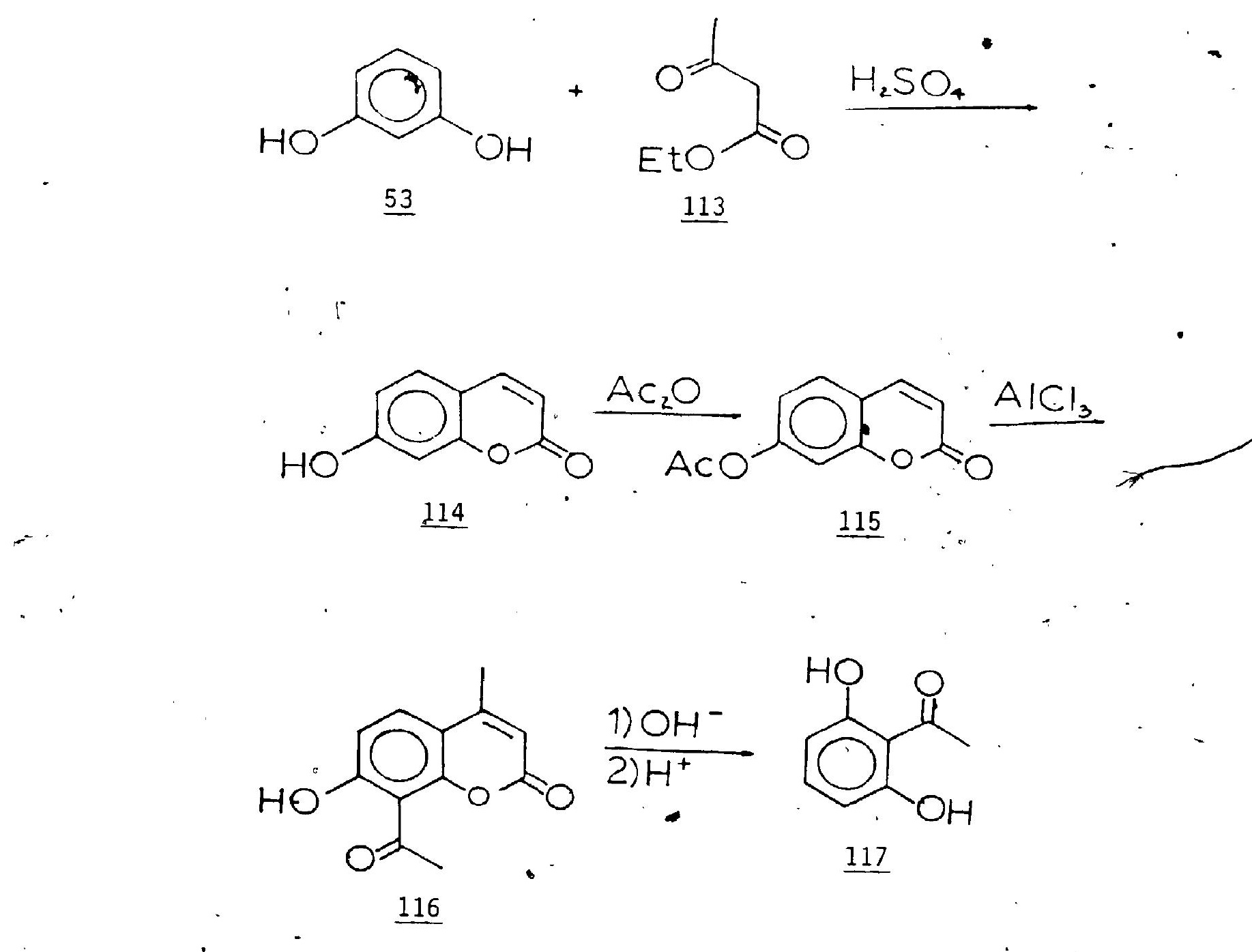

FIGURE 24

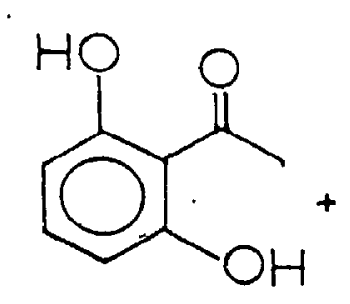

117
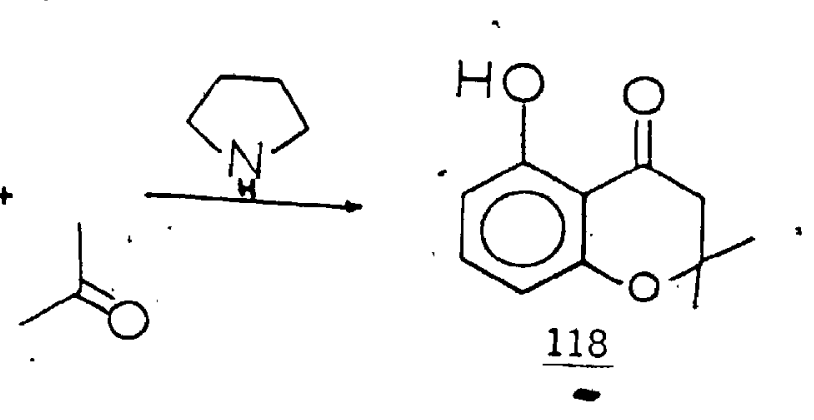

FIGURE 25 


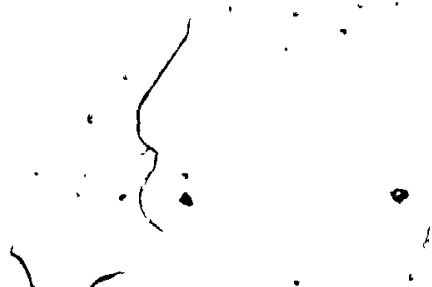

- In view of the strong thelating effect shown by ortho-hydroxy aromatic ketones, an attempt was made to introduce the tosyl group on the phenol under anhydrous phase transfer conditions (powdered $\mathrm{KOH}$, tetrabutylammonium bromide, and p-toluene sulphonyl chloride in THF) ${ }^{89}$. The reaction occurred smoothly. Reduction to the chromanol did not occur with $\mathrm{NaRH}_{4}$, or $\mathrm{KBH}_{4}$ under phase transfer conditions $^{90}$, and treatment with LiAlH $_{4}$ produced only. the degrotected chrománol.

Since introduction of the tosyloxy group proved unsatisfactory, the ace tyl group was next tried as the phenol protecting group since Matsui and co-workers 53 . have reported the 7 iberation of $\mathrm{OH}$ chromenes from the acetylated counterpart under mild saponifying conditions. However, standard acetylating conditions (acetic anhydride, Ryridine) failed to produce a protected product: anhydrous phase transfer conditions gave the desired product $\Gamma$ in excellent yield. Reduction to the corresponding chromanol with $\mathrm{NaBH}_{4}$ failed, and in light of the lability of the acetate group to reducing conditions, this route was discarded. Reduction of the benzyl ether of a $5-\mathrm{OH}$ chromanone had been reported ${ }^{50}$; and so this approach was next tried in the hope that.sufficiently mild conditions 
could be found for deprotection. After benzyl chioride failed to react with the phenol 118 (Figure 26) under standard alkylating conditions, the bromide proved satisfactory. Reduction of $\underline{120}$ with $\mathrm{NaBH}_{4}$ occurred readiqy, as did the subsequent dehydration with p-toluene sulphonic acid. Compound 122, however, proved to be an unsuitable synthetic intermediate since / catalyctic hydrogenation over palladium-charcoal using less than one equivalent of hydrogen yielded only deprotected chroman and unreacted starting material. Subsequent attempts at dealkylation using a wide variety of reagents noted for their mildness al1 failed ${ }^{92-96}$, yieldire intractable tars (Figure. $\because^{*}$

I<smiles>CC1(C)CC(=O)c2c(O)cccc2O1</smiles><smiles>[B]Br</smiles>

$\bullet$

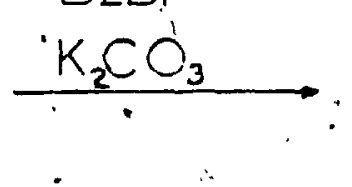

118

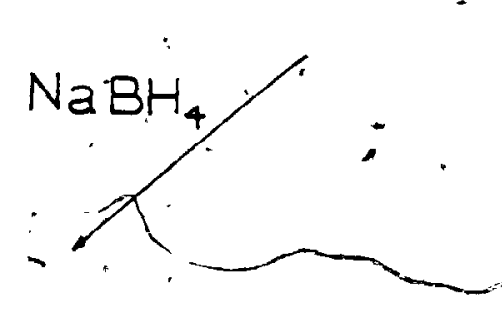

120

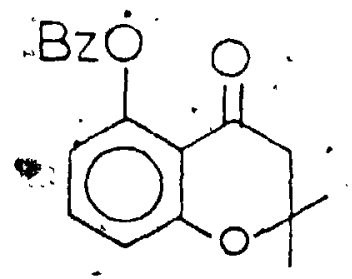




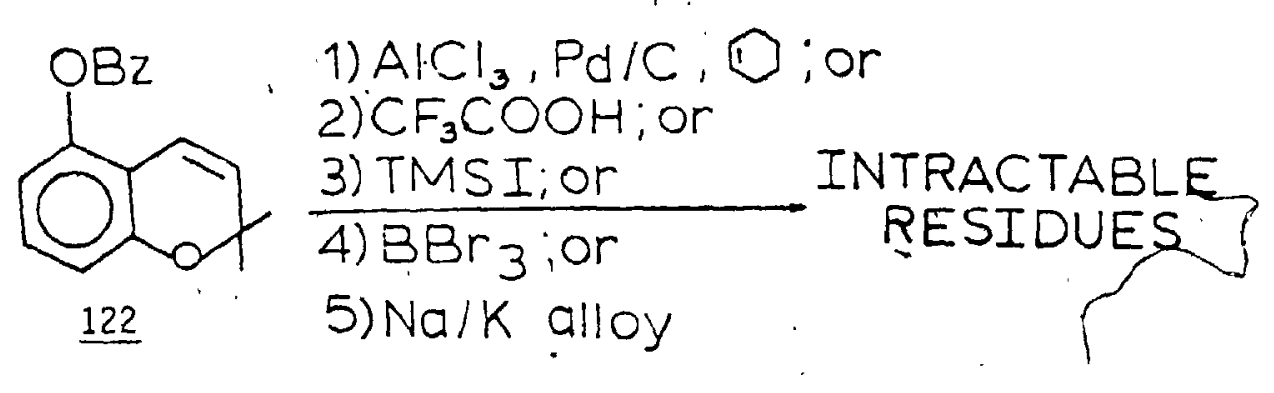

\section{FIGURE 27}

27). The undesired 5-hydroxy chroman was treated with DDQ; again, as in the 7-hydroxy chroman case, only tars were produced.

It was found to be possible to synthesize 5hydroxy chroman via 5-hydroxy-4-chromanol, obtained from 5-hydroxy-4-chromane upon reduction (Figure 28) with $\mathrm{LiAlH}_{4}$. Benzylic deoxygenation occurred upon treatment of the alcohol with $Z n$ metal in acetic<smiles>CC1(C)CC(=O)c2c(O)cccc2O1</smiles>

118

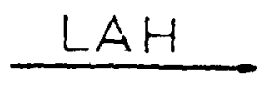<smiles>OO</smiles>

\section{$\mathrm{Zn}$} $\mathrm{Ac \dot {O } H}$<smiles>CC1(C)CCc2c(O)cccc2O1</smiles>

FIGURE 28

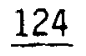


acid. The conditions are mild, compatible with many sensitive functional groups, and yields are good. This approach is an improvement over the standard clemmensen conditions; its general utility, however, is unknown:

Finally, the synthesis of 5-hydroxy chromene was achieved through the use of the phenacy ${ }^{97}$<smiles>CC1(C)CC(O)c2c(OCC(=O)c3ccccc3)cccc2O1</smiles>

123<smiles>CC1(F)C=Cc2c(OCC(=O)c3ccccc3)cccc2O1</smiles>

126

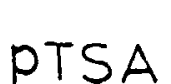

125<smiles>CC1(C)C=Cc2c(O)cc(CCCO)cc2O1</smiles>

103

protecting group (Figure 29). Reaction of, 118 with $\alpha$-bromoacetophenone in $\mathrm{K}_{2} \mathrm{CO}_{3}$ /àcetone or under phase transfer conditions both failed, but the chromanol 
123 did form the phenacyl ether $\underline{125}$ using the former conditions; the ether was formed only at the phenolic hydroxyl. Dehydration was virtually quantitative with $p$-toluenesulphonic acid. The phenacyl ether was cleaved under reducing conditions in high. yield without any evidence of polymerization.

\section{$\because$}

At this point, the feasibility of the base catalysed alkylation of 5-hydroxy-3-chromenes (Figure 4) was examined. For the reaction to occur, an anion at carbon 3 must be dęveloped (Figure 30$)$; thus, the proton at that position would fe exchangeable in the presence of base and $\mathrm{D}_{2} \mathrm{O}$. However, upon incubation of $\underline{103}$ in $\mathrm{D}_{2} \mathrm{O}$ in the presence of $\mathrm{NaOD}$, no change in the integration of

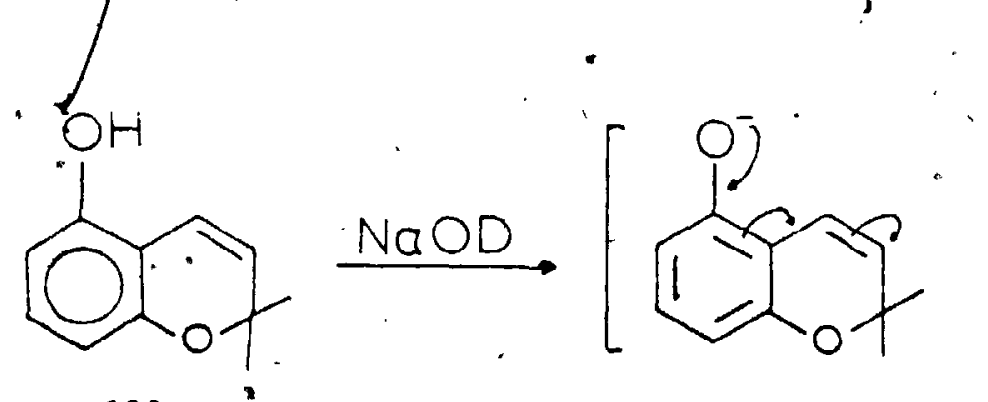

$\underline{103}$

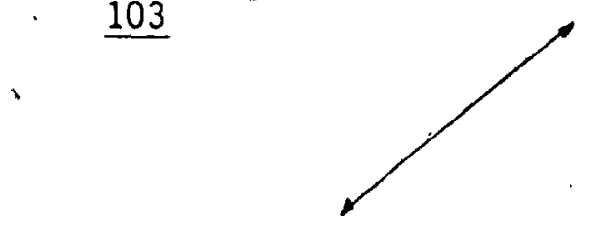

$\therefore$<smiles>[2H]C1=Cc2c(O)cccc2OC1(C)C</smiles>

FIGURE 30 
the appropriate olefinic proton could be detected in the NMR spectrum, even after $20 \mathrm{hrs}$. Chromene 103 also proved unreactive, in

a Diels Alder sense, with cyclopentadiene. This

approach was then judged unsuitable for entry into

1. the cannabinoid skeleton.

Synthesis of 5,7 dihydroxy-4-chromanones. Toward Cannabinoid Analogs

To further investiqate the $A B \rightarrow A B C$ entry

into cannabinoids it was decided to use the 4-

chromanone sys.tem as a synthetic intermediate.

As discussed in the introduction, this system has

been employed by Farènholtz and co-workers ${ }^{17}$ (Figure. 3),

although this example suffered from poor yields.

Development in this vein was undertaken.

5,7-dihydroxy-4-chromanone was synthesized according

to a metriod.by, wolfrom and co-workers 56 : This process,

however, is inappropriate for the synthesis of canna-

binoids from olivetol, :as the unnatural 7-pentyl regio-

isomer (80) is the major product ${ }^{17}$. In an attempt to.

develop the necessary methodology; an alternate route

was chosen, analogous to the one used earlier

(Figure 25) for the synthesis of 5-hydroxy-4-chromanone

(118). Phloroglucinol was acetylitated in very good

yield 98 with acetonitrile in the presence of $\mathrm{HCl}^{9}$ and

$\mathrm{ZnCl}_{2}$. Treatment of the ketone 129 with pyrrolidine 
and acetone afforded a crystalline product with a

- molecular weight of 261 and an NMR spectrum clearly showing'

the presence of, the pyrrolidine system. This was

not the enamine of the expected product, since the

methylene protons $\alpha$ to the ketone were present, and

the ketone itself was evident in the IR. Finaliy, the

correct structure was determined by $\mathrm{X}$-ray crystal1- "

ography (Figure 32) The formation of this compound (Figure 31)

may be envisaged as a Bucherer type of displacement ${ }^{99}$

(Figure 33). Traditionally, Bucherer reactions have

been shown to occur on aromatic nuclei at high

C temperatures and in the presence of sodium bisulphite

(Figure 34). In addition only naphthalene compounds

were sufficiently reactive to undergo reactions with

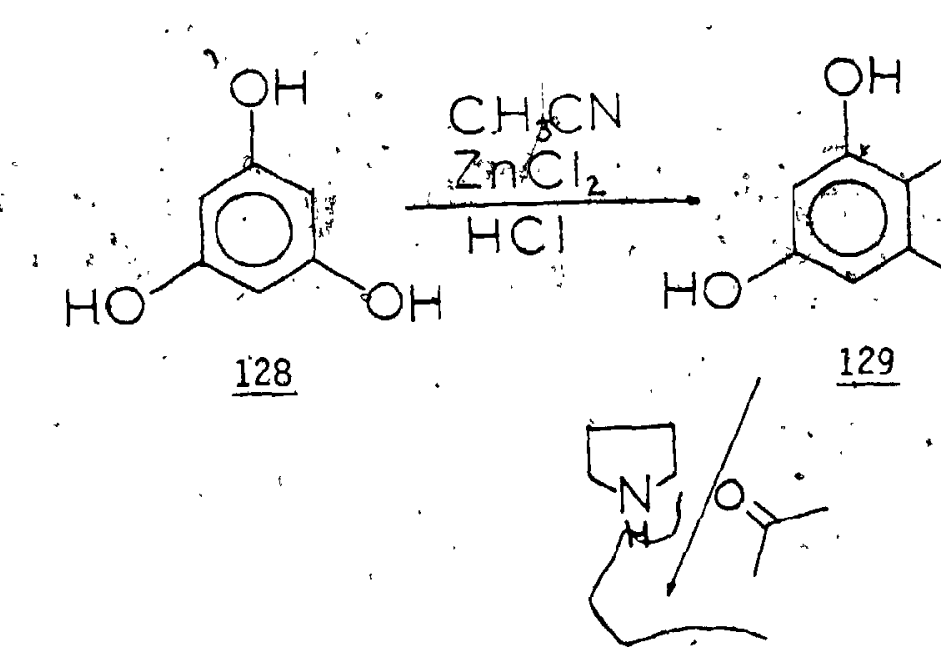

$\checkmark$

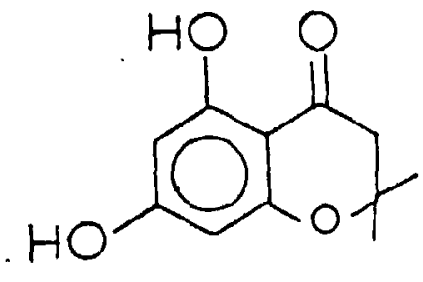

$\underline{130}$

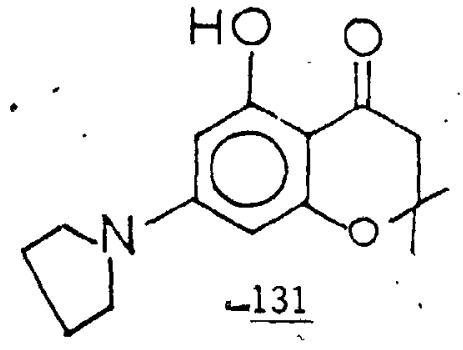

$38 \%$

$0 \%$

FIGURE 31 


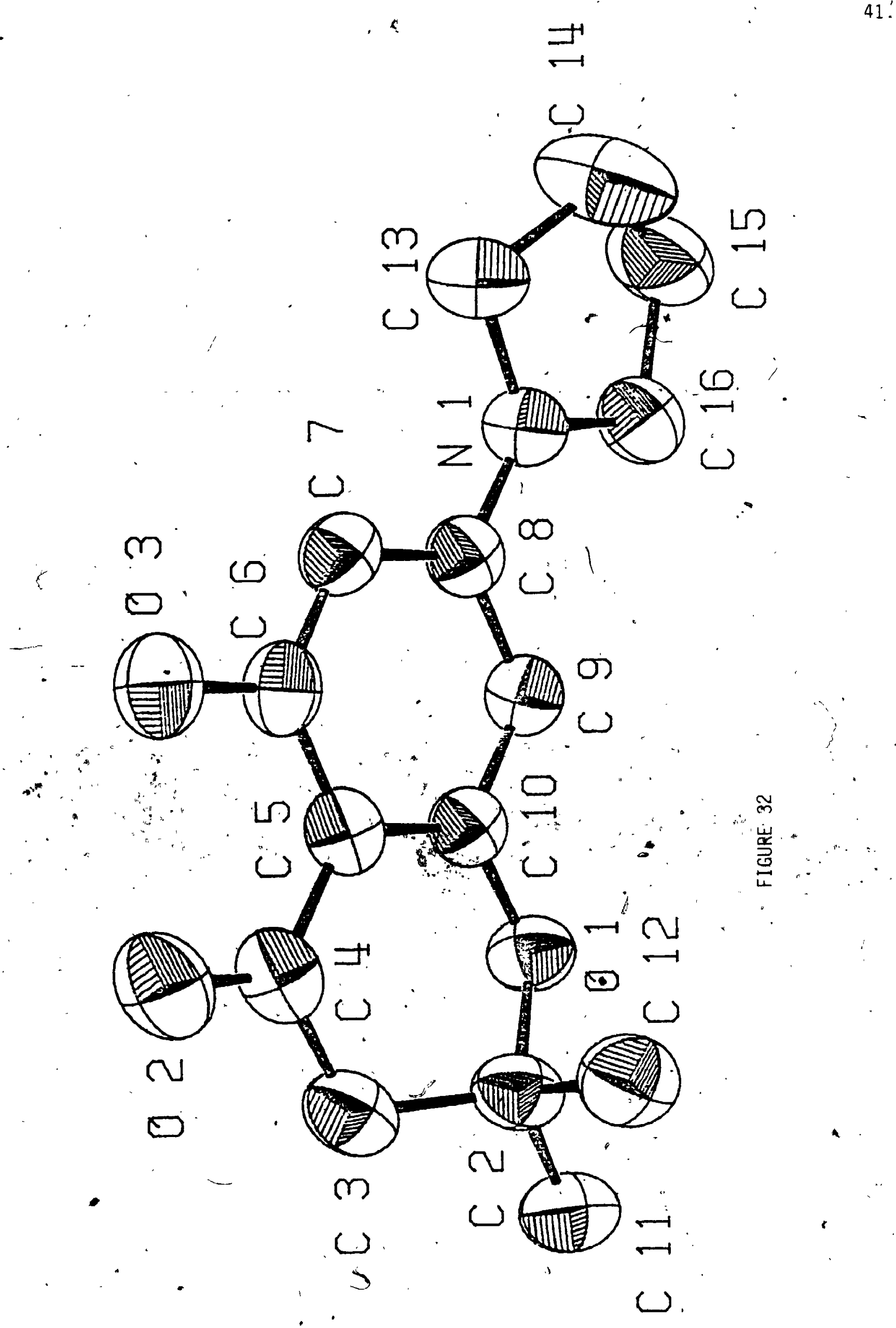



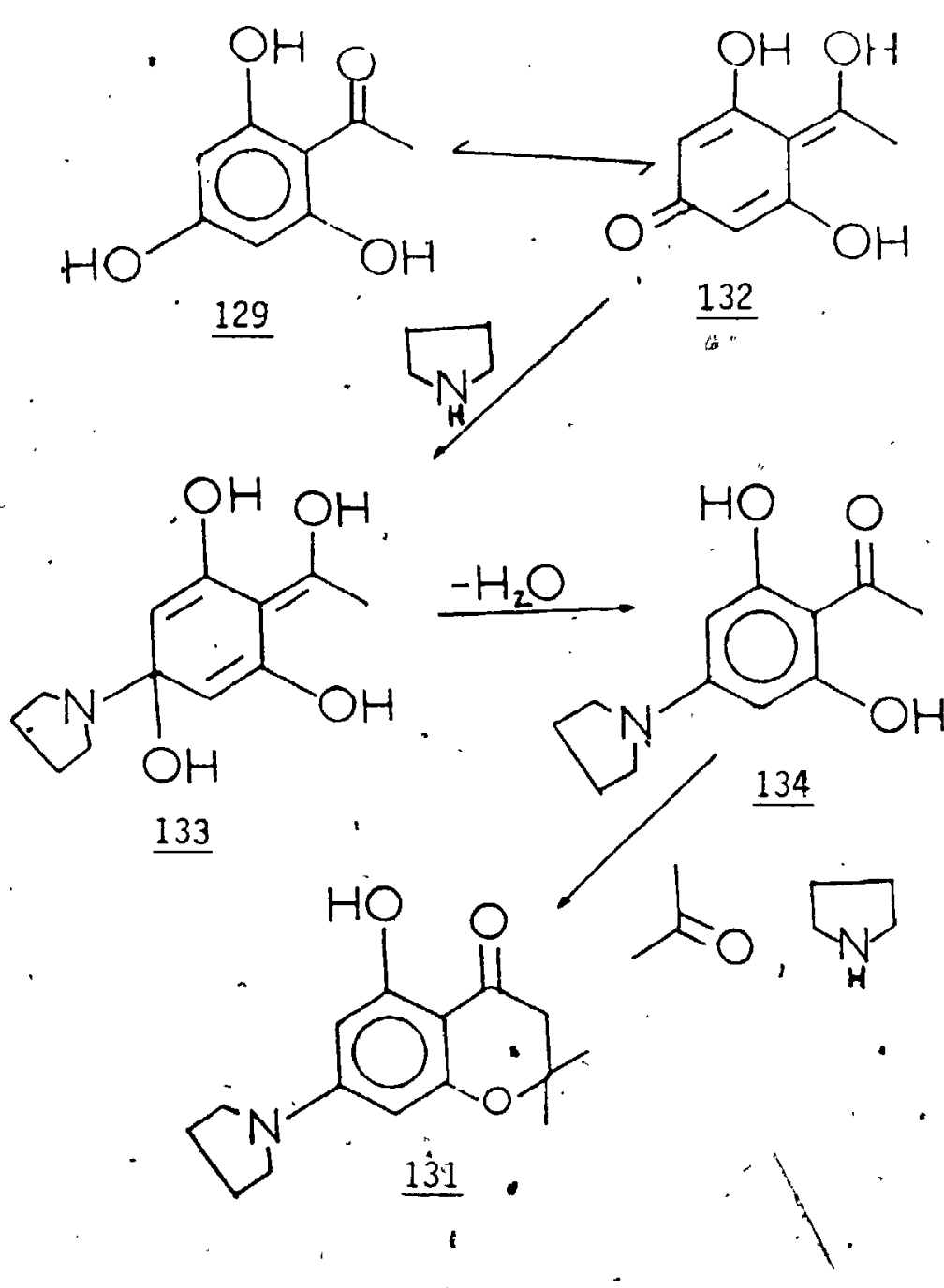

FIGURE 33

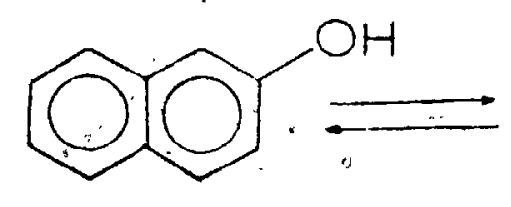

'1.35. $\mathrm{NaHSO}_{3}$

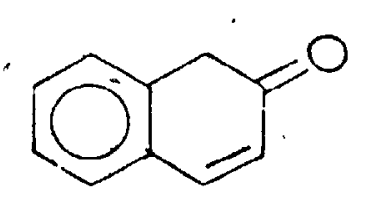

$\underline{135 a}$

-

$\therefore$

- FIGURE, 34
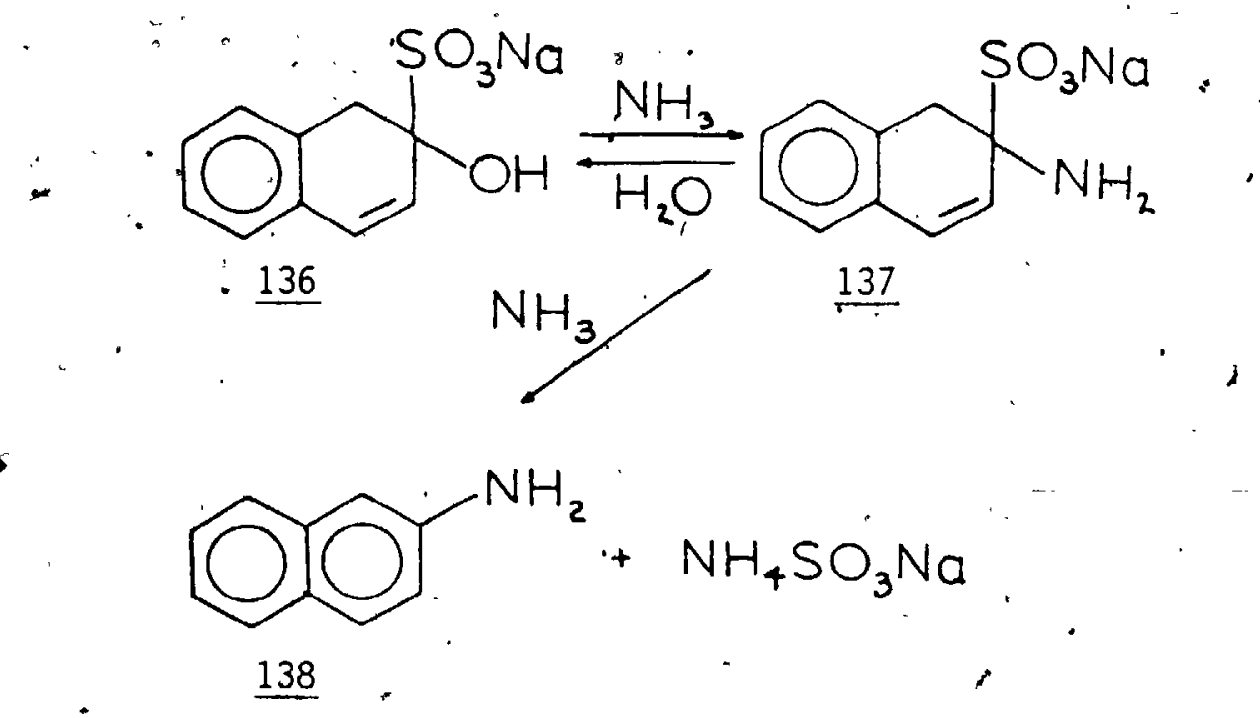
secondary amines. Only the starting material 129 undergoes this reaction as 134 may be isolated in the absence of acetone, while chromanone 130 does not give the Buchener adduct, 131, under the same conditions. This may be due to the destabilization of the required keto resonance form of the phenol by strain introduced by the pyran ring.

To create a model system similar to natural cannabinoids, the hydroxyl group at the 7-position of 5,7-dihydroxy-4-chromanone was butylated with $\mathrm{nBuBr}$ in the presence of $\mathrm{K}_{2} \mathrm{CO}_{3}$ in acetone. Alkylation was facile and-totally selective; as the C-5 hydroxyl experiences strong chelation which renders it unreactive with weak bases and weak alkylating agents. Benzyl bromide, however, was sufficientiy reactive to alkylate the $\mathrm{C}-5 \mathrm{OH}$. Since the reaction conditions were the same, these two substituents could be introduced sequentially in the same pot with little or no loss of yield (Figure 35). The Robinson annelation, under acidic conditions, of 140 was examined: In the presence of $p$-toluene sulphonic acid and methyl vinyl.ketone, 140 afforded a $\cdot 70 \%$ yield of a crystalline compound with a molecular 

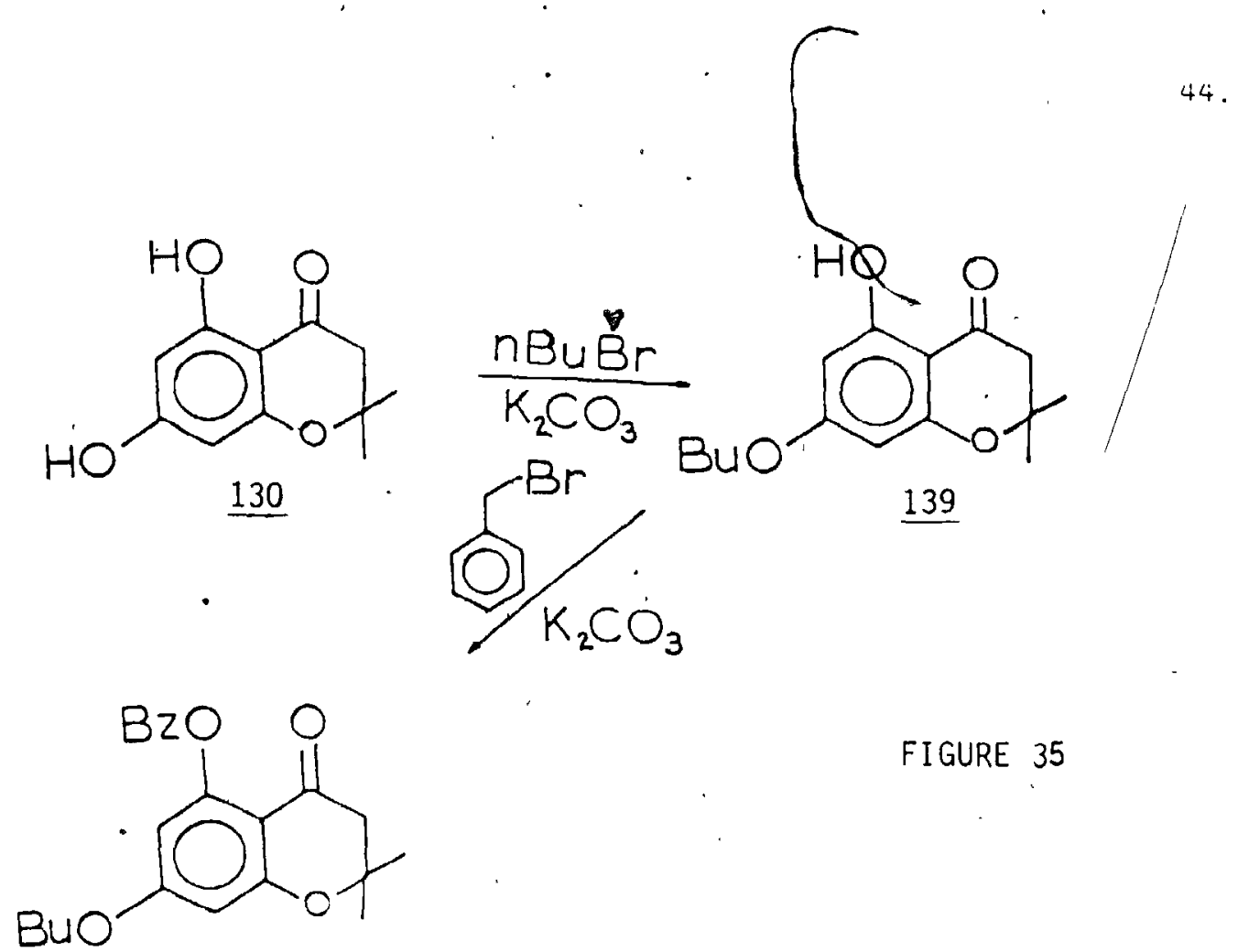

FIGURE 35

$\underline{140}$

weight corresponding to addition of a butanone moiety. However, in the $1_{H-N M R}$ the $C-3$ methylene signal of the chromanone was intact, and only one aromatic proton remained. Aromatic substitution had occurred at either the C-6 or C-8 position (Figure 36 ); determination of the proper structure could not be decided on the basis of spectral data alone, due to the near symmetry of the molecule. This compound was then débenzylated with $\mathrm{H}_{2}$ over $\mathrm{Pd} / \mathrm{C} ;$ the product showed no spectral evidence of interaction between the side chain ketone and the free phenol, nor did it tend to form a hemiketal or enol ether under acidic conditions as miaht be expected for the analog substituted in the 6-position (Figure 37). Structure 145 has thus been assigned for the original alkylation product. 


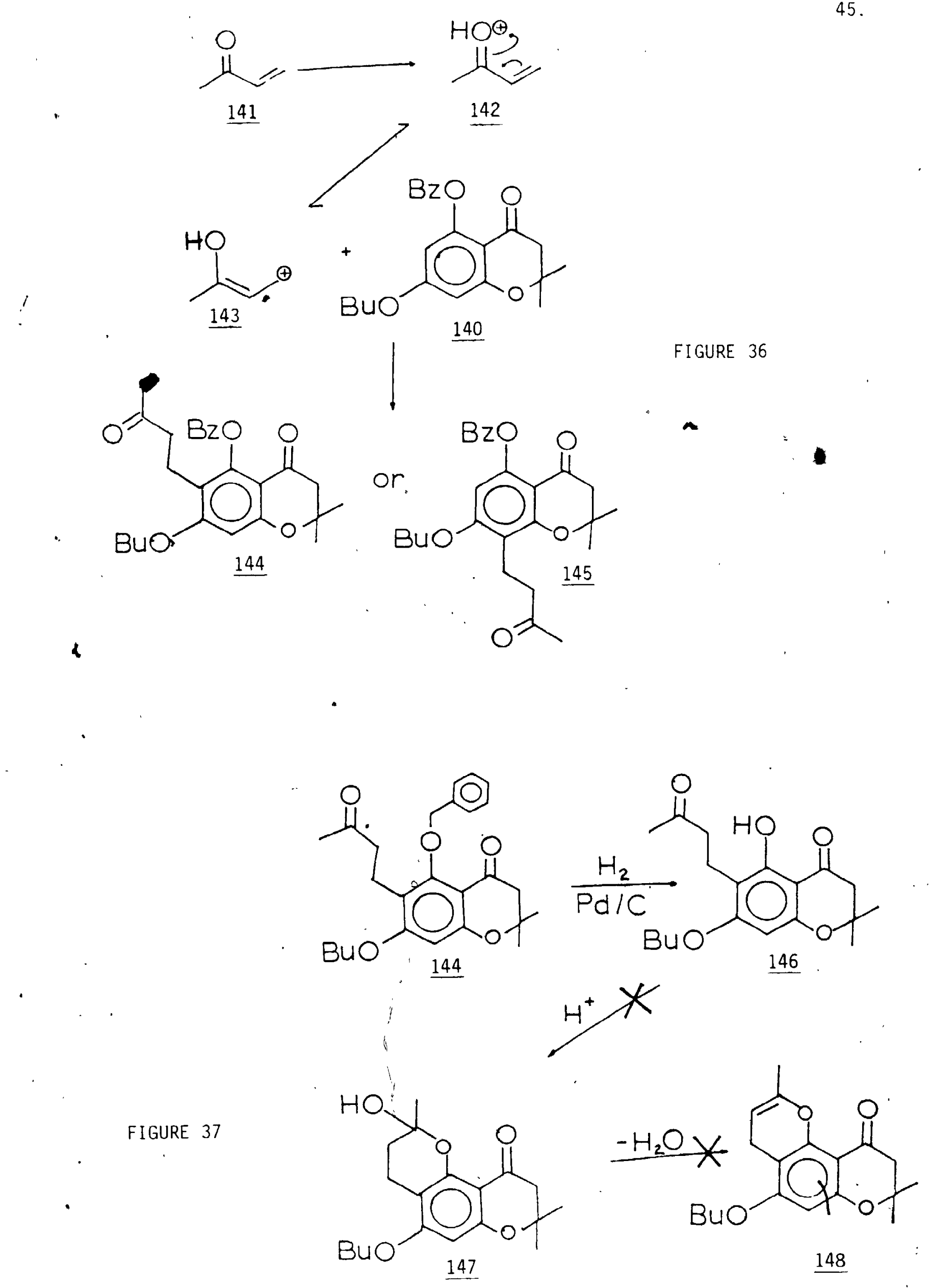




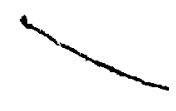

An approach to the alkylation of ketones, developed by Corey 100 , involves the corresponding $N, N$-dimethyl hydrazone as a synthetic intermediate (Figure 38). Treatment with one equivalent of base (e.q., LDA) followed by an appropriate alkylating agent gives the substituted hydrazone in generally good yield. The parent ketone may be regenerated by treatment - with cupric ion ${ }^{101}$. Treatment of ketone 140 with $\mathrm{N}, \mathrm{N}$-dimethyl hydrazine in the presence of an acid catalyst gave only, at best (with $\mathrm{H}_{3} \mathrm{PO}_{4}$ ), a $20 \%$ yield of the hydrazone derivative. Although the desired product could easily be isolated from a complex mixture of products by extraction with aqueous acid, the low yield made this route impractical.

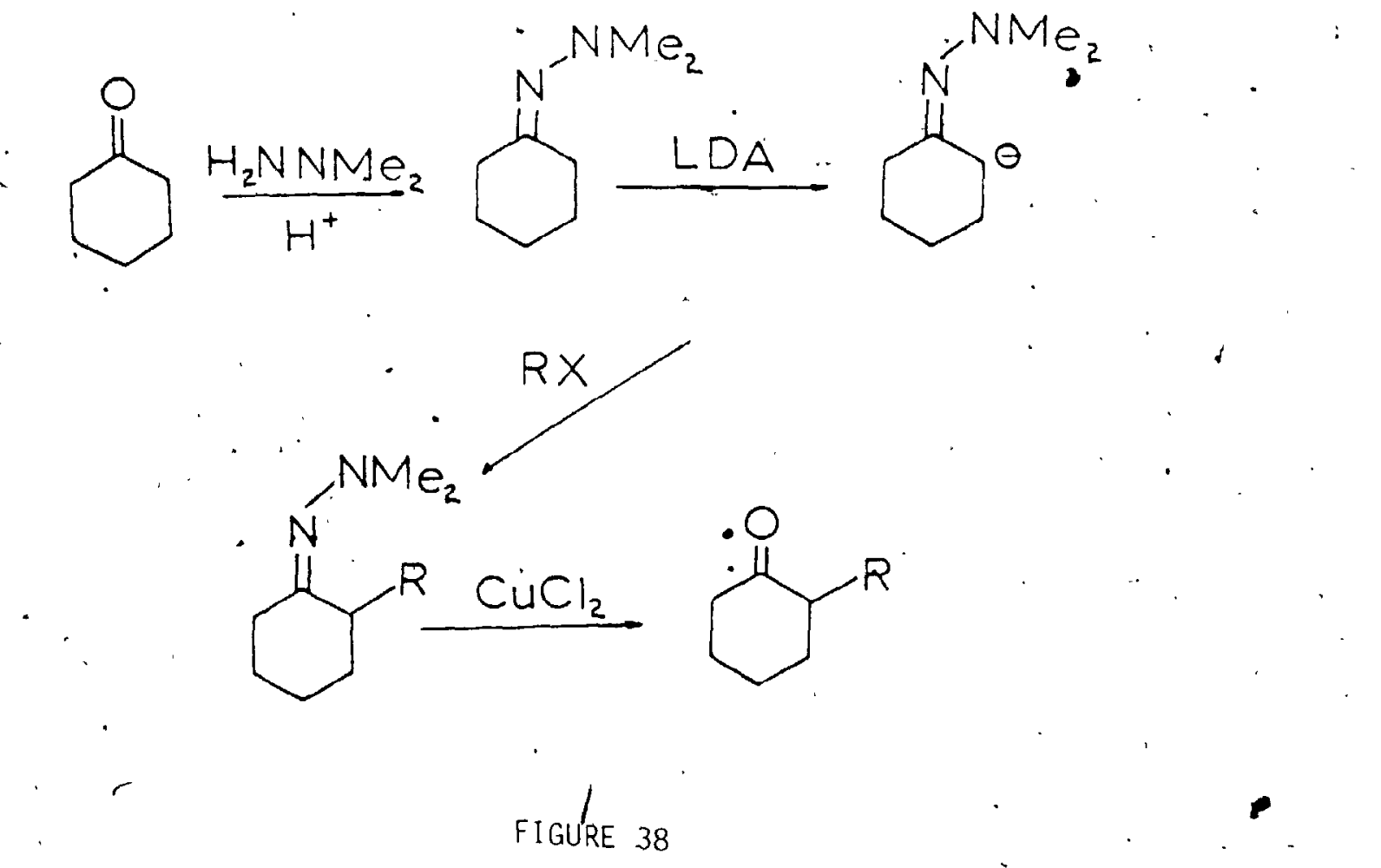


i

An attempt to replicate Farenholtz's procedure ${ }^{17}$ for construction of the C-ring with substrate $\underline{140}$, via the hydroxymethylene derivative (149) met with failure. Upon treatment of 140 with $\mathrm{NaH}$ followed by ethyl formate (Figure 39), hydroxymethylene derivative, 149 was not detected; the

- stable enol 150 appeared to be formed instead. 150 showed no change in molecular weight from 140, and the $\mathrm{C}-3$ methylene at $\delta 2.6$ was replaced by a one proton resonance at $\delta 6.9$ (olefinic proton) and a one proton singlet.at f 14.2 (enol proton) which was exchangeable with $\mathrm{O}_{2} 0$. Miller ${ }^{102}$, using NMR techniques, showed that for certain acenaphthene systems (Figure 40 ), the keto and enol forms wert very close to each . other in energy, but separated by a large, energy barrier; the stability of the enol was increased as

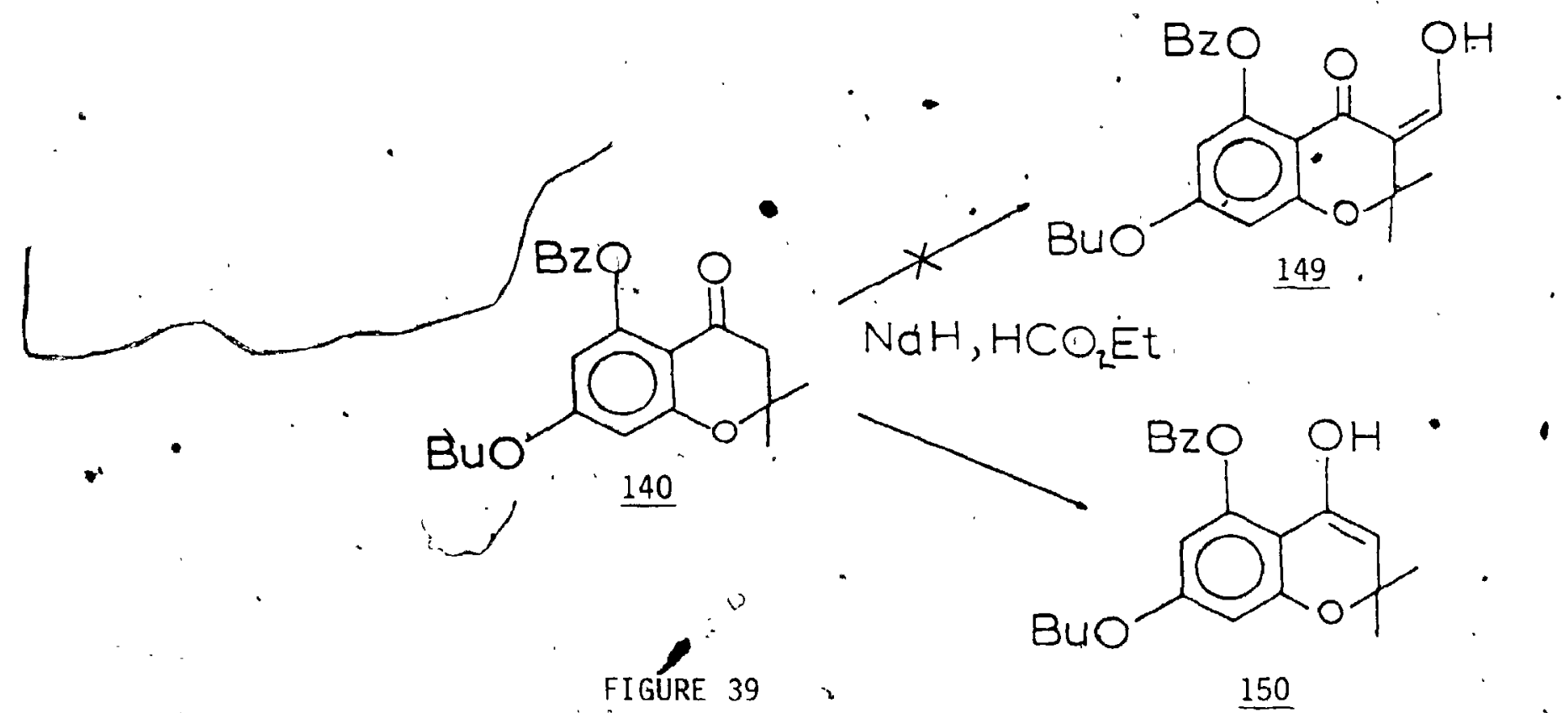


the bulkiness of the ortho groups on the adjacent - aromatic nucleus increased Drieding models of

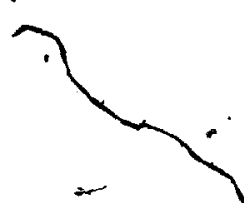
140 and 150 suggest a possible driving force, name iy increased in-plane conjugation with the aromatic nucleus of the latter over the former. In addition, the pyran ring. conformation in 150 puts one of the C-2 gem-dimethyls near the deshielding cone of the enol ${ }^{*}$-system. This is seen in the ${ }^{1} H-N M R$ as a .43

- ppm downfield shift relative to the other methyl group. in

- 1 The alkylation of the enolate derived from 140. and 150 was then examined. Treatment of chromanone 140 with NaH in THF followed by quenching with

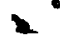

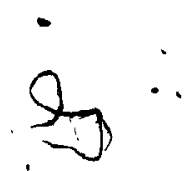

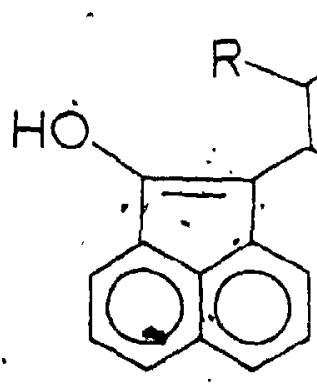

$\underline{151}$

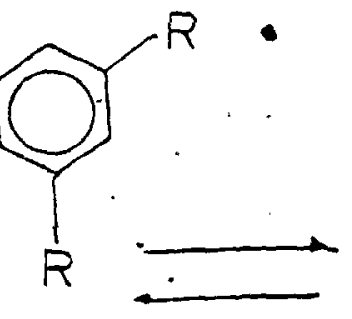

-

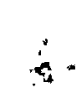<smiles>[R]c1cc([R])c(C2C(=O)c3cccc4cccc2c34)c([R])c1</smiles>

$\cdot 152$

FIGURE 40

Mel afforded only enol 150 , demonstrating a low nucleophilicity by both the $c-3$ carbon and the $c-4$ oxygen. Treatment of the enolatg generated inder the same conditions, with the more active aliyt

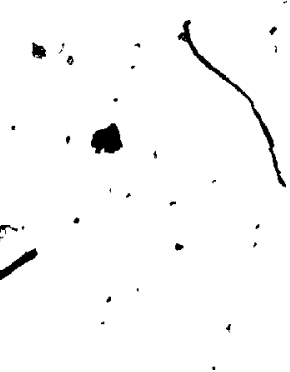

4

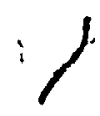<smiles>[3H][3H]</smiles> 
bromide also gave no new products. However, the lithium enolate, generated by treatment with nBuli, in the presence of the strongly co-ordinating solvent. HMPA did afford the C-alkylated product 153 (Figure 41) in good yield along with a small amount of 154 ; the use of $\mathrm{LiH}$ as base instead of nBuLi gives 153 in good yield without any trace of 154 .

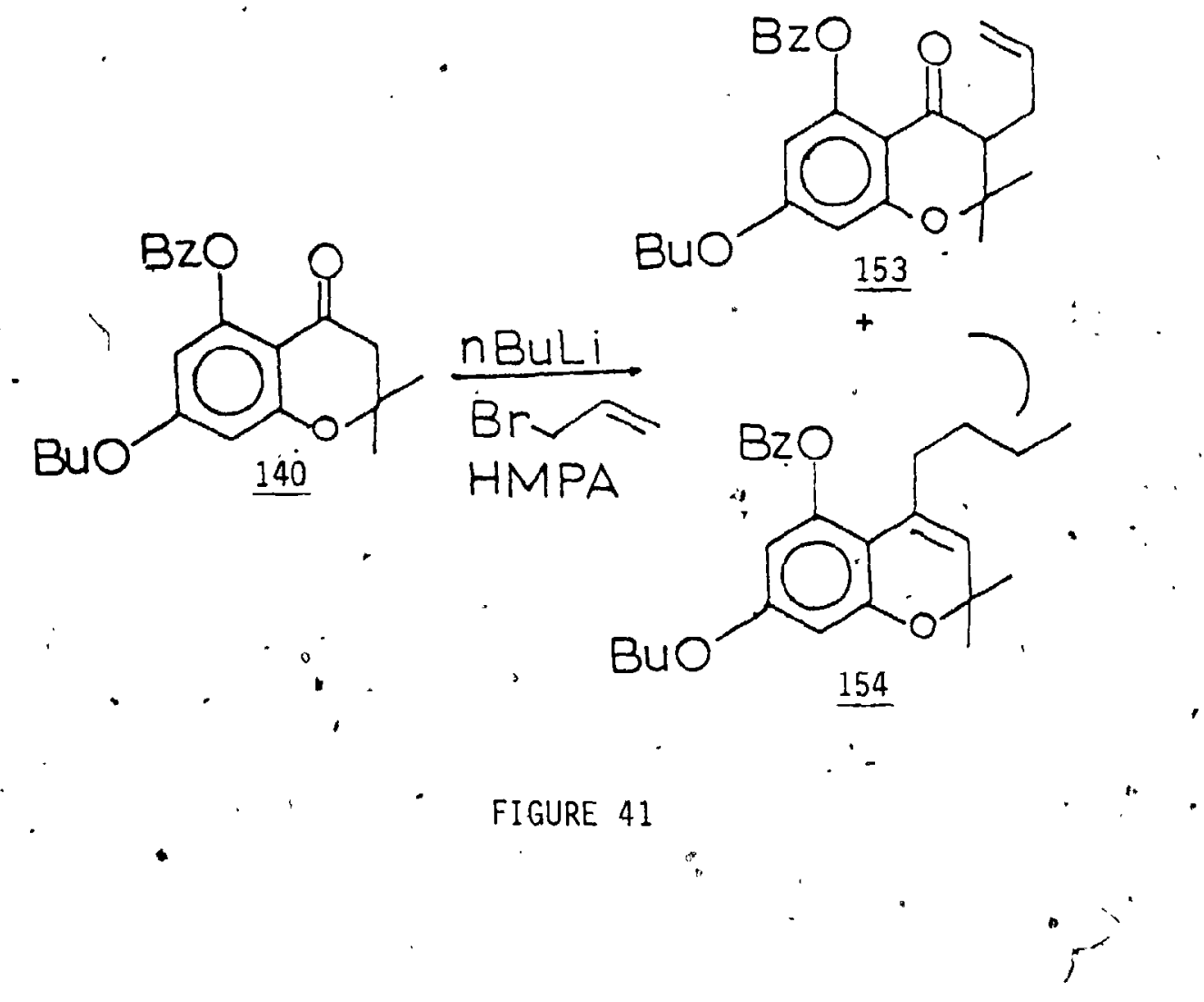


Suggestions for future research

Investigations into the alkylation of the

aforementioned enolate continues. It is believed

that the use of the appropriately functionalized

allylic halides represent an important entry into

the cannabinoid compounds. Two possible approaches

involve the use of the wichterle reagent 103-106,

1,3-dichloro-2-butene or the $\alpha$-halotiglates developed by Stotter ${ }^{107}$ (Figure 42 ).

$-$

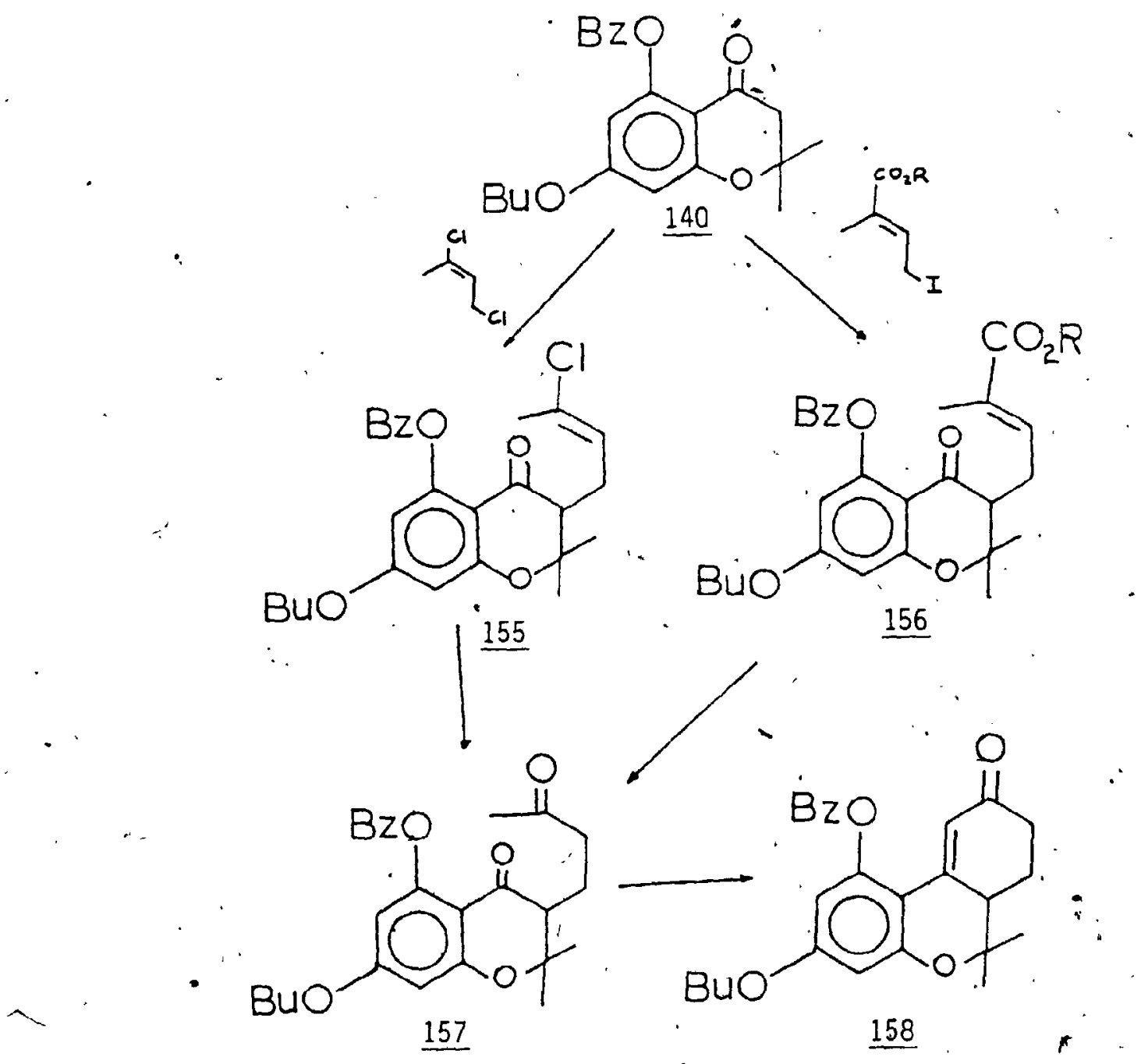




\section{EXPERIMENTAL}

Melting points were determined on a Fisher melting point block or a Mettler FPI melting point apparatus;

all melting points are expressed in degrees Celsius, and are uncorrected. ${ }^{1}$ H-NMR spectra were obtained on Varian EM-360A or Varian T-60A $60 \mathrm{MHz}$ spectrometers using $\mathrm{COCl}_{3}$ as solvent*and tetramethylsilane (TMS) as the internal standard; shifts are expressed in the $\delta$ scale and the following abbreviations used: s, singlet; $d$, doublet; $t$, triplet; $q$, quartet; m, multiplet.. Infra-red (IR) spectra were obtained on a Perkin Elmer 237B grating spectrophotometer using $\mathrm{NaCl}$ windows as the sample support* and polystyrene film as a standard; absorbances are expressed in units of $\mathrm{cm}^{-1}$. Mass spectra were determined with an A.E.I. M.S.. 12 instrument at Trent University; values are expressed as m/e(relative intensity). Combustion analyses were performed by Canadian Microanalytic Laboratöries at Guelph, Ontario.

Thin layer chromatographic plates were obtained from E. Merck Reagents (silica gel F-254, $0.25 \mathrm{~mm}$ layer thickness); preparative thick layer chromatography was performed on similar plates but with a $2 \mathrm{~mm}$ layer

*unless otherwise noted 
of silica gel. Products were detected by viewing under a UV source, or by spraying the plate with $1 \%$ ceric. ammonium nitrate in $50 \%$ aqueous sulphuric acid followed by gentle heating. All ethereal reaction solvents (except for diethyl ether) were dried by refluxing over $\mathrm{Na}$ in the presence of benzophemone until a dark blue colour persisted, and then distilled. Anhydrous diethyl ether was purchased from Mallinckrodt and used directly. Spectral grade sovents were used fordall other reactions were dryness was not critical.

The term 'rotovapped' refers to the removal of solvent in vacuo on a Buchi Rotovapor $R$ rotoevaporator. Also; diethyi ether may be abbreviated as simply 'ether'. Carbon-13 spectra were taken on a Bruker WP-80 1 spctrometer at the National Research Council; Ottawa, Ontario, or on a Varian CFT-20 at Ottawa University, attawa, Ontario. 
Ethyl-2,6-dimethoxy-cinnamate (107) from 105

Based on a method by Mali and Yadev ${ }^{117} .70 \mathrm{~g}$ of

aldehyde $104(4.4 \mathrm{mmol})^{85}$ and phosphorane $105(2.3 \mathrm{~g}$,

$6.6 \mathrm{mmol})^{86}$ were refluxed for one day in $15 \mathrm{ml}$ of toluene

under Ar . The mixture was cooled, washed with 2-10

$\mathrm{ml}$ portions of $2 \mathrm{M} \mathrm{HCl}$, passed through a Florisil pad,

and eluted with $75 \mathrm{ml} \mathrm{CH}_{2} \mathrm{Cl}_{2}$. Removal of the solven't

afforded $.90 \mathrm{~g}(3.8 \mathrm{mmol})$ of cinnamate 107 , essentially

pure by TLC ( $86 \%$ yield). The oilisolidified upon

standing.

M.P. $\quad 78-80$

NMR: $\quad 1.30\left(\mathrm{t}, 3 \mathrm{H}, \mathrm{J}=7 \mathrm{~Hz},-\mathrm{OCH}_{2} \mathrm{CH}_{3}\right) ; 3.85(\mathrm{~s}, 6 \mathrm{H}$,

$\left.-\mathrm{OCH}_{3}\right), 4.27\left(\mathrm{q}, 2 \mathrm{H}, \mathrm{J}=7 \mathrm{~Hz},-\mathrm{OCH}_{2} \mathrm{CH}_{3}\right), 6.53$.

$(\mathrm{d}, 2 \mathrm{H}, \mathrm{J}=7 \mathrm{~Hz}, \mathrm{H}-3$ and $\mathrm{H}-5), 6.87(\mathrm{~d}, 1 \mathrm{H}$,

$J=16 \mathrm{~Hz}, \beta-H), 7.25(t, 1 \mathrm{H}, J=7 \mathrm{~Hz}, \mathrm{H}-4)$,

$7.80(d, 1 H, J=16 \mathrm{~Hz}, \alpha-H)$

IR: $1695(\alpha, \beta$-unsaturated ester)

M.S. $\quad 236(30), 205(54) ; 191(64), 178(12), 177(100)$,

$176(19), 162(18), 161(18), 149(27), 148(45)$,

- $147(17), 134(11), 133(36), 131(12), 121(16)$,

$105(30), 103(16), 92(10), 91(73), 89(22)$,

$85(15), 79(16), 78(19), 77(79), 76(10)$;

$65(21), 63(33), 62(12), 53(11), 52(10$,

$51(85), 50(20), 45(10), 41(24)$ 
$\Delta \Delta^{3}-2,2$-dimethyl-5-hydroxy-benzopyran (103) from 107

To $1.0 \mathrm{~g}$ dry $\mathrm{Mg}$ turnings $(4.3 .5 \mathrm{mmol})$ in $10 \mathrm{ml}$ dry ether under Ar was added, dropwise, $6.7 \mathrm{~g}$ (46 mmo 1 ) methyl iodide in $20 \mathrm{ml}$ dry ether. After refluxing for. $2 \mathrm{~h}$ (until most of the Mg was consumed), $700 \mathrm{mg}$ $(2.9 \mathrm{mmol})$ of ester 107 in $20 \mathrm{ml}$ dry ether was added dropwise, and the mixture stirred for $3 \mathrm{~h}$ at room temperature. Heat was again applied, and the flow of $\mathrm{Ar}$ increased to blow off the solvent. When the volume of the mixture reached about $5 \mathrm{mls}$, the reaction vessel was placed in an $0 i 1$ bath at $160^{\circ}$ and stirring continued for $1 \mathrm{~h}$. After cooling, the reaction. mixture was quenched with saturated aq. $\mathrm{NH}_{4} \mathrm{Cl}$, and the organics extracted with ether. This solution was passed through a Florts1l pad, eluted with $\mathrm{CH}_{2} \mathrm{Cl}_{2}$, the solvent removed, and the residue purified by thick layer chromatography, to give $140 \mathrm{mg}(.79$. mmol, $31 \%$ ) of 103.

M.P. $\quad 125-126$

NMR: $\quad 1.43(\mathrm{~s}, 6 \mathrm{H}, \mathrm{C}-2$ gem dimethyls $), 5.6(\mathrm{~d}, 1 \mathrm{H}, \mathrm{J}=$ $10 \mathrm{~Hz}, \mathrm{H}-3), 6.23-6.53(\mathrm{~m}, 2 \mathrm{H}, \mathrm{H}-6$ and. $\mathrm{H}-8)$, $6.67(\mathrm{~d}, 1 \mathrm{H}, \mathrm{J}=10 \mathrm{~Hz}, \mathrm{H}-4), 6.98(\mathrm{t}, 1 \mathrm{H}$, $J=8 \mathrm{~Hz}, \mathrm{H}-7$ )

IR: $\left(\mathrm{CHCl}_{3}\right): 3300 \mathrm{~m}^{-1}$ (broad, phenolic $\mathrm{OH}$ ) M.S. $176(20), 162(14), 161(100)$ 


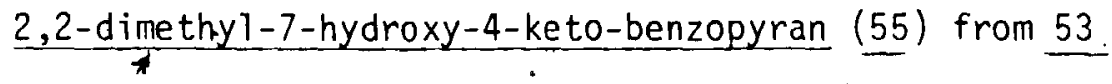

Resorcinol (모) (11.0 g, $100 \mathrm{mmol})$ and $\beta, \beta-$ dimethylacrylic acid (100 g, 100 mol) werêstirred, - under $\mathrm{Ar}$ and at room temperature; in $100 \mathrm{mls} \mathrm{of} \mathrm{POCl}_{3}$. in the presence of $50 \mathrm{~g}$ of $\mathrm{ZnCl}_{2}{ }^{54}$ for $24 \mathrm{~h}$. The mixture was very carefully poured onto 2 litres of : ice, with stirring, and the solids filtered and washed with water. Recrystallization from $\mathrm{MeOH} / \mathrm{H}_{2} \mathrm{O}$ afforded pure $\underline{55}(12.9 \mathrm{~g}, 66.8 \mathrm{mmol}, 67 \%)$.

M.P. $\quad 165$

NMR: (Acetone-d ${ }_{6}$ ) $1: 43(s, 6 \mathrm{H}, \mathrm{C}-2$ gem dimethyls), $2.63(\mathrm{~s}, 2 \mathrm{H}, \mathrm{H}-3), 6.30-6.60(\mathrm{~m}, 2 \mathrm{H}, \mathrm{H}-5$ and $\mathrm{H}-6), 7.67(\mathrm{~d}, 1 \mathrm{H}, \mathrm{J}=8 \mathrm{~Hz}, \mathrm{H}-8), 8.73$ (broad $\mathrm{s}$, $1 \mathrm{H}$, "phenolic H)

IR: $\quad\left(\mathrm{CHCl}_{3}\right) 3250$ (phenolic $\left.\mathrm{OH}\right), 1685(\mathrm{C}=0)$

M.S. $192(2), 177(10), 108(18), 81(12), 80(15), 69(21)$, $63(.15), 56(12), 55(23), 53(38), 52(79), 51(68)$, $50(31), 43(45), 41(100)$ 


\section{2,2-dimethyl-4-keto-7-tosyloxy-benzopyran (109) from 108}

$9.7 \mathrm{~g}(50 \mathrm{mmol})$ of chromànone $108^{56}, 50 \mathrm{~g} \mathrm{~K}_{2} \mathrm{CO}_{3}$

and $9.5 \mathrm{~g}$ ' $\mathrm{p}$-toluene sulphonyl chloride (50 mmol)

were refluxed for 3 hrs: After cooling, the mixture was filtered and the solvent removed on a rotoevaporator.

The residue was recrystallized from $\mathrm{MeOH}-\mathrm{H}_{2} \mathrm{O}$, affording pure crystalline 109 ( $14.9 \mathrm{~g}, 43 \mathrm{mmol}, 86 \%$ yield).

M.P. $\quad 79-80$

NMR: $\quad 1.42(\mathrm{~s}, 6 \mathrm{H}, \mathrm{C}-2$ gem dimethy1s), $2.43(\mathrm{~s}, 3 \mathrm{H}, \ldots$ tosyl $\left.\mathrm{CH}_{3}\right), 2: 70(\mathrm{~s}, 2 \mathrm{H}, \mathrm{H}-3), 6.70$ (broad s, $2 \mathrm{H}, \mathrm{H}-6$ and $\mathrm{H}-8$ ), 7.35 (broad $\mathrm{d}, 2 \mathrm{H}, \mathrm{J}=8 \mathrm{~Hz}$,

$\therefore$ tosyl Ar-H's ortho to sulphone), 7.78 (broad d,

- $3 \mathrm{H}, \mathrm{J}=8 \mathrm{~Hz}$, tosyl Ar-H's ortho to methyl and. $\dot{H}-5)$

IR: $\quad \dot{6} 695 \mathrm{~cm}^{-1}(\mathrm{C}=0)$

M.S. $347(14), 346(56), 332(21), 331(94), 291(35)$, $226(10), ' 155(50), 107(15), 92(11), 91(100)$, $65(21), 63(10), 51(12)$ $m * 317$ 
2,2-dimethyl-4-hydroxy-7-tosyloxy benzopyran (110) from 109

To a suspension of $.41 \mathrm{~g}(10.8 \mathrm{mmol})$ of $\mathrm{LiAlH}_{4}$

in $50 \mathrm{ml}$ ether under Argon at $0^{\circ} \mathrm{C}$ was added,dropwise, $5.0 \mathrm{~g}$ of chromanone 109 (14.4 mmo1) in $50 . \mathrm{ml}$ dry ether After stirring for $4 \mathrm{hrs}$, the reaction was quenched with $20 \mathrm{mr}$ of $20 \%(\mathrm{v} / \mathrm{v})$ aqueous acetic acid.

The mixture was stirred until most of the solids had dissolved (about 1 $\mathrm{hr}$ ), $100 \mathrm{ml}$ ether added, and the mixture was filtered. The aqueous layer was removed, . and the organic layer washed with 2-100 mi portions of saturated aqueous $\mathrm{NaHCO}_{3}$ solut lon. Rotoevaporation followed by recrystallization from $\mathrm{MeOH} / \mathrm{H}_{2} \mathrm{O}$ gave $3.7 \mathrm{~g}$ $(10.8 \mathrm{mmol}, 75 \%)$ of pure crystalline 110.

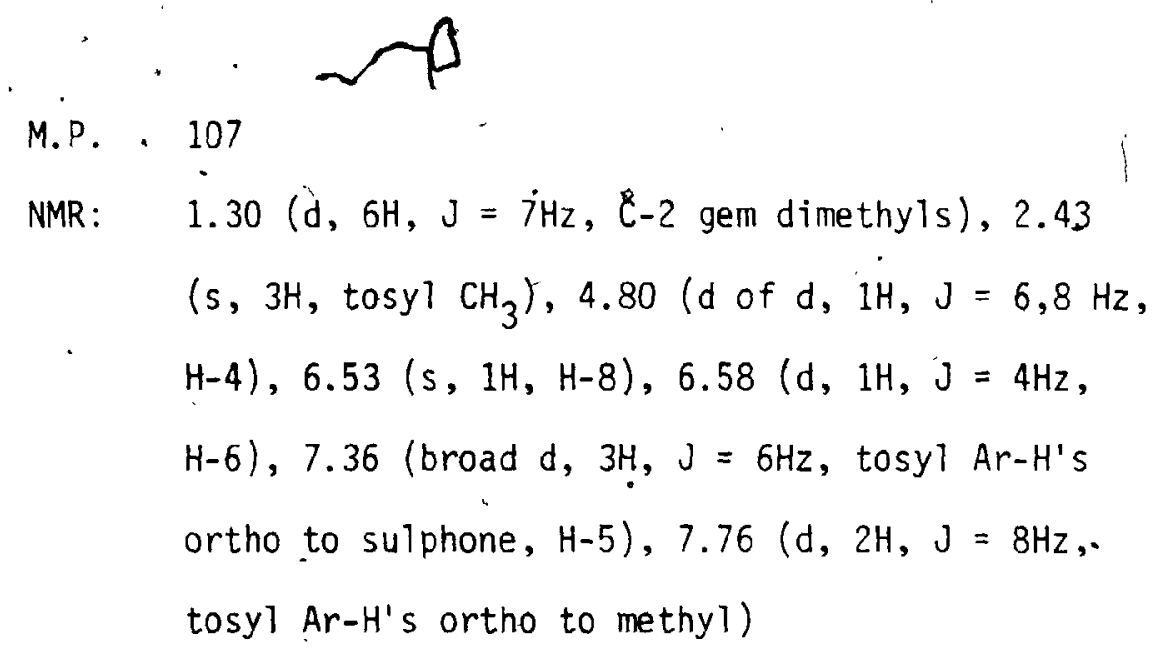


$\Delta^{3}-2,2$-dimethyl-7-tosyloxy benzopyran (111) from 110

$1.00 \mathrm{~g}(2.86 \mathrm{mmol})$ chromanol 110 and $.02 \mathrm{~g}$

p-toluene sulphonic acid were refluxed in $50 \mathrm{ml}$ toluene for 15 min. The slightly pink solution was cooled, washed with saturated $\mathrm{NaHCO}_{3}$ solution, . rotóevaporated, and recrystallized from $\mathrm{MeOH} / \mathrm{H}_{2} \mathrm{O}$. $.90 \mathrm{~g}(2.70 \mathrm{mmol}, 94 \%$ yield $)$ of chromene 111 was obtained as light pink crystals.

M.P. 102

NMR: $\quad 1.73(\mathrm{~s}, 6 \mathrm{H}, \mathrm{C}-2$ gem dimethy $1 \mathrm{~s}), 2.80(\mathrm{~s}, 3 \mathrm{H}$, tosyl $\left.\mathrm{Ar}-\mathrm{CH}_{3}\right), 5.63(\mathrm{~d}, 1 \mathrm{H}, \mathrm{J}=10 \mathrm{~Hz}, \mathrm{H}-3)$, $6.40(\mathrm{~d}, 1 \mathrm{H}, \mathrm{J}=10 \mathrm{~Hz}, \mathrm{H}-4), 6.55$ (s, $1 \mathrm{H}$, . $H-8), 6.62(d, 1 H, j=4 H z, H-6), 7.45$ (broad d, $2 \mathrm{H}, J=6 \mathrm{~Hz}$, tosyl Ar-H's ortho to sulphone), 7.90 (broad dd, 24. $\mathrm{J}=6 \mathrm{~Hz}$, tosyl Ar'H's ortho to methyl)

M.S. $\quad 325(13), 316(16), 315(100), 160(20), 132(10)$, $91(20), 43(13)$

$\mathrm{m}^{*} 301$ 
2,2-dimethy1-5-hydroxy-4-ke to benzopyran (118) from 111

Based on a procedure by Kabbe $59,2,6$-dihydroxy acetophenone $(14.4 \mathrm{~g}, 98.6 \mathrm{mmol})$, pyrollidine $(12.2 \mathrm{~g}$, $172 \mathrm{mmol})$, acetone $(6.0 \mathrm{~g}, 103.5 \mathrm{mmol})$, and $100 \mathrm{ml}$ of toluene were stirred for 4 days under Ar . The mixture was acidified with $100 \mathrm{ml}$ of $2 \mathrm{~N} \mathrm{HCl}$, the organic layer separated and washed with 3-50 $\mathrm{ml}$ portions of saturated aqueous $\mathrm{NaCl}$, and rotoevaporated. The residue was dissolved in $50 \mathrm{ml}$ $\mathrm{CH}_{2} \mathrm{Cl}_{2}$, passed through a Florisil pad, and eluted with $200 \mathrm{ml} \mathrm{CH} \mathrm{Cl}_{2}$. After rotoevaporation, the residue was recrystallized from Ethanol:water, to give 118 as yellow needles $(14.0 \mathrm{~g}, 72.5 \mathrm{mmol}$, $74 \%$ yield).

M.P. $\quad 66$

NMR: $\quad 1.47(\mathrm{~s}, 6 \mathrm{H}, \mathrm{C}-2$, gem-dimethyls), 2.75(s, $2 \mathrm{H}, \mathrm{H}-3), 6.43(\mathrm{~d}, 1 \mathrm{H}, \mathrm{J}=8 \mathrm{~Hz}, \mathrm{H}-6)$, $6.52(d, 1 H, J=8 H z, H-8), 7.40(t, 1 H$, $J=8 \mathrm{~Hz}, \mathrm{H}-7)$

IR: $\quad 3100$ (broad, weak, hydrogen bonded $\mathrm{OH}$ ) 1565 (hydrogen bonded $C=0$ )

M.S. $\quad 192(48), 178(11), 177(100), 137(52), 136(32)$, $108(25), 43(15), 41(11)$ 
2,2-dimethyl-4-keto-5-tosyloxy benzopyran(159) from 118

$1.0 \mathrm{~g}$ chromanone $118(5.2 \mathrm{mmol}), \mathrm{p}$-toluenesulphonyl chloride $(1.1 \mathrm{~g}, 5.7 \mathrm{mmol}), \mathrm{NaOH}(1.0 \mathrm{~g}, 25 \mathrm{mmol})$, and $\operatorname{TEBAC}(.13 \mathrm{~g}, .52 \mathrm{mmol})$ were stirred in $25 \mathrm{ml} \mathrm{CH}_{2} \mathrm{Cl}_{2}$ under Ar for $6 \mathrm{hrs}$. The mixture was passed through a Florisil pad, eluted with $100 \mathrm{ml} \mathrm{CH}_{2} \mathrm{Cl}_{2}$, the solvent removed, and purified by column chromatography (silica gel) to give 159 as a clear oil $(1.3 \mathrm{~g}, 3.7$ mmol, $72 \%$ yield).

NMR: $\quad 1.33(\mathrm{~s}, 6 \mathrm{H}, \mathrm{C}-2$ gem dimethyls $), 2.40(\mathrm{~s}, 3 \mathrm{H}$, tosyl $\left.\mathrm{CH}_{3}\right), 2.57(\mathrm{~s}, 2 \mathrm{H}, \mathrm{H}-3), 6.70-6.97$ $(\mathrm{m}, 2 \mathrm{H}, \mathrm{H}-6$ and $\mathrm{H}-8), 7.33(\mathrm{~d}, 2 \mathrm{H}, \mathrm{J}=8 \mathrm{~Hz}$, tosyl $\mathrm{Ar}-\mathrm{H}^{\prime}$ 's ortho to sulphone), 7.85 (d, $2 \mathrm{H}, J=8 \mathrm{~Hz}$, tosyl Ar-H's ortho to methyl)

IR: $\quad 1700(\mathrm{C}=0)$

M.S. $\quad 346(<1 \%), 91(44), 65(48), 64(20), 63(18), 56(32)$, 5 (28), 52(20), 51(41), 50(17), 49(53), 48(20), $43(18), \quad 41(100)$ 
5-acetoxy-2,2-dimethyl-4-keto-benzopyran (160) from 118

$0.10 \mathrm{~g}$ chromathone $118(.52 \mathrm{mmo1})$, powdered NaOH (:10 g, 2.5 mol) and triethyl benzyl ammonium chloride (TEBAC) $(.025 \mathrm{~g}, .12 \mathrm{mmol})$ were stirred under $\mathrm{Ar}$ in $5 \mathrm{ml}$ dry $\mathrm{CH}_{2} \mathrm{C} / 2$. Acetyl chloride $(2 \mathrm{ml})$ was added dropwise by syringe and the mixture was stirred for 20 minutes. 25. $\mathrm{ml}$ of $\mathrm{CH}_{2} \mathrm{Cl}_{2}$ was then added, the mixture passed through a florisil pad, and eluted

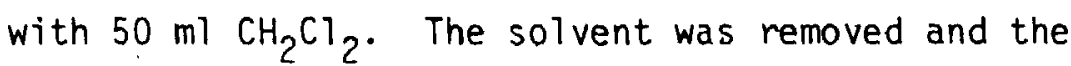
residue purified by thick layer chromatography to give. 11.9 (.47 mmoi, $90 \%$ yield) of 160 .

NMR: $\quad 1.43(\mathrm{~s}, 6 \mathrm{H}, \mathrm{C}-2$ gem dimethy $7 \mathrm{~s}), 2.33(\mathrm{~s}, 3 \mathrm{H}$, acetate $\left.\mathrm{CH}_{3}\right), 2.63(\mathrm{~s}, 2 \mathrm{H}, \mathrm{H}-3), 6.60(\mathrm{~d}, .1 \mathrm{H}$, $J=8 H z, H-6), 6.83(d, 1 H ; J=8 H z, H-8)$,

* $7.43(t, 1 \mathrm{H}, \mathrm{J}=8 \mathrm{~Hz}, \mathrm{H}-7)$.

IR: $\quad 1770 \mathrm{~cm}^{-1}$ (acetate $\left.C=0\right), 1690,(C-4 \quad C=0)$

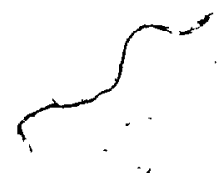


$0.10 \mathrm{~g}$ :chromanone $118(.52-\mathrm{mmol}), .10 \mathrm{~g}$ benziy bromide $(.58 \mathrm{mmol})$, and $.5 \mathrm{~g} \mathrm{~K}_{2} \mathrm{CO}_{3}$ were refluxed in $20 \mathrm{ml}$ acetone for 3 days. The mixture was filtered, rotovapped and taken up in $50 \mathrm{mT}$ ether. After washing with $30 \mathrm{ml} 2 \mathrm{~N} \mathrm{NaOH}$ followed by $30 \mathrm{ml} \mathrm{H}_{2} \mathrm{O}$, the solvent was evaporated. Recrystal1ization from ether/hexane gave $.12 \mathrm{~g} \underline{120}(.43 \mathrm{mmol}, 83 \%)$ as white crystals.

M.P. $\quad 128$

N.M.R. $1.45(\mathrm{~s}, 6 \mathrm{H}, \mathrm{C}-2$ gem dimethyls), $2.70(\mathrm{~s}, 2 \mathrm{H}$, $\mathrm{H}-3), 5.20\left(\mathrm{~s}, 2 \mathrm{H}\right.$, benzylic $\left.\mathrm{CH}_{2}\right), 6.55$ (d, $2 \mathrm{H}$, $\dot{j}=8 \mathrm{~Hz}, \mathrm{H}-6$ and $\mathrm{H}-8), 7.20=7.73(\mathrm{~m}, 6 \mathrm{H}$, aromatic. H) . '

IR: $\quad, 1685 \mathrm{~cm}^{-1}(\mathrm{C}=0)$

M.S. $\quad 282(11), 91(100), 65(13), 41(14)$ 
5-benzyloxy-2,2-dimethyl-4-hydroxy-benzopyran (121) from 120 A

$1.8 \mathrm{~g}$ of chromanone $120(6.3 \mathrm{mmol})$ in $10 \mathrm{ml}$ of Jmethanol was added dropwise to $.34 \mathrm{~g} \mathrm{NaBH}_{4}(9.2 \mathrm{mmol})$ in $30 \mathrm{ml}$ methanol. After stirring overnight under $\mathrm{Ar}$, the excess $\mathrm{NaBH}_{4}$ was destroyed by careful dropwise addition of $30 \mathrm{ml}$ of $2 \mathrm{~N} \mathrm{HCl}$. The resulting solution was added to $100 \mathrm{ml}$ of ether and $100 \mathrm{ml}$ of water in a separatory funme?, the organic layer separated and washed with a saturated sodium bicarbonate solution $(2 \times 50 \mathrm{ml})$. After rotoevaporation, the oily residue (i.7 $\mathrm{g}, 6.0 \mathrm{mmol}, 95 \%$ yield) was found to be pure enough (by $L C$ to proceed to the dehydration step. A small sample was purified by thick layer chromatography for analysis, confirming its jentity as $\underline{121}$.

NMR: $1.32(\mathrm{~s} ; 3 \mathrm{H}, \mathrm{C}-2$ methy $\mathrm{l}), 1.42(\mathrm{~s}, 3 \mathrm{H}, \mathrm{C}-2$ methy 1$), 2.03(\mathrm{~d}, 2 \mathrm{H}, \mathrm{J}=6 \mathrm{~Hz}, \mathrm{H}-3), 3.37$ (broad $s, 1 \mathrm{H}, \mathrm{C}-4 \mathrm{OH}), 5.10(\mathrm{t}, 1 \mathrm{H}, \mathrm{J}=6 \mathrm{~Hz}$, $\mathrm{H}-4), 5.13\left(\mathrm{~s}, 2 \mathrm{H}\right.$, benzyl $\left.\mathrm{CH}_{2}\right), 6.57,(\mathrm{~d}, 2 \mathrm{H}$, $\mathrm{J}=7 \mathrm{~Hz}, \mathrm{H}-6$, and $\mathrm{H}-8), 7.30(\mathrm{t}, 1 \mathrm{H}, \mathrm{J}=7 \mathrm{~Hz}$; $H-7), 7.47(s, 5 H$, benzyl Ar-H)

IR: $\quad 3450 \mathrm{~cm}^{-1}$ (benzylic $\mathrm{OH}$ ) 


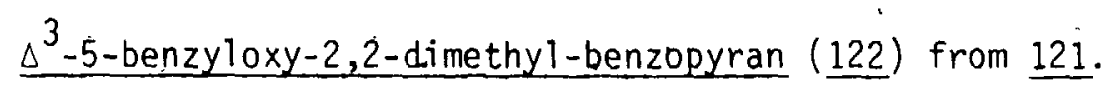

$1.6 \mathrm{~g}$ (5.6 mmol) of chromanol 121 was dissolved in $50 \mathrm{ml}$ of dry toluene. The solution was brought to reflux under $A r$, and $50 \mathrm{mg}$ of $\mathrm{p}$-tóluene'sulphonic acid (.29 mol.) was added in one portion. After refluxing for $15 \mathrm{~min}$, the solution was allowed to. cool and washed with 2-10 ml portions of $2 \mathrm{~N} \mathrm{NaOH}$, followed by $1-50 \mathrm{ml}$ portion of distilled water. The organic layer was passed through a small Florisi.l -pad, eluted with $100 \mathrm{ml} \mathrm{CH}_{2} \mathrm{Cl}_{2}$, and rotoevaporated to give $1.4 \mathrm{~g}$ of chromene $122(5.2 \mathrm{mmol}, 93 \%)$ as a. slightly yellow oil, essentially pure by TLC. A small sample was purified further by thick layer chromatography."

NMR: $\quad 1: 47(\mathrm{~s}, 6 \mathrm{H}, \mathrm{C}-2$ gêm dimethyls $), 5.13(\mathrm{~s}, 2 \mathrm{H}, \ldots$ benzyl $\left.\mathrm{CH}_{2}\right), 5.60(\mathrm{~d}, 1 \mathrm{H}, \mathrm{J}=10 \mathrm{~Hz}, \mathrm{H}-3)^{\prime}$, $6.53(d, 1 H, J=8 H z, H-8), 6.51(d, 1 H, J=$ $8 \mathrm{~Hz}, \mathrm{H}-6), 6.82(\mathrm{~d}, 1 \mathrm{H}, \mathrm{J}=10 \mathrm{~Hz}, \mathrm{H}-4) \cdot 7.47$ (s, $5 \dot{H}$, benzyl. Ár $-\dot{H}$ )

M.S. $266(6), 251(32), 161(12), 91(100), 65(26), 63(10)$, $57(14), 55(12), 51(10), 43(14), 41(200)$ 
5-hydroxy-2,2-dimethy)-benzopyran (124) from (122)

$0.10 \mathrm{~g}$ of chromene $\underline{122}(.37 \mathrm{mmol}), .1 \mathrm{~g} \mathrm{Pd} / \mathrm{C}$, and $5 \mathrm{ml}$ dry ethanol were stirred under a hydrogen atmósphere. When $\sim 8 \mathrm{ml}$ of hydrogens were consumed, the reaction vessel was removed, and the solution " filtered and rotovapped. After separation by thick layer chromatography, $43 \mathrm{mg}$ of starting material was recovered along with $32 \mathrm{mg}$ of 124 (. $18 \mathrm{mmol}, 86 \%$ yield based on recovered starting material).

NMR: $\quad 1.30(s, 6 \mathrm{H}, \mathrm{c}-2$ gem dimethyls), 1.78 ( $t$, $2 \mathrm{H}, J=6 \mathrm{~Hz}, \mathrm{H}-3) ; 2.67$. ( $\mathrm{t}, 2 \mathrm{H}, \mathrm{J}=6 \mathrm{~Hz}$, $H-4), 5.10$ (broad $s, 1 H$, phenolic $0-H$ ), $6.33(\mathrm{~d}, 1 \mathrm{H}, J=8 \mathrm{~Hz}, \mathrm{H}-6), 6.45 \mathrm{dd}, 1 \mathrm{H}$, $\mathrm{J}=8 \mathrm{~Hz}, \mathrm{H}-8), 7.00(\mathrm{t}, 1 \mathrm{H}, \mathrm{J}=8 \mathrm{~Hz}, \mathrm{H}-7)$

IR: $\quad 3350$ (broad, phenolic $\mathrm{O}-\mathrm{H}$ )

M.S. $178(23), 123(100), 122(11), 66(10), 55(15)$, e.52(11), 51(12), 43(32), 41(65), 40(29) 
4,5-dihydroxy-2,2-dimethyl-benzopyran (123) from 118

To a suspension of $.1 \mathrm{~g}(26.3 \mathrm{mmol})$ in $50 \mathrm{ml}$ - anhydrous ether under Ar was àdded,dropwìse, chromanone 118 . (504 mg, $2.23 \mathrm{mmol}$ ) in $20 \mathrm{ml}$ anhydrous ether and stirring continued overnight. After cooling to $0^{\circ} \mathrm{C}$, $1 \mathrm{ml}$ of water, then $1 \mathrm{ml}$ of $3 \mathrm{~N} \mathrm{NaOH}$, and finally $3 \mathrm{mls}$ of water were added sequentially and dropwise to the reaction mixture. The solids were filtered by suction, washed with ether, and the filtrate rotovapped to give $451 \mathrm{mg}(2.32: \mathrm{mmol}, 88 \%)$ of $\underline{123}$ as a clear oil. Purification was unnecessary.

NMR: $\quad 1.27(\mathrm{~s}, 3 \mathrm{H}, \mathrm{C}-2$ methyl), 1.37 (s, $3 \mathrm{H}, \mathrm{C}-2$ methyl), $2.03(\mathrm{~d}, 2 \mathrm{H}, \mathrm{J}=6 \mathrm{~Hz}, \mathrm{H}-3), 3.77$ $(m, 1 \mathrm{H}, \mathrm{C}-4 \mathrm{OH}) ; 5.12(\mathrm{t}, 2 \mathrm{H}, \mathrm{J}=6 \mathrm{~Hz}$, $\mathrm{H}-4), 6.42(\mathrm{~d}, 2 \mathrm{H}, \mathrm{J}=8 \mathrm{~Hz}, \mathrm{H}-6$ and $\mathrm{H}-8)$;

IR: $\quad \begin{aligned} & 7.08(\mathrm{t}, \mathrm{H}, \mathrm{J}=8 \mathrm{~Hz}, \mathrm{H}-7) \\ & 3300 \mathrm{~cm}^{-1} \text { (phenolic } \mathrm{OH}, \text { benzylic OH) }\end{aligned}$

2,2-dimethyl-5-hydroxy-benzopyran (124) from 123

1.0 g ghromanol $123(5.2 \mathrm{mmol}), 2.0 \mathrm{~g} \mathrm{Zn}$ dust

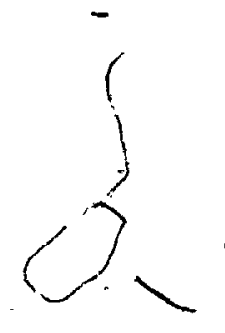
and $20 \mathrm{ml}$ acetic acid were stirred overnight. After addition of $100 \mathrm{ml}$ of methanol solid $\mathrm{NaHCO}_{3}$ was added with vigorous stirring until no further $\mathrm{CO}_{2}$ evolution was noted. The mixture was filtered and rotovapped to afford $.63 \mathrm{~g}(3.5 \mathrm{mmol} ; 67 \%$ yield) of chroman 124, essentially pure by TLC. 
2,2-dimethy 7-4-hydroxy-5-phenacyloxy-benzopyran (125) from $\underline{123}$

$100 \mathrm{mg} \underline{123}$ (.51 mmol), $1 \mathrm{~g} \mathrm{~K}_{2} \mathrm{CO}_{3}$, and phenacyl bromide $(110 \mathrm{mg}, .55 \mathrm{mmol})$ were-refluxed in $20 \mathrm{ml}$ acetone under Ar for $3 \mathrm{hrs}$. The orange solution was filtered, the solvent removed, and the residue purified by thick layer chromatography to give $125(128 \mathrm{mg}$, $.41 \mathrm{mmol}, 81 \%)$ as a yellow oil.

NMR: $\quad 1.34(\mathrm{~s}, 3 \mathrm{H}, \mathrm{C}-2$ methy $), 1.43(\mathrm{~s}, 3 \mathrm{H} ; \mathrm{C}-2$

: methy $), 2.08(\mathrm{~d}, 2 \mathrm{H}, \mathrm{J}=6 \mathrm{~Hz}, \mathrm{H}-3), 5.13(\mathrm{t}, \cdot$ $1 \mathrm{H}, \mathrm{J}=6 \mathrm{~Hz}, \mathrm{H}-4), 5.39 \$ 5.24$, benzyl' $\left.\mathrm{CH}_{2}\right)$,

- $6.41(\mathrm{~d}, 2 \mathrm{H}, \mathrm{J}=8 \mathrm{~Hz}, \mathrm{H}-6$ and $\mathrm{H}-8 \mathrm{-}), 6.90^{\circ}(\mathrm{t}$, $1 \mathrm{H}, \mathrm{J}=8 \mathrm{~Hz}, \mathrm{H}-7), 7.30-8: 10(\mathrm{~m}, 6 \mathrm{H}$, phenacy 1

Ar-H)

IR: $3450 \mathrm{~cm}^{-1}$ (benżylic OH), $1700 \mathrm{~cm}^{-1}$. (phenacy] $\mathrm{C}=0)$. . .

M.S. $312(5), 279(12), 193 .(20), 192(53), 177(37), 141(15)$, $137(98), 136(23) 0,135(22), 134(13) ; 121(11), 120(11)$, 106(19), 105(100), 91(40), 78(13), 77(76), 65(26), $45(13), 41(24)$ 


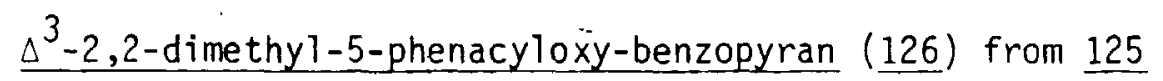

$100 \mathrm{mg} \underline{125}$ (.32 mmol) was dissolved in $10 \mathrm{ml}$ toluene, and brought to reflux under Ar. p-Toluene sulphonic acid ( $1 \mathrm{mg}$ ) was added, and 'reflux was continued for 15-min. After allowing the solution to cool, it was washed with $20 \mathrm{ml}$ of $2 \mathrm{~N} \mathrm{NaOH}$, passed through a small. Florisil pad, and eluted with $50 \mathrm{ml}$ $\mathrm{CH}_{2} \mathrm{Cl}_{2}$. Removal of the solvent gave chromene $\underline{126}$ (89 mg, .30 mmol, 93\% yield), essentially pure by TLC.

NMR: $\quad 1.42(\mathrm{~s}, 6 \mathrm{H}, \mathrm{C} .-2$ gem dimethyls $), .5 .25(\mathrm{~s}, 2 \mathrm{H}$, phenacyl $\left.\mathrm{CH}_{2}\right), 5.57(\mathrm{~d}, 1 \mathrm{H}, \mathrm{J}=10 \mathrm{~Hz} ; \dot{H}=3$ ), $6.32(d, 1 H, J=8 H z, H-8), 6.34(d, 1 H, J=$ $8 \mathrm{~Hz}, \dot{H}-6)$

IR: $\quad 1700 \mathrm{~cm}^{-1}(\mathrm{C}=0)$

M.S: $\quad 294(12), 105(48), 103(18), 91(22), 78(24)$, $77(100), 76(10), 65(43), 63(30), 55(21), 53(19)$, $52(28), 51(100), 50(54), 43(91), 41(70) ;-40(19)$

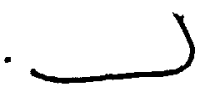

$$
\text { n }
$$


$\underline{\Delta^{3}-2,2-\text { dimethy } 7-5-\text { hydroxy-benzopyran (103) from } 126}$

$140 \mathrm{mg}$ of $\underline{126}(.48 \mathrm{mmol})$ was dissolved in a mixture of $5 \mathrm{ml} \mathrm{H} \mathrm{H}_{2} \mathrm{O}$ and $15 \mathrm{ml}$ glacial acetic acid. After adding zinc dust $(.13 \mathrm{~g}, 2.0 \mathrm{mmol})$ the solution was stirred under $A \dot{r}$ overnight. The mixture was filtered,diluted with $50 \mathrm{ml}$ of methanol, and. neutralized with solid $\mathrm{NaHCO}_{3}$ under vigorous

$\therefore$ stirring until no $\mathrm{CO}_{2}$ evolution was apparent. The mixture was again filtered, and the solvent removed. Pure 103 was obtained by thick layer chromatography $(62 \mathrm{mg}, .35 \mathrm{mmol}, 74 \%$ ) as pale white flakep.

M.P. $\quad 125-126$

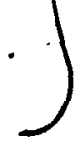

NMR: $\quad 1.43(\mathrm{~s}, 6 \mathrm{H}, \mathrm{C}-2$ gem dimethyls $), 5.6(\mathrm{~d}, 1 \mathrm{H}$, , $\mathrm{J}=10 \mathrm{~Hz}, \hat{H}-3), 6.23-6.53(\mathrm{~m}, 2 \mathrm{H}, \mathrm{H}-6$ and $H-8), 6.67(d, 1 H, J=10 \mathrm{~Hz}, H-4), 6.98(t$, $1 \mathrm{H}, \mathrm{J}=8 \mathrm{~Hz}$ )

IR: $\quad\left(\mathrm{CHCl}_{3}\right): 3300 \mathrm{~cm}^{-1}$ (broad, phenolic $\mathrm{OH}$ )

M.S. $.176(20), 162(14), 161(100)$ 
2,2-dimethyl-5-hydroxy-4-keto-7-pyrrol idinyl-benzopyran

(131) from 129

A mixture of acetophenone $\underline{129}(3.1 \mathrm{~g}, 19.1 \mathrm{mmol})^{98}$,

pyrrolidine $(3.2 \mathrm{ml}, 2.7 \mathrm{~g}, 38.0 \mathrm{mmol})$ and acetone

$(1.6 \mathrm{~g}, 3.3 .3 \mathrm{mmol})$ were heated in $75 \mathrm{mls}$ of toluene

until all of .the solids were dissolved $\left(\sim 40^{\circ} \mathrm{C}\right)$, under

Ar. Stirring was continued for 3 days, after which

the reaction was cooled, acidified with $2 \mathrm{~N} \mathrm{HCl}$, and

the organic layer rotovapped. The residue was dissolved

in $\mathrm{CH}_{2} \mathrm{Cl}_{2}$, passed through Florisil, and eluted with

$\mathrm{CH}_{2} \mathrm{Cl}_{2}$. After removal of the solvent, the remaining '

material was recrystallized from $\mathrm{MeOH} / \mathrm{H}_{2} \mathrm{O}$, to give

i. $9 \mathrm{~g}(7.2 \mathrm{mmol}, 38 \%$ yield $)$ of pure 131 .

M.P. $\quad 143-144$

NMR: $\quad 1.45(\mathrm{~s}, 6 \mathrm{H}, \mathrm{C}-2$ gem dimethyls $), 2.00(\mathrm{~m}, 4 \mathrm{H}$, pyrrolidinyl $\mathrm{H}_{3}$ and $\left.\mathrm{H}_{4}\right), 2.63(\mathrm{~s}, 2 \mathrm{H}, \mathrm{H}-3)$,

$3.35\left(t, 4 \mathrm{H}, \mathrm{J}=6 \mathrm{~Hz}\right.$, pyrrolidinyl $\mathrm{H}_{2}$ and $\left.\mathrm{H}_{5}\right)$,

5.63 (broad S, $2 \mathrm{H}, \mathrm{H}-6$ and $\mathrm{H}-8)^{\circ}$

IR: (KBr pellet): $3450 \mathrm{~cm}^{-1}$ (phenolic OH) 1665

( aromatic hydrogen bonded $\mathrm{C}=0$ )

M.S. $262(18), 261(100), 260(18), 246(52), 206(47)$, $205(24), 50(10), 41(10) ; m^{*} .232$

$C^{13}: \quad 25.35,\left(9, C-2^{*}\right.$ gem dimethyls), 26.92 ( $t$, pyrrolidinyl $C-3$ and $C-4), 47.45(t, C-3), 47.70(9$;

pyrrolidiny $1 \mathrm{C}-1$ and $\mathrm{C}-5), 91.28(\mathrm{~d}, \mathrm{C}-8), 91.39(\mathrm{~d}, \mathrm{C}-6)$, $99.10(\mathrm{~s}, \mathrm{C}-10), 154.78(\mathrm{~s}, \mathrm{C}-7), 160.83(\mathrm{~s}, \mathrm{C}-5)$, $163.56(s, C-9), 193.47(s, C-4) \cdot$ 
Elem. Analysis: Calc. C, 68.67; H, 7.70; N, 5.34

Found $C, 68.81 ; H, 7.44 ; N, 5.38$

2,6-dihydroxy-4-pyrrol idinyl-acetophenone (161) from 129

A mixture of $100 \mathrm{mg}(.617 \mathrm{mmol})$ acetophenone $\underline{129}$,

and $1 \mathrm{ml}$ of pyrroljdine were stirred at $\sim 40^{\circ} \mathrm{C}$ under Ar for 3 days in: $10 \mathrm{mls}$ of toluene. After cooling, the solvent was removed on the rotovap and the residue dissolved in $\mathrm{CH}_{2} \mathrm{Cl}_{2}$, passed-through a Florisil pad, and eluted with more $\mathrm{CH}_{2} \mathrm{Cl}_{2}$. Purification by thick làyer chromatography gave 161 as an $0 i 1$ (41 mg, .19 mmol, $31 \%)$.

NMR: $\quad 1.80-2.16(\mathrm{~m}, 44$, pyrrolidinyl $H-3$ and $H-4)$, $2.5 \mathrm{~s}\left(\mathrm{~s}, 3 \mathrm{H}, \mathrm{COCH}_{3}\right), 3.10-3.47(\mathrm{~m}, 4 \mathrm{H}$, pyrrolidinyl $\mathrm{H}-1$ and $\mathrm{H}-5$ ), 5.67 ( $\mathrm{s}, 2 \mathrm{H}, \mathrm{H}-3$ and $\mathrm{H}-5$ )

IR: $\quad 3300 \mathrm{~cm}^{-1}$ (broad, phenolic $\left.\mathrm{OH}\right), 1635 \mathrm{~cm}^{-1}$ (aromatic hydrogen bonded $\mathrm{C}=0$ )

M.S. $221(52), 220(15), 207(12), 206(100), 191(10)$, $70(11), 43(11) ; m^{\star} 192$ 
5,7-dihydroxy-2,2-dimethy 1-4-keto-benzopyran (130) from 128

Phloroglucinol (128) (14.8 g, $117 \mathrm{mmol})$ and.

$\beta, \beta$-dimethyl acrylic acid $(12.0 \mathrm{~g}, 12.0 \mathrm{mmol})$ were stirred in $80 \mathrm{ml}$ of $\mathrm{BF}_{3}$ etherate, under Argon at room temperature, for 24 hrs. 56 The mixture was poured carefully into 1 litre of water and beiled for 10 minute. After cooling, the yellow solids were filtered, giving essentially pure $130(13.0 \mathrm{~g}, 6 \dot{2} .5$ mmol, 53\%).

M.P. $\quad 195$

NMR: (acètone- $\left.d_{6}\right): 1.40(\mathrm{~s}, 6 \mathrm{H}, \mathrm{C}-2$ gem dimethyls), $2.68(\mathrm{~s}, 2 \mathrm{H}, \mathrm{H}-3), 4.30$ (broad $\mathrm{s}, 2 \mathrm{H}$, phenol $\mathrm{OH}), 5.85(\mathrm{~s}, 2 \mathrm{H}, \mathrm{H}-6$ and $\mathrm{H}-8)$

i

IR: $\quad(\mathrm{KBr}$ pellet): 3150 (broad, phenolic OH) 1635 $(\mathrm{C}=0)$

M.S. $209(17), 208(66), 194(12), 193(100), 176(11)$, $161(66), 154(66), 152(36), 149(26), \cdot 124(29)$, $123(12), 96(12), 91(11), 77(13) ; 59(36), 57(15)$, $56(11), 54(10), 51(15), 50(14), 43(52), 41(56)$ 
$1.00 \mathrm{~g}$ (4.81 molol) chromanone $\underline{130}, .66 \mathrm{~g}(4.8$ mmol) $n$-butyl bromide, and $2.5 \mathrm{~g} \mathrm{~K}_{2} \mathrm{CO}_{3}$ were refluxed in $30 \mathrm{ml}$ of acetone for $12 \mathrm{hrs}$. The mixture was cooled, fiftered, and rotovapped. The residue was placed on a Florisil pad and eluted with $100 \mathrm{mT} \mathrm{CH}_{2} \mathrm{Cl}_{2}$. Rotoevaporation gave $1.15 \mathrm{~g}$ of $\underline{139}(4.35 \mathrm{mmol}, 91 \%)$, which crystallized upon standing.

M.P. $\quad 52-53$

NMR: $\quad .92(t, 3 \mathrm{H}, \mathrm{J}=7 \mathrm{~Hz}, \mathrm{H}-4,1.45(\mathrm{~s}, 6 \mathrm{H}, \mathrm{C}-2 \mathrm{gem}$ dimethyls), $2.67(\mathrm{~s}, 2 \mathrm{H}, \mathrm{H}-3), 3.98(\mathrm{t}, 2 \mathrm{H}$, . $J=6 \mathrm{~Hz}, \mathrm{H}-1$ ), 6.00 (broad $5,2 \mathrm{H}, \mathrm{H}-6$ and $\mathrm{H}-8$ )

IR: $1645 \mathrm{~cm}^{-1}$ (hydrogen bonded $\mathrm{C}=0$ )

M.S. $265(16), 264(88), 250(15), 249(83), 209(43)$, 208(100), 189(11), 188(88), 179(11), 153(52), $152(35), 124(27), 123(20), 83(11), 69(18)$, $55(13), 41(24) ; m^{*} 179,164,150$ 
1.26 .43 (d, benzy1 $C+3$ and $C-5$ ), 127.35 (d, benzy? $C-4), 128.48$ (d, benzyl $C-2$ and $C-6$ ), 136.54 (s, benzy $\mathrm{C}-1), 160.55$ (s, C-5), 163.15 ( $\mathrm{s}$, $\mathrm{C}-7), 165.23(\mathrm{~s}, \mathrm{C}-9), 188.91(\mathrm{~s}, \mathrm{C}-4)$

5-benzyloxy-8-(3-keto-butyl)-7-butbxy-2,2-dimethyl-4-keto-benzopyran benzopyran (145) from $\underline{140}$

Chromanone $140(4.7 \mathrm{~g}, 13.3$ mmol $)$, methyl vinyl ketone $(7 \mathrm{ml}, 6.0 \mathrm{~g}, 86 \mathrm{mmol})$, and p-toluene sulphonic acid $(.4 \mathrm{~g}, 2.1 \mathrm{mmol})$ were stirred in $50 \mathrm{ml} \mathrm{CH}_{2} \mathrm{Cl}_{2}$ under Ar for three days. The mixture was washed with aqueous $\mathrm{NaHCO}_{3}$, passed through Florisil, eluted with $\mathrm{CH}_{2} \mathrm{Cl}_{2}$, and the solvent removed. The residue was recrystallized from hexane to give $\underline{145}(4.7 \mathrm{~g}, 11.1 \mathrm{mmol}, 83 \%$ yield $)$

M.P. $\quad 94.6$

NMR: $\quad 1.43(\mathrm{~s}, 6 \mathrm{H}, \mathrm{C}-2$ gem dimethyls $), 2.17(\mathrm{~s}, 3 \mathrm{H}$, butanonyl $\left.\mathrm{COCH}_{3}\right), 2.63(\mathrm{~s}, 2 \mathrm{H}, \mathrm{H}-3), 2.80$ ? $\left(t, 2 \mathrm{H}, J={ }^{\prime} 6 \mathrm{~Hz}\right.$, butanony $\left.1 \mathrm{CH}_{2} \mathrm{CO}\right), 4.02(t, 2 \mathrm{H}$, . $\left.J=6 \mathrm{~Hz}, \mathrm{H}-1^{\prime}\right), 5.23\left(\mathrm{~s}, 2 \mathrm{H}\right.$, benzy $\left.1 \mathrm{CH}_{2}\right), 6.20$ (broad s, 2H, H-6 and $\mathrm{H}-8$ ), $7.27-7.83(\mathrm{~m}, 5 \mathrm{H}$, benzyl Ar-H)

IR: $\quad\left(\mathrm{KBr}\right.$ pel1/et): $1714 \mathrm{~cm}^{-1}$ (butanonyl $\left.\mathrm{C}=0\right), 1675 \mathrm{~cm}^{-1}$ (aromatic $\mathrm{C}=0$ ).

Elemental Analysis: Calc. C, 73.58; H, 7.55

Found $\mathrm{C}, 73.62 ; \mathrm{H}, 7.57$ 


$$
\begin{aligned}
& \text { :M.S. 425(13), 424(43), 277(11), 179(11), } 91(100) \text {, } \\
& 43(19), 41(10) \\
& C^{13}: \quad 13.75\left(C-4^{\prime}\right), 17.64\left(C-3^{\prime}\right), 19.28 \text { (butanónyl } \\
& \left.\mathrm{COCH} \mathrm{CH}_{3}\right), 26.72\left(\mathrm{C}-2 \text { gem dimethyls), } 29.64^{-\mathrm{a}}\right.
\end{aligned}
$$

(butanonyl $\left.\mathrm{CH}_{2} \mathrm{CO}\right), 31.18\left(\mathrm{C}-2^{\prime}\right), 43.27$ (butanonyl benzylic $\mathrm{CH}_{2}$ )

$50.28(\mathrm{C}-3), 68.08\left(\mathrm{C}-1^{\prime}\right), 70.84$ (benly $\left.1 \mathrm{CH}_{2}\right)$,

$78.55(\mathrm{C}-2), 91.09(\dot{C}+6), 105.85(\mathrm{C}-8), 109.89$

$(C-10), 126.93$ (benzy) $C-3$ and $C-5$ ), 127.84

(benzyl C-4), 128.75 (benzy] $C-2$ and $C-6$ ),

137.07 (benzyl C-1), $159.60(C-5), \$ 159.87$

$(C-7), 162.91(C-9), 190.15(C-3), 209.19$

(butanony $\underline{\mathrm{C}}=0$ )

7-butoxy-2,2-dimethy 1-5-hydroxy-4-keto-8-(3-keto-buty1)benzopyran (146) from 144

$360 \mathrm{mg}$ ( $849 \mathrm{mmol}$ ) of chromanone 144 and a small amount of palladium charcoal ( $20 \mathrm{mg}$ ) were shaken together, in $20 \mathrm{ml}$ of dry EtOH under a hydrogen atmosphere at 1 ATM overnight. . The mixture was filtered, and the solvent removed on the rotovap, to give essentially pure $146(272 \mathrm{mg}, .814 \mathrm{mmo}), 96 \%)$.

NMR: $\quad 1.40(\mathrm{~s}, 6 \mathrm{H}, \mathrm{C}-2$ gem dimethyls $), 2.12(\mathrm{~s}, 3 \mathrm{H}$, butanonyl $\left.\mathrm{COCH}_{3}\right), 2.63(\mathrm{~s}, 2 \mathrm{H}, \mathrm{H}-3), 3.96$ $\left(t, 2 \mathrm{H}, \mathrm{J}=6 \mathrm{~Hz}, \mathrm{H}-1^{\prime}\right), 5.94(\mathrm{~s}, 2 \mathrm{H}, \mathrm{H}-6$ and $\mathrm{H}-8)$

IR: $\quad 1715 \mathrm{~cm}^{-1}$ (butanony $\mathrm{C}=0$ ), $1640 \mathrm{~cm}^{-1}$ (aromatic $\mathrm{C}=0$ ) M.S. $\quad 334(.4), 69(14), 57(12), 55(17), 443(100), 41(77)$ 
5-benzyloxy-7-butoxy-2,2-dimethyl-4-keto-benzopyran

(140) from 139

To $40 \mathrm{ml}$ of dry acetone was added $1.4 \mathrm{~g}$ of chromanone $139-(5.3 \mathrm{mmol}), \mathrm{K}_{2} \mathrm{CO}_{3}(2.0 \mathrm{~g})$, and $.63 \mathrm{ml}$ benzyl bromide $(.91 \mathrm{~g}, 5.3 \mathrm{mmol})$. The mixture was refluxed overnight under $A r$, cooled, and filtered. The solvent was rotovapped off; the residue dissolved in $\mathrm{CH}_{2} \mathrm{Cl}_{2}$, placed on a Florisil pad, and eluted with more $\mathrm{CH}_{2} \mathrm{Cl}_{2}$. The solvent was removed, and the residue recrystallized from hexane to give $\underline{140}$ as white crystals (1.7. $9,4.8 \mathrm{mmol}, 91 \%$ yield).

$j 6$. 
0

7-butoxy-2,2-dimethyl-4-(N',N'-dimethyl-hydrazonyl)5-hydroxy-benzopyran (162) from 140

$1.5 \mathrm{~g}$ of chromanone, $140(4.25 \mathrm{mmol})$ and $\mathrm{N}, \mathrm{N}-$ dimethylhydrazine $(1.01 \mathrm{~g}, 16.9 \mathrm{mmol})$ were dissolved in $10 \mathrm{ml}$ of dry ethanol, and stirred under $\mathrm{Ar} . \quad A$ drop of conc. $\mathrm{HCl}$ was added, ámd the mixture refluxed overnight. After cooling, the solvent was removed on the rotovap and the residue dissolved in ether. The organic phase was extracted with $2 \mathrm{~N} \mathrm{HCl}^{\text {; }}$

- alkalinization of the aqueous phase and extraction with ether followed by rotoevaporation gave an oil (which was essentially one spot by .TLC); total. yield of 162 was $853 \mathrm{mg}(2.16 \mathrm{mmol}, 51 \%)$. A small sample was purified further by thick layer chromatography.

NMR: $1.33(\mathrm{~s}, 6 \mathrm{H}, \mathrm{C}-2$ gem dimethy $1 \mathrm{~s}), 2.58(\mathrm{~s}, 6 \mathrm{H}$, $\mathrm{N}$-methyls), $2.92(\mathrm{~s} ; 2 \mathrm{H}, \mathrm{H}-3 ; 3.93$ ( $\mathrm{t}, 2 \mathrm{H}$; $\left.J=6 \mathrm{~Hz}, \mathrm{H}-1^{\prime}\right), 5.10\left(\mathrm{~s}, 2 \mathrm{H}\right.$, benzylic $\left.\mathrm{CH}_{2}\right), r$ $6.08(\bar{d}, 1 \mathrm{H}, \mathrm{J}=2 \mathrm{~Hz}, \mathrm{H}-\dot{6}), 6.23(\mathrm{~d}, 1 \mathrm{H}$, $J=2 \mathrm{~Hz}, \mathrm{H}-8), 7.16-7.86(\mathrm{~m}, 5 \mathrm{H}$, benzyl Ar-H)

IR: 1670 (weak, $C=N) . \therefore$

'M.5. 396(19), $354(30), 353(10) ; 352(33), 306(25)$, $291(13), 290(21), 277(16), 275(18), 262(10)$, 249(11), 233(13), 206(10), 193(13), 177(10), $92(10), 91(100), 55)(15), 44(12), 4(16) ;$ $\mathrm{m}^{\star} 313$. 
Purification of the original organic phase gave 163 as an $0 i 1(132 \mathrm{mg}, . .43 \mathrm{mmol}, 10 \%)$

MR: $1.40(\mathrm{~s}, 6 \mathrm{H}, \mathrm{C}-2$ gem dimethy $1 \mathrm{~s}), 2.55(\mathrm{~s}, 6 \mathrm{H}$, $\mathrm{N}$-methyls), $2.88(\mathrm{~s}, 2 \mathrm{H}, \mathrm{H}-3), 3.92(t, 2 \mathrm{H}$, $\left.J=6 \mathrm{~Hz}, \mathrm{H}-\mathrm{I}^{\prime}\right), 5.88(\mathrm{~d}, 1 \mathrm{H}, J=2 \mathrm{~Hz}, \mathrm{H}-6)$, $6.02(\delta, 1 \mathrm{H}, \mathrm{J}=2 \mathrm{~Hz}, \mathrm{H}-8)$

IR: $\quad 3350 \mathrm{~cm}^{-1}$ (phenotic $\mathrm{OH}$ ), $1660 . \mathrm{cm}^{-1}$ (weak, $\mathrm{C}=\mathrm{N}$ )

M.S. $\quad 307(16), 306(100), 291(29), 264(15), 250^{2}(18)$, $249(13), 208(22), 207(28), 206(11), 205(10)$, . $153(13), 153(11), 69(11), 57(10), 55(14)$, $44(26), 43(11), 41(21) ; m^{\star} 204,171^{*}$

$\Delta^{3}=5$-benzyloxy-7-butoxy-2,2-dimethyl-4-hydroxy-benzapyran (150) from $\underline{140}$

To $10 \mathrm{ml}$ of dry DME under Ar was added NaH (50 $\mathrm{mg}, 2.1 \mathrm{mmol}$ ) followed by dropwise addition by syringe of chromanone $140(300 \mathrm{mg}, .848 \mathrm{mmol})$ in $5 \mathrm{ml}$ dry. DME. After stirring overnight, the reaction was, quenched with $2 \mathrm{~N} / \mathrm{HCl}$; excess water and diethyl ether were then adfed, the organic layer removed, and the aqueous layer extracted with another portion of ether. The combined ether portions were rotovapped and purified by thick layer chromatography, giving $\underline{150}\left(234^{\circ} \mathrm{mg}, .661 \mathrm{mmol}\right.$, - $78 \%$ ) as a clear oil. 
NMR: $\quad 1.63(\mathrm{~s}, 3 \mathrm{H}, \mathrm{C}-2$ methy 1$), 2.08(\mathrm{~s}, 3 \mathrm{H}, \mathrm{C}-2$ methyl), $4.00\left(t,{ }_{2} \mathrm{H}, J=6 \mathrm{~Hz}, H-1^{\prime}\right), 5.07$ $\left(\mathrm{s}, 2 \mathrm{H}\right.$, benzylic $\left.\mathrm{CH}_{2}\right), 6.03-6.20$ (superimposed doublets, $2 \mathrm{H}, \mathrm{J}=5 \mathrm{~Hz}, \mathrm{H}-6$ and $\mathrm{H}-8), 6.87$ $(\mathrm{m}, 1 \mathrm{H}, \mathrm{H}-3), 7.47$ (s, 5H, benzyl Ar-H), $14.2\left(\mathrm{~s}, 1 \mathrm{H}\right.$, exchangeable with $\mathrm{D}_{2} \mathrm{O}, \mathrm{C}-4$ $\mathrm{OH})$

M.S. - $354(5), 339(23), 91(100), 83(11) ; m^{\star} 325$ $\left(\frac{C^{13} \operatorname{MMR} 13.79,\left(q, c^{-4^{\prime}}\right), 19 \% 17\left(t, c-3^{\prime}\right), 21.16}{\left(q,{ }^{\circ}-2 \text { methyl) }, 27.40(q, c-2 \text { methyl), }\right.}\right.$ $31.03\left(t, c-2^{\prime}\right), 67.99\left(t, c-1^{\prime}\right), 71.07$ ( $t$, benzy1 $\left.\mathrm{CH}_{2}\right), 92.20(\mathrm{~d}, \mathrm{C}-8), 94.47$ $(d, C-6), 127.21(d, C-3), 127.94(d$, benzyl $C-3$ and $\dot{C}-5), 128.25$ (d, benzyl $C-4), i 28.58$ (d, benzyl $C-2$ and $C-6$ ), 135.86 (s, benzyl $c-1),-151.98(s, c-10)$, $161.26(s, C-5), 165.20(s, C-9), 167.98$. $(s, C-9), 187.15(s, C-4)$

5-benzyloxy-7-butoxy-2,2-dimethy 7-4-keto-3-(2propeny1)-benzopyran (153) from 140

A mixture of chromanone $\underline{140}(200 \mathrm{mg}, .565 \mathrm{mmol})$, LiH . $25 \mathrm{mg}, 3.1 \mathrm{mmol})$, allyl bromide $(.25 \mathrm{ml}, .35 \mathrm{~g}$, $2.89 \mathrm{mmol})$ and HMPA $(.1 \mathrm{ml})$ were stirred under $\mathrm{Ar}$ in $5 \mathrm{ml}$ of dry ethew for three days. After quenching with $2 \mathrm{~N} \mathrm{HCl}$, the ether layer was removed, rotovapped, 
and the residue purified by thick layer chromatography, giving $\underline{153}(158 \mathrm{mg}, .401 \mathrm{mmol})$.

NMR: $\quad 1.85(\mathrm{~s}, 3 \mathrm{H}, \mathrm{G}-2$ methy 1$), 2.13(\mathrm{~s}, 3 \mathrm{H}, \mathrm{C}-2$ methy 1$)$, $3.95\left(\mathrm{t}, 2 \mathrm{H}, \mathrm{J}=6 \mathrm{~Hz}, \mathrm{H}-1^{\prime}\right), 4.43-4.63(\mathrm{~m}, 2 \mathrm{H}$,

a terminal methylene), $5.10\left(\mathrm{~s}, 2 \mathrm{H}\right.$, benzylic $\left.\mathrm{CH}_{2}\right)$, 7.43 ( $\mathrm{s}, 5 \mathrm{H}$, (benz $\mathrm{Ar}-\mathrm{H}$ )

IR: $\quad 1675^{\circ} \mathrm{cm}^{-1}(\mathrm{C}=0)$

M.S. $394(12), 379(16), 91(100)$,

$83(31), 41(15)$

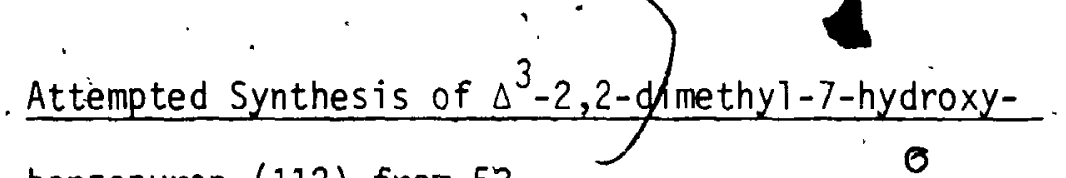
benzopyran (112) from $\underline{53}$

A mixture of resorcinol $(4.3 \mathrm{~g}, 39.1 \mathrm{mmol})$ and

2,2-dimethoxy-2-methyl-2-butanol $73 .(4.3 \mathrm{~g}, 34.6 \mathrm{mmol}) \quad{ }^{\prime}$

were refluxed in $10 \mathrm{ml}$ of pyridine, under Ar. After

$24 \mathrm{hrs}$, TLC showed intact 5 tarting material and no new products.

Attempted Synthes is of $\Delta^{3}-5,7$-dihydroxy-2,2-dimethylbenzopyran (164) from 128

A mixture of phloroglucinol $(1.26 \mathrm{~g}, 10.0 \mathrm{mmol})$

and $73(1.48 \mathrm{~g}, 19.0 \mathrm{mmol})$ were refluxed in $10 \mathrm{~m}$ of pyridine, under Ar. After $24 \mathrm{hrs}$, TLC showed that no new materials were formed. 
Attempted Synthesis of $\Delta^{3}-2,2$-dimethyl-7-hydroxy-benzopyran (112) from $\underline{113}$

Chroman 112 (300 mg, $1.54 \mathrm{mmol}$ ) and DDQ (300 mg) were-refluxed under $\mathrm{Ar}$, in $50 \mathrm{mls}$ of dry benzene, for 2 hr. TLC revealed no isolatable products (i.e. a long streak).

\section{Attempted Synthes is of 2,2-dimethyl-4-hydroxy-5-tosyloxy-} benzopyran (165) from $\underline{118}$

a) Cbromanone $118\left(100 \mathrm{mg}, 288 \mathrm{mmol}^{2}\right), \mathrm{KBH}_{4}(100 \mathrm{mg})^{90}$; and triethylbenzy? ammonium chloride $(25 \mathrm{mg})$ were stirred in a mixtlre of $2 \mathrm{mls}$ of water and $2 \mathrm{mls}$ of benzene, under. Ar, overnight. TLC showed intact starting material and no new products.

b) Chromanone $118(500 \mathrm{mg}, 1.44 \mathrm{mmol})$ in $20 \mathrm{~m} / \mathrm{s}$ dry ether was added dropwise, by syringe, to a suspension of $\mathrm{LiAlH}_{4}(50 \mathrm{mg}, 1.3 \mathrm{mmol})$ in $20 \mathrm{mls}$ dry ether, and mixture stirred under A'rgon for $3 \mathrm{hrs}$. The reaction . was quenched by addition of $.50 \mathrm{mls}$ water, then .50 $\mathrm{mls} 3 \mathrm{~N} \mathrm{NaOH}$, and finally $1.5 \mathrm{~m} / \mathrm{s}$ water. The solids were filtered, wäshed with ether, and the combined filtrates rotovapped, to give $254 \mathrm{mg}$ ( $1.31 \mathrm{mmol}$;) 91\%) of deprotected chromanol 123. 
Attempted Synthesis of $\Delta^{3} 22,2$-dimethy $1-7-h y d r o x y$-benzopyran (112) from 111

To a solution of chromene 111 (300 mg, .887

mol) in $10 \mathrm{mls}$ ethanol under Ar was added $675 \mathrm{mg}$ of

- $\mathrm{KOH}$ in $5 \mathrm{mis} \mathrm{EtOH.'-} \mathrm{The} \mathrm{mixture} \mathrm{was} \mathrm{heated} \mathrm{to} 50^{\circ} \mathrm{C}$

for $1 \mathrm{hr}$, cooled and taken to $\mathrm{pH} 7$ with acetic acid.

Addition of $100 \mathrm{mls}$ of water followed by extraction

- with ether gave a residue which showed a long streak on TLC (no isolatable products).

\section{Attempted Synthes is of 5 -acetoxy-2,2-dimethyy-4-keto-} benzopyran (166) from 118

Chromanone $118(400 \mathrm{mg}, 2.08 \mathrm{mmol})$ was refluxed under Ar in a mixture of $5 \mathrm{mls}$ of acetic anhydride and $5 \mathrm{mls}$ of.pyridine, overnight. TLC showed intact material and no new materials.

\section{Attempted Synthesis of 5-acetoxy-2,2-dimethyl-4-hydroxy-} benzopyran (16Z) from 166

Chromanone $166(300 \mathrm{mg}, 1.28 \mathrm{mmol})$ in $10 \mathrm{mls}$ dry dioxane was added dropwise, under Ar, to a suspension of $100 \mathrm{mg} \mathrm{NaBH} 4$ in $10 \mathrm{mls}$ dioxane. The mixture was stirred overnight, and then a small sample was quenched with $2 \mathrm{~N}$ $\mathrm{HCl}$. TLC showed intact starting material and to new products. 
Attempted Synthesis of $\Delta^{3}-2,2$-dimethyl-5-hydroxy-benzopyran (103) from 122

The debenzylation of 122 was attempted under a variety of conditions; they are listed below:

a) Chromene $122(100 \mathrm{mg}, .373 \mathrm{mmol}) \mathrm{Pd} / \mathrm{C}(20 \mathrm{mg})$ and $\mathrm{AlCl}_{3}(1 \mathrm{mg})$ were refluxed under $\mathrm{Ar}$ in $10 \mathrm{mls}$ of cyclohexene for $24 \mathrm{hrs}$. TLC showed a long streak (no isolatable products).

b) Chromene $122(100 \mathrm{mg}, .373 \mathrm{mmol})$ was dissolved in $5 \mathrm{mis} \mathrm{CH}_{2} \mathrm{El}_{2}$ under $\mathrm{Ar}$, and cooled to $0^{\circ} \mathrm{C}$. Trichloro acetic acid $(.04 \mathrm{ml}, 65 \mathrm{mg}, 40 \mathrm{mmol})$ was added dropwise by syringe, and the mixture stirred for $\frac{1}{2} \mathrm{hr}$. After quenching with $1 \mathrm{ml}$ sat'd $\mathrm{NaHCO}_{3}, * \mathrm{TLC}$ showed a long streak (no isolatable products).

f) Chromene $122(100 \mathrm{mg}, .373 \mathrm{mmol})$ was dissolved in $5 \mathrm{mls} \mathrm{CHCl}_{3}$ under $\mathrm{Ar}$, and cooled to $0^{\circ} \mathrm{C}$. Trimethe silyliodide (74 ma,..373 mol) was added dropwise: by syringe and the mixture stirred for $\frac{1}{2} \mathrm{hr}$. After addition of $1 \mathrm{ml}$ of methanol, followed by $1 \mathrm{ml}$ of $\mathrm{H}_{2} \mathrm{O}$, TLC showed no isolated próducts (i.e. long streak).

d)'Chromene 122 (100.mg, .373 mmol) was dissolved in $5, \mathrm{ml} \mathrm{CH}_{2} \mathrm{Cl}_{2}$, under $\mathrm{Ar}$, and cooled to $0^{\circ} \mathrm{C} . \mathrm{BBr}_{3}$ (.04- $\mathrm{ml}, .09 \mathrm{~g}, .4 \mathrm{mmol}$ ) in $1 \mathrm{ml}^{-} \mathrm{CH}_{2} \mathrm{Cl}_{2}$ was added by syringe, dropwise, and the mixture stirred for 2 hrs. After the addition of $1 \mathrm{ml}$ of $\mathrm{MeOH}$ followed 
by $1 \cdot \mathrm{ml}$ of $\mathrm{H}_{2} \mathrm{O}$, TLC showed no isolatable products (i.e. long streak)

e) Na-K alloy was prepared by heating sodium (76 mg, $3.3 \mathrm{mmol}$ ) and potassium (240 mg, $6.3 \mathrm{mmol}$ ) in $30 \mathrm{mls}$ of xylene until melting had occurred. The molten . alloy was cooled and transferred by pipette to 10 $\mathrm{mls}$ of $65-110^{\circ}$ petroleum ether $(10 \mathrm{mis})$ under $\mathrm{Ar}$. To this was added $122(300 \mathrm{mg}, 1.12 \mathrm{mmol})$ in $10 \mathrm{mis}$ of $65-110^{\circ}$ pet. ether, dropwise by syringe. The . mixture was refluxed for $2 \mathrm{hrs}$, and then carefully quenched with $\mathrm{MeOH}$, followed by water. TLC showed, no isolatable products (i.e. long streak).

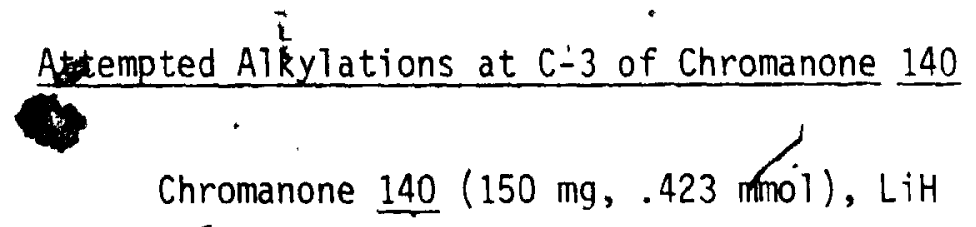

(50 $\mathrm{mg}, 6.3 \mathrm{mmol})$ and HMPA $(.1 \mathrm{ml})$ were stirred in dry diethyl ether $(15 \mathrm{mls})$, under $\mathrm{Ar}$, in the presence of either MeI $(500 \mathrm{mg}, 3.31 "$ mmol) or 4-tosyloxy-2-butanone ethylene ketal (143 mg, . $.500 \mathrm{mmol}$ ), for $24 \mathrm{hrs}$. TLC showed onily the formation of enol 150 . 
References

1. E.F. Domino, Ann. N.Y. Acad. Sci., 191, 166 (1971).

2. T.S. Herman, L.H. Einhorn, S.E: Jones, C. Nagy, A.B. Chester, J.C. Dean, B. Furans, S.D.'Williams, S.A. Leigh, R.T. Door, T.E.. Moon, N. Engl. J. Med., 300, 1295 (1979).

3. R.K. Razdan, B. Zitko-Terris, H.G. Pars, N.P. Plotnikoff, P.W. Dodge, A.T. Dren, J. Kyncyl, P. Somani, J. Med. Chem., 19, 454 (1976).

4. M. Winn, D. Arendsen, P. Dodge, A. Dren, D. Dunnigan, R. Hallas, K. Hwang; J. Kyncyl, Y. Lee, N. Plotnikoff, P. Young, H. Zaugg, H.C. Dalze1l, and R.K. Razdan, J. Med. Chem., 19, 461 (1976).

5. S.F. Brunk, R. Noyes, D.H. Avery and A. Canter, J. Cl in. Pharmacol., 15, 664 (1974).

6: M. Staquet, C. Gantt, and D. Machin, Clin. Pharmacol. Ther. , 23, 397 (1978)

7. P.R. Jochimsen, R.L. Lawton, K. Versteeg, R. Noyes, Clin. Pharmacol: Ther. 24, 223 (1978).

8. G.M. Milne, A. Weissman, B.K. Koe, M.R. Johnson, Pharmacologist, 20, 243 (1978).

9. L. Lemberger, R. McMahon, R. Archer, K. Matsumoto, - and H. Rowe, Clitim Pharmacol. Ther. 15, 380 (1974).

10. L. Lemberger and $\mathrm{H}$. Rowe, $\mathrm{Cl}$ in. Pharmacol. Ther., 18, 720 (1975).

- 11. (a) L. Vachon, M.K. Fitzgerald, N.H. Sotliday, J.A. Gould, E.A. Gaensler, N. Engl. Jour. Med., 288, 985 (1973).

(b) D.P. Tashkin, B.J. Shapiro, I.M. Frank, N. Engl. J. Med., 289, 336 (1973).

12. I: Greenberg, J. Kuehnle, J.H. Mendelson, and J.G. Bernstein, Psychopharmacology, 49, 79 (1976).

13. P.F. Conscroe, G.C. Wood, and H. Bauschbaum, J. Am. Med. Assoc., 234, 306 (1975).

14. R.S. Hepler, I.M. Frank, J.Am. Med. Assoc.; 217, 1392 (1971).

15. R. Mechoul am ynd Y. Gaoni, J.Am.Chem. Soc. 87, 3/3 (1975). 
16. "The Total Synthesis of Natural Products", Vol. 4, 1981, Ed. by John ApSimon, John Wiley \& Sons, New York.

17. K.E. Fahrenholtz, M. Lurie and R.W. Kierstead, J. Am. Chem. Soc., 89, 5934 (1967).

18. R.A. Archer, W.B. Blanchard, W.A. Day, D.W. Johnson, E.R. Lavagnino, C.W. Ryan, J. Org. Chem., 42, 2277 (1977).

19. G.R. Handrick, R.K. Razdan, D.B. Uliss, H.C. Dalzell, J. Org. Chem., 42, 2563 (1977).

20. T.Y. Jen, G.A. Hughes, H. Smith, J. Am. Chem. Soc., 89, 4551 (1967).

21. H. Kochi, M. Matsui, Agr. Biol. Chem., 31, 625 (1967).

22. P. Schmialek, Z. Naturforsch, 16B, 461 (1961).

23. C.M. Williams, Nature, 178212 (1950).

24. K.J. Judy, D.A. Schooley, L.L. Dunham, M.S. Ha11, B.J. Bergot, J.B. Sidda11, Proc. Nat1. Acad. Sci., U.S.A. 70,1504 (1973).

25. W.S. Bowers, Science, 164, 323 (1969).

26. F.M. Pallos, J.J.. Menn, P.E. Letchworth, J.B. Miaullis, Nature, 232, 486 (19971).

27. C.A. Hendrick, G.B. Staal, J.B. Sidda11, J. Agr. Food Chem., 21, 354 (1973).

28. W.S. Bowers, T. Ohta, J.S. Cleere, P.A. Marsella, Science, . 193, 542 (1976).

29. T.R. Kasturi, T. Manithomas, Tetrahedron Lett., 2573 (1967).

30. A.R. Alertsen, Acta. Chem. Scand., 9, 1725 (1955).

31. W.S. Bowers, G.E. Pratt Nature, 265, 548 (1977).

32. M.P. Pener, L. Orshan, J. de Wi.lde, Nature, 272, 350 (1975).

33. W. S. Bowers, T. Ohtân R.J. Kuhr, J. Agr. Food Chem., 25, 478 (1977).

34. W.S. Bowers, M.E. Burt, R.J. Kühr, Pest. Biochem. Phys. $\frac{9}{i}, 300$ (1978).

35. W.S. Bowers, M.E. Burt, R.J. Kuhr, Byr11: Environ. Contam. Toxicol., 22, 886 (1971). 
36. W.S. Bowers, D.M. Sodurland, A. Messequer, J. Aqric.

\section{Food Chem., 28, 724 (1980).}

37. R.C. Jennings, A.P. Ottridge, J. Chem. Soc. Chem. Commun., 920 (1979).

38. G.E Pratt, R.C. Jennings, A.F. Hannett, G.T. Brooks, Nofure, 284, 320 (1980).

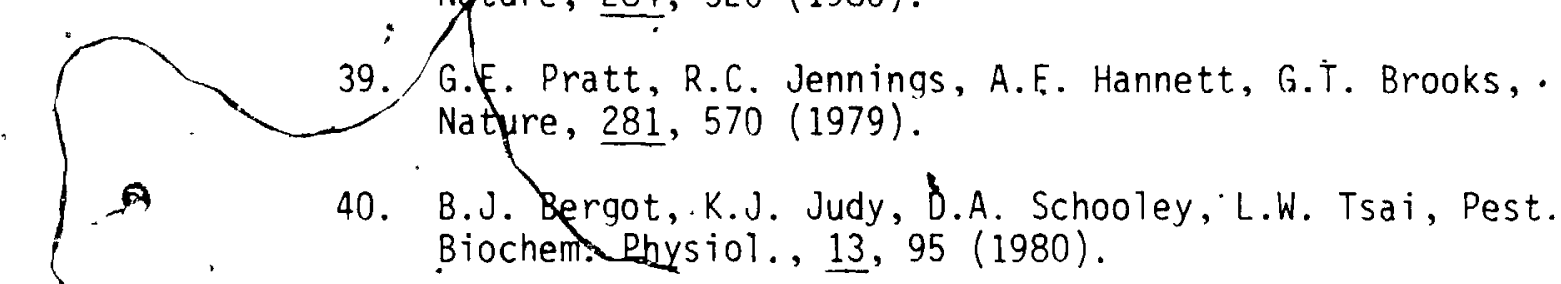

41. A.V. Vyas, N.B. Mulchandani, J. Biochem., 19, 2597 (1980).

42. J. Houben, Chem. Ber., 37, 489 (1904).

43. H. Becker, T. Fellenberg, Justus Liebigs Ann. Chem., 356, 281 (1907).

44. W. Beneze, J. Eisenbeiss, H. Schmid, Hetr. Chim. Acta, 39, 923 (1956).

45. F. Camps, J. Col1, A. Messeguer, M.A. Pericas, Tetrahedron Lett. 21, 2361 (1980).

46. T. Ohta; W. Bowers., Chem. Pharm. Bu11., 25, 2785 (1977).

47. A. Banerji, N. Goomes Ind. J. Chem., 20B, 144 (1981).

48. R. Huls, Bull. Soc. Chim.-Belg., 6b, 409 (1957).

49. R. Livingstone and M.C. Whiting, J. Chem. Soc., 602 (1960).

50. H. Fukami, M. Nakayama, M. Nakajima, Agr. Biol. Chiem., 25,243 (1961).

51. T.R. Kasturi and T. Manithomas, Tetrahedron Lett., 2573 (1967).

52. M. Schwarz, J. Heterocyc1. Chem., 14, 333 (1977).

53. V. Miyano, M. Matsui, Chem. Ber., 31, 397 (1958).

54. P. Iyer, G. Shah, Ind. J.'Chem., 6, 227 (1967).

55. A. Jefferson, 1. Moore, F. Scheinmann, J. Chem. Soc. C, 151 (1967).

56. M.L. Wolfrom, F. Kómitsky, Jr., J.H. Looker, J. Org. Chem. 30, 144 (1964). 
57. F. Camps, J. Col1., A. Messeguer, M.A. Pericas, S. Ricart, W.S. Bowers, D.M. Soderland, Synthesis, 725 (1980).

58. A. Banerji, N. Gooner, Tetrahedron Lett., 38, 3685 (1979).

59. H.J. Kabbe, Synthesis, 886 (1978).

- 60. H. Fukami, M. Nakajima, Agr. Biol. Chem., 25, 247 (1961).

61. H. Bhat, K. Venkataráman, Tetrahedron 19, 77 (1963).

62. V. Gujral, S. Gupta, Bu11. Chem. Soc, Jpn ., 52, 3679 (1979).

63. A. Jain, R. Gupta, P. Sarpal, Tetrahedron 34, 3563 (1978).-

64. A. Jain, R. Khazanchi, A. Kumar, Tetrahedron, 34 , 3569 (1978).

65. A. Jain, D. Juli, R. Gupta, Ind. J. Chem., 16B, 611 (1978).

66. C. Gardil10, R, Cricchio, L. Merlin, Tetrahedron 24, 4825 (1968).

67. C. Sheelink, G. Marshal1, J. Org. Chem., 44, 1429 (1979).

68. Y. Tachibana, Bu11. Chem. Soc. 'Jpn., 53, 555 (1980). .

69. G. Cardillo, M. Orena, G. Porzi, S. Sandri, J. Chem. Soc. Chem. Commun., 830,(1979).

70. M. Tsukayama, Bull. Chem. Soc. Jpn., 50, 459 (1977).

71. T. Meikle, R. Stevens, J. Chem. Soc. Chem. Commun.; Perkin I, 2563 (1979).

72. A. Bongini, G. Cardillo, M. Orena, G. Porzi, S. Sandri, Tetrahedron Lett. 27, 2545 (1979).

73. W. Bandaranayáke, L. Crombie, 0. Whitney, J. Chem. Soc. (C), 811 (1971).

74. F. Camps, 'J. Col1., A. Messeguer, M. Pericas, J. Heterocycl. Chem., 17, 207 (1980).

75. G. Sartori, G. Casiraghi, L. Bolzoni, G. Casnati, J. Org. Chem., 44, 803 (1979).

76. I. Iwai, J. Ide, Chem. Pharm. Bull. 10, 926 (1962). 


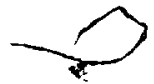

77. J. Hilubucek, E: Ritchie, W.C. Taylor, Tetrahedron Lett., 17, 1369 (1969).

78. M. Ansari, K. Mathur, V. Ahluwdila, Ind. J. Chem., 16B, 702 (1978).

79. L. Crömbie, K. Mackenzie, J. Chem. Soc., 2285 (1968).

80. M. Baldwin, I. \$ick, A. Konnizak, Tetrahedron 16; 210 (1961).

81. E. Collins, P. Shannon, J.Chem. Soc., Perkins I, 944 (1974).

82. A. Mathur, Ind. J. Chem., 1065 (1977).

83. V. Ahluwalia, K. Bhat, C. Prakash, S. Bâa,. But1. Chem. Soc. Jpn, 53, 1070, (1980).

84. B. Beqasse, M. LeCorre, Tetrahedron 36, 3409 $(1980)$.

85. H. Christensen, Syñth. Commun., 5, 65. (1975).

36. von 0. Isler, H. Butmann, M. Montavon, R. Rueqq, G. Ryser, P. Zeller, Helv. Chimica Acta, 40, 1247 (1957).

87. A. Abad, D. Melitier, J. Peté, C. Portelle, Tetrahedron Lett., 47, 4555 (1971).

88. S. Danishefsky, T.'Kitahara, J. Am. Chem. Sóc., 96, 7807 (1974).

89. G.C. Amin, N.M. Shah; Org. Synth. Coll. Vol. 3, p. 280 .

90. V:0. I11i, Tetrahedron Lett., 26, 2431 (1979).

100. Based on a method by S. Colonname $R$. Fornaster; Synthes is, 531 (1975).

101:- G. 01 ah, G.K. Prakask, S.C. Narang, Synthes is," 825 (1978).

102. J. Marsh, L. Goodman, J. Org. Chem., 30, 2491 (1965).

103. M. Jung, M. Lyster, J. Org. Chem., 42, 3761 (1977).

194. Based on a method by J. McOmie, M. Watts, D. West, Tetrahedron, 24, 2289 (1968).

105. K. Markiewitz, C. Dawson, J. Org. Chem. :30, 1610, (1905). 


$$
22
$$


106: J. Hendrickson, C: Kandall, 'retrahedron Lett. ; $\underline{5}$, $\therefore 343(1970)$.

107. A. Vogei, "Textbook of Practicai Organic "Chemistry", 4th ed., Longman Group Ltd., London p. 7.82. , 1979

108. Organic. Reactions, Vol. 1, p. 105, John Wiley and Sơns, New York., 1963.

'109. E. Corey, D. Enders, Tetrahedron Lett., .1, (1976).

110. E. Corey, S. Knapp, Tetrahedron Rett., 41, 3667 (.19ק6).

11. A.R. Miller, J. Org. Chem., 41, 3599 (1976).

112. V. Prelog; P. Barman, M. Zimmerman, Helv. Chim. Acta, 32, $1284(1949)$. .

113. S. Julia, Bul1. Soc. Chim. Fr., 21, 780 (1954).

124. L. Hutch, R: Perry Jr., J. Am. Chem. Soc., 77, ' " 1136 (1955).

115. H. Yoshiokay K. Takashaki, M. Kobayashi, Tetrahedron - Lett., 37, 3489 (1978)..

116. P. Stotter, K. Hi11, Tetrahedron Lett., 21, 1679 $(1975)$.

117. R.S. Mali ! and- V.J. Yadà, Synthesis, 465(1977) 

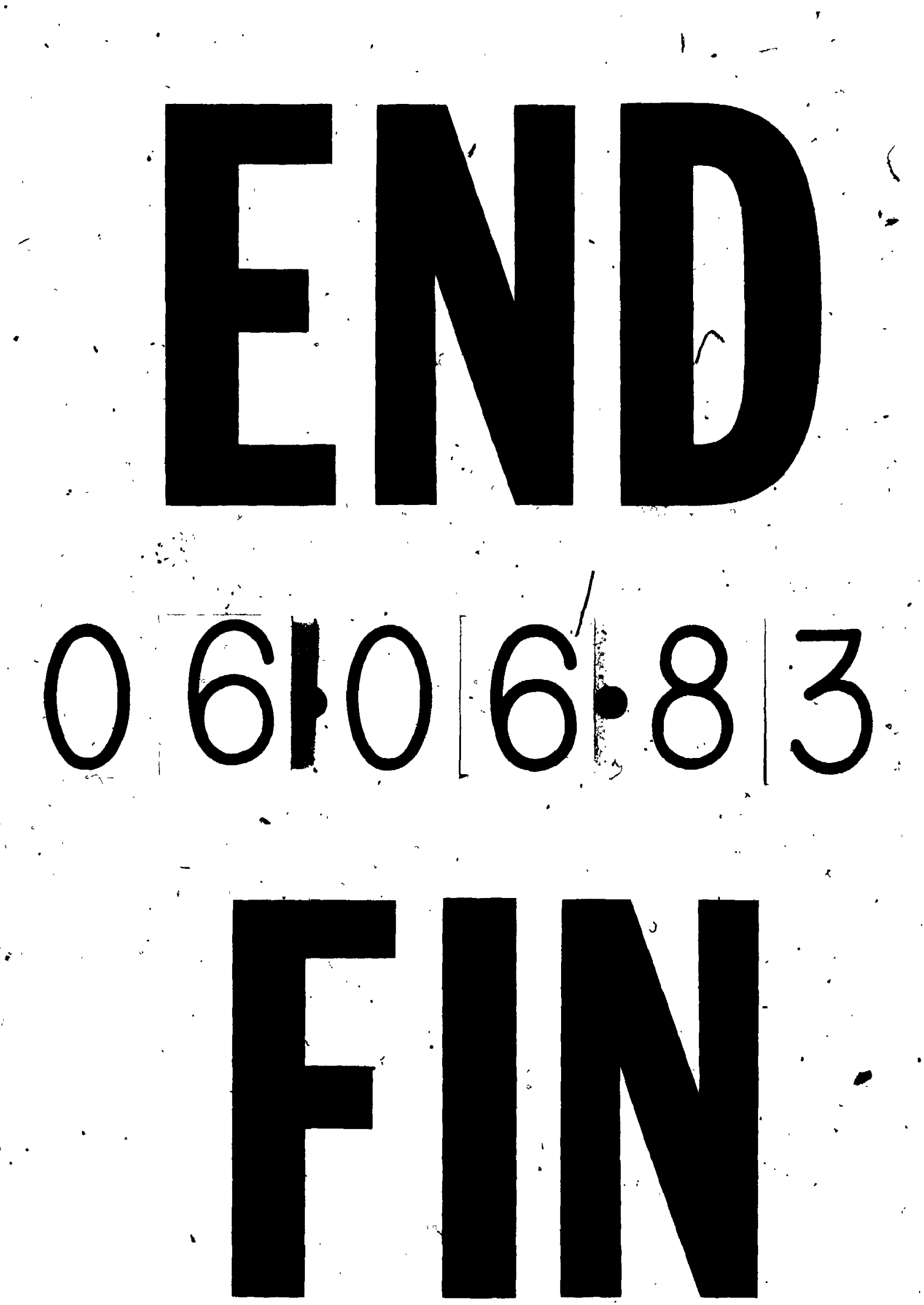